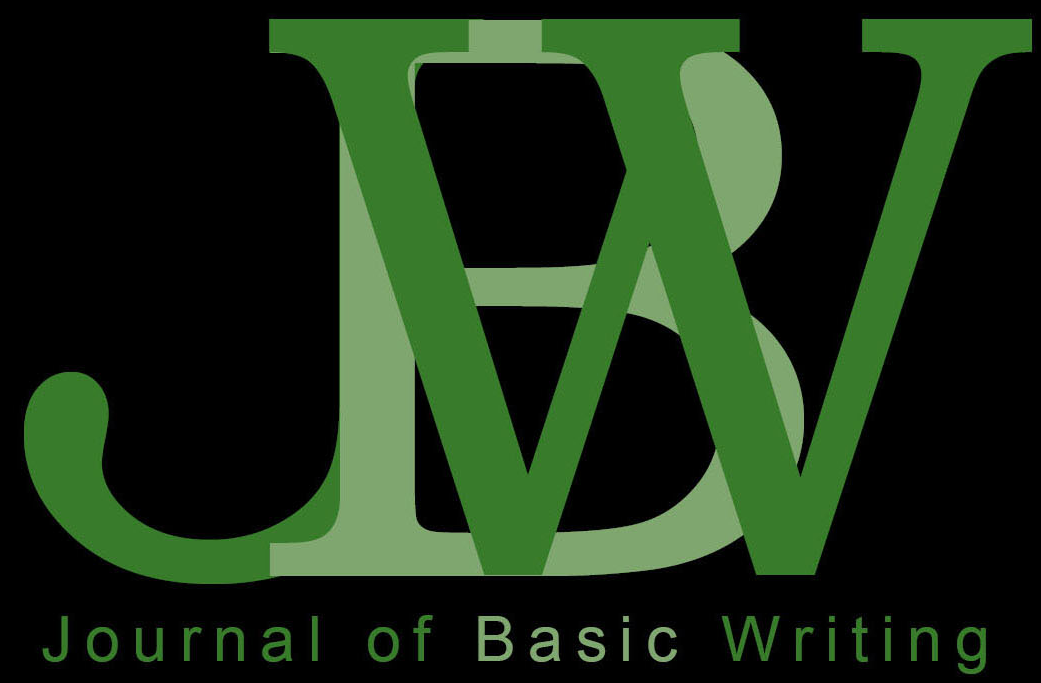

Beyond Assimilation: Tribal Colleges, Basic Writing, and the Exigencies of Settler Colonialism Christie Toth

Noticing the Way: Translingual Possibility and Basic Writers

Sarah Stanley

A Basic Writing Course Design to Promote Writer Identity: Three Analyses of Student Papers Barbara Bird

Subversive Complicity and Basic Writing Across the Curriculum Victor Villanueva

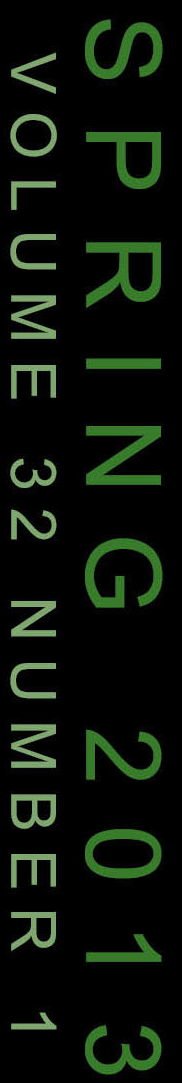





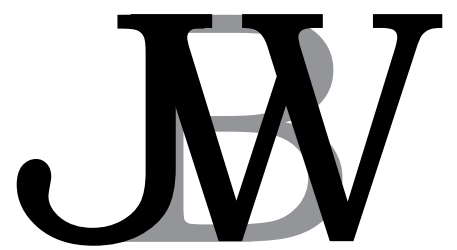

Journal of Basic Writing

VOLUME 32 NUMBER 1 Spring 2013

The Journal of Basic Writing publishes articles of theory, research, and teaching practices related to basic writing. Articles are refereed by members of the Editorial Board (see overleaf) and the Editors.

\section{Hope Parisi and Cheryl C. Smith}

Editors

Ann Del Principe

Associate Editor

\section{Rebecca Mlynarczyk and Bonne August} Consulting Editors

\section{Angela J. Francis and Dominique Zino}

Editorial Assistants

\section{Maria Scordaras}

Business Manager

The Journal of Basic Writing is published twice a year, in the spring and fall, with support from the City University of New York, Office of Academic Affairs. We welcome unsolicited manuscripts and ask authors to consult the detailed "Call for Articles" in this issue. Subscriptions for individuals are $\$ 20.00$ for one year and $\$ 35.00$ for two years; subscriptions for institutions are $\$ 30.00$ for one year and $\$ 45.00$ for two years. Foreign postage is $\$ 10.00$ extra per year. For subscription inquiries or updates, contact:

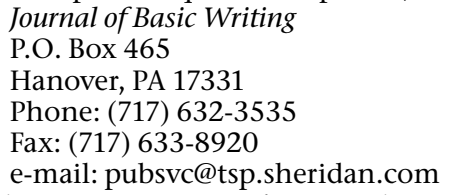

Published by the City University of New York since 1975 Cover and logo design by Kimon Frank

Copyright $(2012$ by the Journal of Basic Writing

ISSN 0147-1635 


\section{JOURNAL OF BASIC WRITING}

\section{EDITORIAL BOARD}

Linda Adler-Kassner

University of California, Santa Barbara

Christopher Anson

North Carolina State University

Hannah Ashley

West Chester University

David Bartholomae

University of Pittsburgh

Sarah Benesch

College of Staten Island, CUNY

Susan Naomi Bernstein

Arizona State University

Lynn Z. Bloom

University of Connecticut, Storrs

Gay Brookes

Borough of Manhattan Comm. College, CUNY

Martha Clark Cummings

Kingsborough Community College, CUNY

Suellynn Duffey

Georgia Southern University

Chitralekha Duttagupta

Utah Valley University

Gregory Glau

Northern Arizona University

Laura Gray-Rosendale

Northern Arizona University

Karen L. Greenberg

Hunter College, CUNY

Kim Gunter

Appalachian State University

Susanmarie Harrington

University of Vermont

Donald J. Kraemer

California Polytechnic State University

Patricia O. Laurence

City College, CUNY

Andrea A. Lunsford

Stanford University

Jane Maher

Nassau Community College, SUNY

Paul Kei Matsuda

Arizona State University

\section{Mark McBeth}

John Jay College and Graduate Center, CUNY

Geraldine McNenny

Chapman University
Susan Miller

University of Utah

Deborah Mutnick

Long Island University

Nathaniel Norment, Jr.

Temple University

\section{George Otte}

Graduate Center, CUNY

\section{Matthew Pavesich}

Georgetown University

Thomas Peele

City College, CUNY

Wendy Ryden

Long Island University

Yolanda Sealey-Ruiz

Teachers College, Columbia University

Charles I. Schuster

University of Wisconsin, Milwaukee

Tony Silva

Purdue University

Trudy Smoke

Hunter College, CUNY

\section{Linda Stine}

Lincoln University

Lynn Quitman Troyka

Queensborough Comm. College, CUNY, ret.

Evelyn E. Webb

Miss. State Board for Comm. and Junior Colleges

Harvey S. Wiener

LaGuardia Community College, Emeritus 


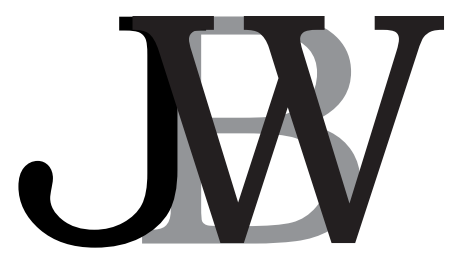

Journal of Basic Writing

Beyond Assimilation: Tribal Colleges, Basic Writing, and the Exigencies of Settler Colonialism

Christie Toth

Noticing the Way: Translingual Possibility and Basic Writers

Sarah Stanley

A Basic Writing Course Design to Promote Writer

Identity: Three Analyses of Student Papers

\section{Barbara Bird}

Subversive Complicity and Basic Writing

Victor Villanueva 


\title{
CALL FOR ARTICLES
}

We welcome manuscripts of 15-25 pages, double spaced, on topics related to basic and ESL writing, broadly interpreted. Submissions should follow current MLA guidelines. Manuscripts are refereed anonymously. To assure impartial review, include name(s), affiliation(s), mailing and e-mail addresses, and a short biographical note for publication on the cover page only. The second page should include the title but no author identification, an abstract of about 150 words, and a list of 4-5 key words. Endnotes should be kept to a minimum. It is the author's responsibility to obtain written permission for including excerpts from student writing.

We prefer that contributions be submitted as Word document attachments via email to: hopekcc@aol.com and Cheryl.Smith@baruch.cuny.edu. If electronic submission is not possible, mail five copies of the manuscript and abstract to:

\author{
Professor Hope Parisi \\ Co-Editor, JBW \\ Department of English \\ Kingsborough Community College, CUNY \\ 2001 Oriental Blvd. \\ Brooklyn, NY 11235
}

You will receive a confirmation of receipt; a report on the status of your submission will follow in about sixteen weeks.

All manuscripts must focus clearly on basic writing and must add substantively to the existing literature. We seek manuscripts that are original, stimulating, well-grounded in theory, and clearly related to practice. Work that reiterates what is known or work previously published will not be considered.

We invite authors to write about such matters as classroom practices in relation to basic-writing or second-language theory; cognitive and rhetorical theories and their relation to basic writing; social, psychological, and cultural implications of literacy; discourse theory; grammar, spelling, and error analysis; linguistics; computers and new technologies in basic writing; assessment and evaluation; writing center practices; teaching logs and the development of new methodologies; and cross-disciplinary studies combining basic writing with psychology, anthropology, journalism, and art. We publish observational studies as well as theoretical discussions on relationships between basic writing and reading, or the study of literature, or speech, or listening. The term "basic writer" is used with wide diversity today, sometimes referring to a student from a highly oral tradition with little experience in writing academic discourse, and sometimes referring to a student whose academic writing is fluent but otherwise deficient. To help readers, therefore, authors should describe clearly the student population which they are discussing.

We particularly encourage a variety of manuscripts: speculative discussions which venture fresh interpretations; essays which draw heavily on student writing as supportive evidence for new observations; research reports, written in non-technical language, which offer observations previously unknown or unsubstantiated; and collaborative writings which provocatively debate more than one side of a central controversy. 


\section{EDITORS' COLUMN}

One of the strongest definitions of basic writing in our field emerges out of Bruce Horner's exploration of its location-institutionally, materially, and ideologically at the periphery. It is fortunate that basic writing practitioners are not easily daunted by such a location; we know to embrace it politically as a place for "refusing to settle for fixed designations of what is and isn't literacy, or illiteracy, fixed designations of who is and isn't educable or worthy of education, and fixed designations of what we do and don't know about literacy and its learning and teaching" (7). Here we find high ground for mapping needs and naming competencies, for seeing the "experience of difficulty," as both Horner and James Slevin note, as "a re-location of earlier and other struggles" (Horner 6). To us, in our scholarship and in our pedagogy, this challenge is foundational and incessant.

This issue of $J B W$ reflects the waves of movement that continue to carry us forward, with metaphors of relocation and travel especially resonant. In our first article, "Beyond Assimilation: Tribal Colleges, Basic Writing, and the Exigencies of Settler Colonialism," Christie Toth packs a Ford hatchback with what little she knows, at first, of how to build a course for basic writers at Diné College, the oldest tribal college of North America. Recognizing that "local context is a defining characteristic in basic writing pedagogy," Toth reflects on her own personal and professional dislocation, which becomes the impetus for exploring larger disparities of educational equity and access for her students at Diné. In light of their histories within longstanding systems of institutional misunderstandings and exclusion, she asks, "What do tribal colleges want from writing?" and how best to evolve a basic writing course to meet local potential and need? The result is Basic Writing 100B which, while responsive to local exigencies, offers a route to language competence and self-determinism grown from a colonial history.

Our next article, "Noticing the Way: Translingual Possibility and Basic Writers," by Sarah Stanley, finds us similarly relocated at the intersection of Second Language Acquisition and Translingualism, a locale Horner knows well in his own efforts to open basic writing to this new, crossgenerative terrain. Stanley's starting point is to address some instructors' hesitance to venture past strict notions of error toward what a translingual perspective offers: a "social negotiation" of error, "in other words, an agility with translingual possibility." The way toward such possibility, Stanley 
holds, is to recognize that basic writers may still need the vantage of the "privilege[d] ... standardized reader, who can choose to read through language," but who, in becoming a partner to the basic writer in noticing error, resists that privilege. While still valuing a translingual understanding of error "as less a 'feature of text' than a feature of 'context," basic writing teachers can help students notice and puzzle over those moments "where the distinction between an error and mistake can be muddled," thereby "allowing [a new notion of] noticing to unfold." Stanley's thoughtful construction of a sentence workshop for students offers a lens for basic writing teachers to discern these distinctions and allow "translingual possibilities" in the classroom to emerge.

In "A Basic Writing Course to Promote Writer Identity: Three Analyses of Student Papers," Barbara Bird gets us traversing again-between BW and FYW classrooms and between Writing about Writing pedagogies and social identity theory. As Bird reports, new thinking about WAW and social identity theory led her and some colleagues to devise a curriculum based on writing content and Roz Ivanič's markers of academic writer identity. Over time, Bird and her colleagues noticed "clearer claims, ... [quotes] connected to. . claims," and "significant expansion of depth, logic, and discussions of each claim." In short, they found strong evidence of both discoursal and authorial identities in student writing. Bird describes her process to textually document the growth and stability of "writer identities across time" to the extent that these identities, as Ivanič asserts, are interpretable through student text. Her article conjoins discourses of basic writing, transfer theory, WAW, identity, and Bartholomean themes of involving basic writers in scholarship that strongly joins them "as colleagues. . . [to the] academic enterprise" (Bartholomae 11).

Lastly, we take a more expansive look at the transversive power of basic writing with our fourth article, Victor Villanueva's "Subversive Complicity and Basic Writing Across the Curriculum," drawn from the author's Keynote at the Conference on Basic Writing workshop at the 2013 Conference on College Composition and Communication. Like Horner, Villanueva redraws the lines defining the periphery-beyond the basic writing classroom and across the entire curriculum. His assertion, he says, is "simple": "time for basic writing to get out from under," time "to inculcate a Basic Writing Across the Curriculum. . . a time yet again to move away from the concept that basic writers are in need of remedies." Opening up our view of the field, his words encourage us to travel alongside our students, toward an educational system reinvented to encompass 
the fullest range of rhetorical talent and capacity. Through a vision both optimistic and generative, Villanueva acknowledges that social movements have long histories of having to forge inroads through backdoor means, or "the trickster's ways" - among these, the Puerto Rican "jaiberia," or "a jaiba rhetoric," grown from colonization.

Assuming roles that may irk us, Villanueva observes, may also afford us means for effective "troubling" of unproductive policies and practices. As he cites sociologists Grosfoguel, Negron-Muntaner, and Goeras on Diana Fuss's work: "there can be a mimicry of subversion where the deliberate performance of a role does not entail identification." He advocates alliances for our students across the curriculum to promote "[our students'] mimicry, their conscious invention of the university" to capture "the potential of changing the university, broadening the university's conceptions of discourses in action, of the rhetorics that are always at play." The location of basic writing, therefore, must keep shifting to enable a more varied and inclusive experience of writing for basic writers across the curriculum - with "more members of the university discovering that, at bottom, we are all creatures of the word."

\section{-Hope Parisi and Cheryl C. Smith}

\section{Notes}

Bartholomae, David. "Inventing the University." Journal of Basic Writing 5.1 (1986): 4-23. Print.

Horner, Bruce. "Relocating Basic Writing." Journal of Basic Writing 30.2 (2011): 5-23. Print. 


\title{
Beyond "Assimilation": Tribal Colleges, Basic Writing, and the Exigencies of Settler Colonialism
}

\section{Christie Toth}

\begin{abstract}
This article discusses basic writing pedagogy at a two-year tribal college, an institution type that has not been visible in the basic writing literature to date. In many tribal college contexts, socioeconomic challenges, under-resourced $\mathrm{K}-12$ schools, and linguistic diversity all contribute to high student placement rates into "developmental" writing courses. Operating from the understanding that tribal college writing curricula are assertions of rhetorical sovereignty, I present a narrative of the pedagogical reasoning that led me to structure my basic writing course around the exigencies of U.S. settler colonialism-that is, the settler state's ongoing political, social, and economic project of controlling Indigenous peoples, lands, and resources. This approach encourages Native American students to develop critical language awareness and invites them to consider the importance of writing for furthering the interests of their communities and nations while meeting the tribal college's self-determined learning outcomes.
\end{abstract}

KEYWORDS: Native American, tribal college, settler colonialism, language diversity, basic writing

In the early days of August 2012, I spent a lot of time in the parking lot outside my apartment in Ann Arbor, Michigan, trying to figure out how I was going to fit everything I needed for four months on the Navajo Nation into my tiny Ford hatchback. I was a graduate student-a white woman just past my thirtieth birthday-and I would be spending the fall semester conducting ethnographic research with writing faculty at Diné College, the oldest and largest tribally controlled college in North America. I grew up in a military family, which should have made me better at packing and may have left me a little too comfortable skittering across the country without a clear sense of what my living situation would be. Despite many phone calls and emails, I had no solid plan for housing when I got to the Southwest, so I was carrying camping gear in addition to clothing for three high desert seasons, plus dozens of books on Diné1 history and culture, Indigenous

Christie Toth has taught basic, first-year, and advanced writing in a variety of twoand four-year college settings. She is Assistant Professor in the University of Utah's Department of Writing and Rhetoric Studies. Her research has appeared in College Composition and Communication, Teaching English in the Two-Year College, Writing Program Administration, Assessing Writing, and Higher Education: Handbook of Theory and Practice. 
rhetorics, and composition theory. In the end, I stuffed my car to the roof and started driving, relying on my side mirrors and trusting that I would figure out where to sleep once I arrived.

Even as I was preparing to research writing pedagogy with Diné College faculty, I was also scrambling to pull together my own syllabus for English 100B, the basic writing course I would be teaching that fall at one of the college's branch campuses. Teaching this course was partly a matter of principle: informed by my readings in feminist and Indigenous methodologies (Cushman; Powell and Takayoshi; Smith; Wilson), I strove to make reciprocity an integral part of my research design. The Navajo Nation is very rural, and the college has difficulty attracting qualified part-time faculty for its more remote campuses. I was a credentialed English instructor, so it made sense to everyone involved that I would help fill this need while I was around. Furthermore, I believed teaching the course would make important contributions to my study: if I hoped to understand the local context in which Diné College faculty taught writing, there was no substitute for rolling up my sleeves and experiencing the work firsthand. Finally, as a practical matter, my research funding fell well short of the actual cost of conducting fieldwork, and my Diné College adjunct pay would just about cover gasoline and oatmeal for the semester.

As I was loading up my car that August, I was pretty clear on why I was teaching English 100B, but I still needed to make some key decisions about how. I had taught basic writing before, at a community college in suburban Oregon, but I was persuaded by the arguments of scholars like Lynn Troyka, Patricia Bizzell ("Basic Writing”), and George Otte and Rebecca Mlynarczyk that local context is a defining consideration in basic writing pedagogy. This seemed particularly important at Diné College, which was founded to serve a student population that has historically struggled at off-reservation institutions (Stein, Tribally Controlled; Tierney; Clark). I was, by that point, well versed in the (small) body of composition literature on working with Native American students. This literature often echoes the field of basic writing's longstanding concern with disjunctures between students' home cultures and that of postsecondary education (e.g. Bizzell, "What Happens"; Lu, "From Silence to Words"; "Conflict"; Fox), emphasizing potential conflicts between the languages, rhetorical practices, and interpersonal norms in Native communities and those of the "dominant culture" (Ruoff; Barwell; Glau; Grijalva; Gray-Rosendale, Bird, and Bullock; Zolbrod, "Teaching”; "Reading and Writing"). While this literature demonstrates a laudable respect for $\mathrm{Na}$ tive students and their communities, by the summer of 2012 I was coming to 
find its near-exclusive focus on cultural difference increasingly unsatisfying.

In the year and a half leading up to my fieldwork, I had made several weeklong visits to Diné College: I sat in on classes, chatted with faculty and staff, and worked with many students individually on their writing assignments and other coursework. These experiences gave me a deep appreciation for the college's mission to support Diné nation-building - that is, efforts to foster the social, economic, and political self-determination of the Navajo Nation-while "sustaining/revitalizing" Diné language and heritage knowledge (McCarty and Lee 103). However, my visits also fueled a growing unease with the discourses of Native cultural difference that pervade much of the composition scholarship. The Diné students I met were remarkably diverse-linguistically, spiritually, and academically—and not nearly as "other" as the literature seemed to suggest. The discourses of cultural difference, I came to believe, function to obscure what Native rhetorics scholar Scott Lyons calls "the irreducible modernity and diversity that inheres in every Native community and has for some time" ("Actually Existing" 297, emphasis in the original). While there are certainly differences on the Navajo Nation, differences that many would describe as "cultural," they are neither monolithic nor static; Bizzell made a similar point about basic writing students more than a decade ago ("Basic Writing").

By August 2012, I had come to agree with Lyons that "developing [tribal college] literacy pedagogy...requires paying close attention not so much to 'cultural difference' as to politics" "Fencing" 86, emphasis in the original)-specifically, to the structures of ongoing U.S. settler colonialism, the settler state's project of controlling Indigenous peoples, lands, and resources. These structures give rise to many of the challenges Native students and their communities face and present major exigencies for Native writing. As I designed my English 100B course, I wanted to move beyond the well-worn framework of culturally responsive pedagogy (Gay; Ginsberg and Wlodkowski) and instead develop what historiographer of rhetorical education David Gold calls locally responsive pedagogy: teaching approaches that "take into account the needs and desires of diverse communities" (153). I had an urgent sense that this locale is profoundly shaped by settler colonialism, and that the rhetorical exigencies settler colonialism presents cut across the diversity of twenty-first century Diné society, constituting a pressing rationale for acquiring academic literacies.

These were the theoretical issues I was contemplating that summer as I thought about English 100B. Ultimately, however, I had to approach my course planning the same way I did my housing situation: by packing for all 
imaginable eventualities and then hitting the road, paying careful attention to my mirrors and being prepared to adjust course as needed. Thanks to help from friends and the kindness of strangers, I found a place to stay within a week of arriving at Diné College. I also devised an approach to English 100B that, while far from perfect, might offer useful insight to faculty teaching basic writing at other tribal colleges and off-reservation institutions with large Native student populations. Rather than a fully articulated curriculum or the findings of an empirical study, what this essay offers is a narrative of pedagogical reasoning. First, I provide some background on tribal collegesan institution type that has not previously been visible in the basic writing literature-and examine the construction of basic writers at Diné College. Then, I lay out the theoretical basis for the course I designed, followed by a discussion of some of the more promising teaching practices I attempted. I argue that the rhetorical exigencies of settler colonialism can offer an inclusive and politically engaged frame for basic writing instruction at tribal colleges. This frame fosters a critical locally responsive pedagogy that extends the longstanding commitment to social justice in basic writing studies and invites students to grapple with Lyons' important question, "What do American Indians want from writing?" ("Rhetorical Sovereignty" 447).

\section{WHAT DO TRIBAL COLLEGES WANT FROM WRITING?}

In order to grasp the reasoning behind the English 100B course I designed, it is important to understand the origins and distinctive mission of the thirty-seven tribally controlled colleges and universities across the United States today. When the tribal college movement began in the late 1960s, Native American students were the most underrepresented minority group in postsecondary education (Wright and Tierney). Among those who did enroll in college during this period, academic success rates were low: in 1970, researchers estimated that the overall attrition rate for Native students in any kind of postsecondary education was around 75\% (Boyer). During this period, many tribal nations were seeking increased political and economic self-determination, and these efforts were sometimes hampered by a lack of tribal members with sufficient education to take over reservation functions and services. The Native self-determination and burgeoning community college movements came together with the establishment of the first tribal colleges. Navajo Community College (later renamed Diné College) was founded in 1968, and over the subsequent decades, tribal nations from Arizona to Alaska to Michigan found the combination of vocational, "developmental," and 
academic curricula offered by the community college model well suited to the needs of their communities (Stein, Tribally Controlled). While some tribal colleges now offer four-year degrees in select fields, most remain primarily associates-granting institutions that prepare a significant number of their students to transfer to off-reservation universities (AIHEC Fact Book).

Most tribal colleges share the comprehensive, open-access missions of community colleges while maintaining their own unique cultural and community development missions. Nearly all offer courses in tribal history, heritage culture, and language(s). Many also integrate tribally-specific content and pedagogical approaches across the curriculum—the Diné Educational Philosophy, a four-step cyclical model for learning derived from traditional Diné epistemological frameworks, is one such example (Willeto; Toth). In addition to serving the important goal of sustaining and revitalizing tribal languages, knowledges, and values, these curricula are intended to strengthen students' identities and foster their academic success, both at the tribal college and, for those who transfer, at off-reservation institutions where they will often be minoritized. Many graduates will bring their expertise and professional credentials back to their reservation communities, assuming leadership positions and contributing to local economic development. In the broadest sense, then, the purpose of tribal colleges is to further their nations' political, economic, and cultural self-determination and, ultimately, to protect and extend their sovereignty.

As Lyons observes, the term sovereignty is complex and contested in Native intellectual circles, and its meanings have shifted over time ("Rhetorical Sovereignty"). However, this concept is essential for understanding why writing pedagogies at tribal colleges are not simply a matter of culture. Rather, such pedagogies contribute to the multigenerational project of asserting tribal nations' distinctive legal status as nations and working with other Indigenous peoples to build the legal structures for global recognition. Lyons writes:

Our claims to sovereignty entail much more than arguments for tax exempt status or the right to build and operate casinos; they are nothing less than our attempt to survive and flourish as a people. Sovereignty is the guiding story of our pursuit of self-determination, the general strategy by which we aim to best recover our losses from the ravages of colonization: our lands, our languages, our cultures, our self-respect. For indigenous people everywhere, sovereignty is an ideal principle, the beacon by which we seek the paths to agency and power and 
Tribal colleges are both manifestations and vehicles of educational self-determination-they assert tribal sovereignty-and through their curricula and programs, they prepare Native students to participate in the social, political, and economic project of nation-building. Because academic literacies are essential for succeeding in postsecondary education, both before and after transfer, tribal college writing courses have an important role to play in this project.

\section{CONSTRUCTING “BASIC WRITERS” AT DINÉ COLLEGE}

Even as tribal colleges pursue these broad social and political goals, issues of student academic preparation remain a persistent challenge. The nature of this challenge reflects major themes in the basic writing literature: students' socioeconomic status, their language diversity and prior literacy experiences, and the ideological dimensions of writing placement. In 2007, $57 \%$ of first-time entering tribal college students enrolled in developmental writing courses (AIHEC Fact Book), and at Diné College, these rates are even higher. The college assesses incoming students using ACCUPLACER, a computer-based test employed by more than $60 \%$ of community colleges nationwide (Scott-Clayton) that includes multiple-choice questions about reading comprehension and grammar and usage, as well as an impromptu machine-scored writing task. Readers of JBW are likely familiar with disciplinary critiques of both multiple-choice tests and machine-scoring for writing placement, so I will not rehearse those arguments here (for recent overviews, see Perelman; Condon). According to one Diné College instructor I spoke with, more than $90 \%$ of incoming Diné College students place into developmental reading and/or writing, figures that are consistent with those reported by Kay Thurston in the late 1990s.

The reasons for these placement rates are complex. As at many open-access institutions, some Diné College students have little experience with computerized testing formats, have poor or out-of-practice test-taking skills, or a lack of understanding of the stakes of the placement exam (Hughes and Scott-Clayton; Scott-Clayton). Likewise, some students are entering college with a GED, are returning after long breaks in their schooling, or received inadequate academic preparation in their K-12 schools, whether on- or off-reservation. During my dissertation research, I conducted longitudinal interviews with sixteen Diné College students, all of whom self-identified as 
Diné (two also identified as Zuni and/or Hopi, and one as African American). Seven of these students described major disruptions or relocations during their K-12 schooling, nearly all related to socioeconomic challenges. Almost a third of Navajo Nation households have incomes of less that $\$ 15,000$ a year: $38 \%$ of reservation residents and $44 \%$ of children are considered to be living in poverty (Demographic Analysis). Poverty-related experiences during childhood - a function of the structures of settler colonialism-likely affect the academic preparation of many Diné College students.

Settler colonialism has also resulted in an ongoing process of "language shift" on the Navajo Nation (House), creating complex patterns of linguistic diversity among Diné College students that affect writing placement. There are over 300,000 enrolled members of the Navajo Nation, roughly 174,000 of whom live within reservation borders: around two-thirds of these residents are fluent speakers of Diné bizaad. Although Diné bizaad is considered the healthiest Indigenous language in North America, intergenerational transmission has declined dramatically since the 1960s; fewer than 25\% of Diné children now speak the language fluently (Schaengold; McCarty, Romero-Little, and Zepeda). Some Diné College students-particularly those who are older-grew up speaking Diné bizaad as their primary home language, learning English through schooling, popular media, and time spent off-reservation. In their day-to-day lives, many of these bilingual students "shuttle" (Canagarajah, "Place" 593) between English, Diné bizaad, and Navlish - a contact variety of Diné bizaad that integrate English words and phrases as well as some syntactical structures-depending on the age, language proficiencies, and ethnic background of the person with whom they are speaking (Schaengold; Webster, "On Intimate Grammars"). The four students in my dissertation study who fit this linguistic profile were all over the age of thirty. The majority of younger Diné College students, however, have been raised in bilingual or monolingual English-speaking households, and their proficiency in Diné bizaad varies. In their research with Diné youth, Teresa McCarty, Mary Romero-Little, and Tiffany Lee found that many students understand the language, even if they cannot speak it fluently. This was the case for ten of the sixteen students in my study, all of whom were in their late teens and twenties. Only two students reported not understanding Diné bizaad at all.

To further complicate the linguistic picture, most Diné College students, whether bilingual or not, speak some version of Navajo English. As linguistic anthropologist Anthony Webster describes, Navajo English "differs on phonological, morphological, syntactic, discourse, and lexical grounds" 
from the "ideologically-privileged abstraction called Standard English" ("Still”" 79), as well as from the written abstraction I will call Edited American English (EAE). Students' familiarity with conventions of Standard English and EAE varies depending on their geographical experiences, prior schooling, and the nature of their media consumption and literacy practices. Compared to African American Vernacular English and other well-established English language varieties, however, Diné society has cultivated relatively little pride in Navajo English, perhaps because identification with Diné bizaad remains so strong (Schaengold). In the midst of all of this linguistic complexity, one thing is clear: Diné College students bring a unique range of locally-specific language experiences to the writing classroom. Many have spent their lives in communities where "translanguaging" - "the ability of multilingual speakers to shuttle between languages, treating the diverse languages that form their repertoire as an integrated system" (Canagarajah, "Codemeshing" 401)-is the norm.

Although translingual theory enables us to understand Diné College students' multilingualism as a resource (Canagarajah, "Codemeshing"; Horner, Lu, Royster, and Trimbur; Horner), features of Navajo English often appear in students' academic writing in ways that their instructors find problematic (Thurston). Some attribute students' difficulties with EAE to living in an "oral culture" (Zolbrod, "Reading and Writing"; "On the Reservation"), an assertion that reproduces binaristic theories of literacy and orality that have long been critiqued in composition studies (see Daniell, "Against the Great Leap"; "Narratives of Literacy"). My own interviews with Diné College students suggest that they engage in a wide range of literacy practices, and most have done so since they were small children (see below). However, the majority of tribal college students are among the first generation in their families to attend college (Stein, "Tribal Colleges") and may not have spent as much time in the kinds of language, literacy, and learning environments that, as Mike Rose has shown many times over, foster the academic achievement of middle-class students. All of these factors likely influence Diné College students' performance on the ACCUPLACER, which assigns a high value to "sentence structure" and "mechanical conventions" ("ACCUPLACER") - in other words, to EAE. These factors also contribute to a general perception among Diné College faculty, both Diné and non-Diné, that many of their students are underprepared for college-level writing and benefit from the extra time and instruction provided by developmental writing courses (Thurston; Toth).

WHAT DOES DINÉ COLLEGE WANT FROM WRITING? 
The self-determined learning goals for tribal college writing courses might be understood as enactments of what Lyons calls rhetorical sovereignty, which he defines as "the inherent right and ability of peoples to determine their own communicative needs and desires...to decide for themselves the goals, modes, styles, and languages of public discourse" ("Rhetorical Sovereignty" 449-50). As I was planning my basic writing course, I was eager to respect the rhetorical sovereignty of the Navajo Nation, so the question at the forefront of my mind was, "What does Diné College want from English 100B?" To answer this question, I turned first to the course catalog, which describes English 100B as follows: "This course advances students' abilities to write well-crafted and grammatical essays, with appropriate and effective word choice. Elements of expository prose are emphasized. Advanced grammar and other discrete skills are taught as necessary ("2012-2013 Catalog" 87)." The description prioritizes two key learning objectives: the ability to compose in a genre described as an "expository" essay, and the ability to produce "grammatical" writing, which I understand to mean making effective use of the conventions of EAE. When I asked my supervisor for additional direction, his only requirements were to a) use the inexpensive Grammar to Go textbook preferred by the lead English instructor at the branch campus; b) format my syllabus according to the common template used throughout the college, and c) integrate the four-step Diné Educational Philosophy into the course. Beyond that, the design of my English 100B section was up to me.

Looking for more guidance, I turned to the Diné College mission statement. In addition to reiterating the Diné Educational Philosophy, the 2012 statement expresses a commitment "to advance quality student learning" in three areas:

- In study of Diné language, history and culture.

- In preparation for further studies and employment in a multi-cultural and technological world.

- In fostering social responsibility, community service and scholarly research that contribute to the social, economic and cultural well being of the Navajo Nation. (“2011-2012 Catalog” 8)

Elsewhere, I discuss how I and the Diné College faculty in my dissertation study have used the Diné Educational Philosophy to teach writing as a process (Toth). In this essay, I focus on how I endeavored to meet the other three objectives expressed in this mission statement: to provide students 
with opportunities to learn about Diné language, history, and culture; to equip them with the transferable abilities they will need to succeed in multicultural academic and work settings; and to prepare them to further the well-being of the Navajo Nation. As I discuss below, placing the exigencies of settler colonialism at the center of the course enabled me to address all of these objectives while honoring the college's self-determined goals for English 100B.

The college's objectives were, however, only part of the equation. As Patrick Sullivan observes, motivation plays a key role in students' persistence and the quality of their learning, particularly in basic writing courses. In order to achieve the college's goals for the course, I needed to tap into students' intrinsic motivation: I needed to consider what they wanted from writing. This was no simple question. Native people have a complex historical relationship with the "heretofore compromised technology of writing" (Lyons, "Rhetorical Sovereignty" 447):

[T] he duplicitous interrelationships between writing, violence, and colonization developed during the nineteenth century-not only in the boarding schools but at the signings of hundreds of treaties, most of which were dishonored by whites-would set into motion a persistent distrust of the written word in English, one that resonates in homes and schools and courts of law still today. If our respect for the Word remains resolute, our faith in the written word is compromised at best. (Lyons, "Rhetorical Sovereignty" 449)

As veteran Diné College writing faculty Kay Thurston and Paul Zolbrod ("Reading and Writing") have described, this "persistent distrust of the written word in English" has particular force on the Navajo Nation, where much of the middle-aged population learned English in schools, often Burea of Indian Affairs boarding schools that they entered as young children separated from their families. The emotions surrounding memories of these experiences-and the social changes they have fueled—can be conflicted and intense (Spolsky; House).

In my own experience, Diné College students' attitudes toward literacy vary. While fourteen of the sixteen students I interviewed for my dissertation had placed into basic writing, nearly all described participating in a range of out-of-school literacy practices. Two students expressed outright dislike for reading and writing, but five regularly read books for their own enjoyment or interest; four were avid writers of fiction, screenplays, or poetry; two 
kept personal journals; two often wrote in their places of employment; and one regularly composed bilingual sermons for his independent Christian church. All were engaged in various forms of digital reading and writing, from web design and blogging to text-messaging and Facebook (Toth). Despite these rich extracurricular literacy practices, however, the perceived role of English-medium instruction in the process of language shift- and the prevalence of drill-and-grill grammar instruction in many Diné people's K-12 educational experiences-have contributed to an "ambivalence" about school-based literacies among some segments of Diné society (Thurston 35). In short, teaching basic writing at Diné College means reckoning with students' complex and variable relationships to a technology that has been compromised by its association with the settler state.

As I planned my English 100B course, I knew I also needed to consider my own identity and positionality at Diné College. I was, after all, the latest in a long line of bilagáana (white/Anglo) English teachers that many of my students would have encountered over the course of their schooling. I had to ask myself what I wanted with tribal college writing instruction. Why did I think teaching writing was important and worthwhile in this setting, despite the uncomfortable specter of assimilationism? The answer to these questions, I came to believe, is the essential role that writing plays in contending with the structures of U.S. settler colonialism.

\section{BASIC WRITING, MEET SETTLER COLONIAL STUDIES}

Over the last two decades, postcolonial theory-with its powerful concepts of borderlands, contact zones, and hybridity-has had a major influence on basic writing studies. However, most postcolonial theory derives from critical examinations of exploitation colonialism-for example, the British colonial presence in South Asia-which is a distinct historical formation from the ongoing settler colonialism that has led to independent settler states like Canada, Australia, New Zealand, and the United States. Without denying the important insights of postcolonial theory, I believe the scenes and purposes of tribal college basic writing are better understood through settler colonial theory, which addresses the actual power structures in which Native students live, learn, and write. Indeed, any writing pedagogy which aims to develop students' critical awareness of local, national, and global structures of inequality stands to benefit from an understanding of settler colonialism.

Historian Lorenzo Veracini offers a helpful articulation of the distinc- 
tions between settler and exploitation colonialism. First, while exploitation colonialism requires the physical presence of nonindigenous colonial administrators, these individuals generally consider themselves to be temporary residents: they are citizens of the imperial nation-state and will eventually return to their home country. Settler colonialism, however, involves the permanent settlement of nonindigenous people on Indigenous lands, which results in the formation of an independent settler state. Thus, in settler colonial contexts, "invasion is a structure, not an event" (Wolfe 388). Second, exploitation colonialism aims to control the labor, extractive resources, and markets of the colony: as Veracini memorably puts in, exploitation colonialism says to the colonized, "'you, work for me"” (1). Settler colonialism, however, is motivated primarily by a drive to acquire land and therefore seeks to dispossess and eliminate the Indigenous peoples who have prior claims to that land. It says to the colonized, "'you, go away'"(Veracini 1), although the mechanisms by which it attempts this vary across time and place. The United States, for example, used a combination of treaty-making, forced removal, land allotment policies, and outright warfare and genocidal violence to acquire Native land throughout the late-eighteenth and nineteenth centuries. The "domestic dependent nation" status of the 566 tribal nations currently recognized by the federal government-a legal status that distinguishes many (although not all) Native peoples from other minoritized racial and ethnic groups in the United States-is the result of this particular settler colonial history.

Veracini argues that a defining feature of settler colonialism is an ongoing effort to erase the state's history and current status as a settler state by obscuring the continued existence of Indigenous peoples and/or denying their prospects for long-term survival. Settler culture may be eager to appropriate images of Indigenous people as a means of asserting local or national identities (sports mascots being one highly visible example). However, such representations typically consign Indigeneity to the past or present Native people as endangered and in the process of disappearing (see The Last of the Mohicans, for example, or the ubiquitous "End of the Trail" sculpture of the slumped, defeated Indian riding away from the vanquished frontier). Because settler colonialism wants Indigenous people to go away, their very survival is a form of resistance: continued Indigenous presence calls attention to the settler state as a settler state by revealing that the project of settlement is incomplete. It undermines the narratives of Native vanishment, perhaps tragic but always inevitable, that have long justified the settler colonial project.

As Veracini is careful to note, however, resisting settler colonialism 
does not mean undoing settler colonialism. While it may be possible to expel the colonizers in the context of exploitation colonialism, the realities of settler demographics and political independence render the physical decolonization of settler states unlikely. Rather, because the logic of settler colonialism is to "extinguish the settler colonial relation"- that is, to negate treaty agreements and the legal structures of tribal sovereignty- "the struggle against settler colonialism must aim to keep the settler-indigenous relationship intact" (Veracini 7). In short, resisting settler colonialism means maintaining Native political alterity, rejecting both "the melting pot" and uncritical forms of multiculturalism that celebrate Native cultural heritage but fail to acknowledge tribal nations' distinctive legal status.

Settler colonial theory offers a helpful lens through which to consider Lyons' question, "What do American Indians want from writing?" Writing has clearly played an important role in the machinations of settler colonialism-print is the medium that has codified U.S. legal structures that sanction dispossession. Writing has also been a means of producing and reproducing representations of Native people that either consign them to a frontier past, cast them as incapable of self-governance in the present, or invoke narratives of tragedy, "fragility" (Veracini 4), and cultural loss that deny the possibility of positive Native futures. On the other hand, writing is also a means by which Native people have resisted settler colonialism. Tribal nations have used-and often repurposed - written documents like treaties and legislation to hold on to tribal lands, reassert land-use rights, and resist environmental exploitation on and near their landbases.

Likewise, written Native self-representations can assert what author and literary critic Gerald Vizenor calls "Native presence": that is, an insistence on the continued existence of Native communities and nations and a refusal to allow contemporary Native lives to be characterized by notions of "victimry" (vii). These Native self-representations counter settler colonial narratives of tragedy and vanishment that deny the role of Indigenous people in the settler state's future. As Malea Powell demonstrates, Native people have long used writing to "refigure 'the Indian'" (400), 'the Indian' being a settler colonial construction rather than an accurate depiction of existing Native people or communities. Thus, "compromised" though it may be, writing is an important technology for confronting settler ideologies with tribally specific representations that assert Native presence and futurity. As long as there is Indigenous land to be taken or exploited, sovereignties to be undermined or disregarded, or Native presence to be obscured, the ever-evolving structures of U.S. settler colonialism will present important 
exigencies for Native writing.

Settler colonial theory also offers a useful reframing of the conversation about Native American students in basic writing studies. More than a decade ago, in the JBW article "Rethinking the Basic Writing Frontier," Laura Gray-Rosendale, Loyola Bird, and Judith Bullock made the important observation that Native students have been rendered invisible by the frontier metaphors, regional biases, racialized preconceptions, and urban focus of basic writing scholarship. Since that article was published, settler colonial studies has emerged as a distinctive field, one that provides a theoretical apparatus and critical vocabulary that helps explain the scholarly oversights that Gray-Rosendale and her colleagues identify. For example, we might understand the absence of Native students in basic writing scholarship - and the uncritical use of frontier discourses to describe teaching and knowledge-making - as a function of settler colonial ideologies that deny the continued presence of Native communities and their ongoing claims to the land.

Furthermore, settler colonial theory provides insight into why Gray-Rosendale and her co-authors experience success with the pedagogical approaches they have developed for working with Native students. For instance, Gray-Rosendale describes inviting her students to analyze popular representations of Native people and "critique how mainstream American culture constructs us all" - to "challenge the American government" and "a United States that constructs Native Americans as "others"” (84). From the perspective of settler colonial studies, I understand her to be giving students the opportunity to grapple with how settler culture circulates anachronistic and homogenizing stereotypes that deny twenty-first century Native presence in order to obscure the reality that the American government presides over a settler state.

However, settler colonial theory also reveals a persistent discursive tension in "Rethinking the Basic Writing Frontier." Although the authors acknowledge that Native students' "lives and experiences var[y] greatly from one another" (95), they repeatedly cite the risk of "assimilation" in basic writing courses: of "taking [students] away from their entire cultures, traditions, rituals, and family structures" (79). While the authors' respect for Native students' heritage and values is admirable, they seem to unwittingly reproduce discourses of Native cultural difference that elide the "modernity and diversity of...actually existing Indian nation[s] (Lyons, "Actually Existing" 297). Such elisions have political implications. For instance, the authors invoke the commonplace of Native students "mov[ing] between 
two worlds" (88), which, as educational ethnographer Donna Deyhle argues, functions to obscure the racialized socioeconomic structures that actually undermine Native students' academic success. By employing these discourses, Gray-Rosendale and her colleagues may inadvertently play into what Maureen Konkle calls the "inordinate focus on Native difference and cultural identity" that abets colonialism by distracting from the political dimensions of Native people's experiences (7).

Lyons asserts that "the discourses of assimilation and authenticity... have always been language games designed for Indians to lose" ("Actually Existing" 303). And indeed, Gray-Rosendale, Bird, and Bullock's focus on the perils of assimilation lead them to overlook the fact that Native students-and the tribal nations that often subsidize those students' education through scholarships-might seek out academic literacies for the purpose of furthering tribal self-determination. Moreover, the "language games" of assimilation situate academic literacies on the non-Native side of a dangerous binary, ignoring the reality that a great deal of basic writing instruction for Native students takes place in tribally controlled colleges. If tribal college writing curricula are assertions of rhetorical sovereignty, a means of resisting settler colonialism by maintaining Native political alterity, then tribal college writing instruction is, by definition, the opposite of assimilation. In its most productive iterations, then, settler colonial theory refocuses attention on Native sovereignty, dispossession, and continued claims to the land, offering a politically engaged way out of the pedagogical double-bind created by the discourses of assimilation, authenticity, and monolithic Native cultural difference. I am fortunate to have the benefit of these theoretical developments as I respond to Gray-Rosendale, Bird, and Bullock's important and (alas) largely unheeded call for more attention to Native American students in basic writing studies.

A brief methodological note before I turn to what I actually did in English 100B: Writing retrospectively, it is easy to present this narrative of pedagogical reasoning as though I had the entire trip mapped out from the beginning, and to imply that I traveled alone, with nothing but a Ford full of theory for company. On the contrary, the practices I describe in the remainder of this essay emerged from an ongoing and often frantic interweaving of my own disciplinary frameworks with what I was learning through interviews and classroom observations over the course of my ethnographic research. Likewise, my teaching functioned as a kind of preliminary analysis of these data, laying the groundwork for the theorization of locally responsive composition pedagogy at Diné College that I developed in my dissertation. The 
research and the teaching were thus inextricably bound up in one another. This essay presents my experiences of the teaching side of the journey, and I take sole responsibility for any questionable detours. However, my English 100B course would not have been what it was without the local knowledge generously shared by my Diné College colleagues and their students.

\section{ENGAGING WITH SETTLER COLONIALISM IN ENGLISH 100B}

The eleven students in my English 100B course were, in many ways, a microcosm of the diversity and complexity of contemporary Diné society. While all self-identified as Diné, several also described themselves as having Pueblo, Mexican, and/or Anglo ancestry. Three students were bilingual, and several of the others understood spoken Diné bizaad to varying degrees, but others said they had little or no understanding of the language. Likewise, students' spiritual identities were diverse and overlapping. Over the course of the semester, they mentioned participating in traditional Diné spiritual practices, the Native American Church, the Church of Jesus Christ of Latter-Day Saints, and other Christian denominations. Furthermore, like the students who participated in my dissertation study, the students in 100B held a wide variety of personal interests and were engaged in an array extracurricular literacy practices.

They ranged in age from eighteen to their late twenties. Some had young children of their own, and several others had major child or eldercare responsibilities within their families. About half of the students had lived their entire lives on the Navajo Nation; others had moved on and off reservation repeatedly throughout their childhood and early adulthood. All of the students lived with immediate or extended family. While several students resided within five miles of the branch campus, others were commuting from as far as fifty miles away, and maintaining reliable transportation to campus was sometimes challenging. For nearly all of the students in the class, personal or family finances were a constant pressure.

The students' academic backgrounds were also diverse. Several had graduated from high school that spring, a few were continuing Diné College students who had been enrolled in English 100A the previous semester, and some were newly enrolled at Diné College but had previously attended other postsecondary institutions, either on- or off-reservation. The rest were entering college for the first time after breaks in their schooling that ranged from a year to a decade. While most of the students had at least some experience using computers for schoolwork, a few struggled with relatively basic skills 
like creating and saving Word documents or attaching email files. Nearly all of the students were among the first generation in their family to attend college. While many were still figuring out their long-term academic and career goals, most expressed a desire for greater financial security for themselves and their families, and several also sought careers that would enable them to contribute to improving life in their communities.

Many of the challenges these students faced in pursuing postsecondary education were bound up in the structures of settler colonialism. These structures have fostered reservation socioeconomic conditions in which unemployment is high, the quality of K-12 education is inconsistent, and poverty-related logistical difficulties and social problems can disrupt students' schooling at every stage. In this section, I discuss three of the more successful ways in which I sought to foreground the rhetorical exigencies of settler colonialism in English 100B while meeting Diné College's self-determined learning goals for the course. First, we contextualized EAE in relation to settler colonialism. Then, we examined how Diné people have historically used writing to resist settler colonialism. Finally, we discussed how Native activists have employed writing as part of broader "transnational indigenous movement[s]" (Huhndorf 366) - both within and beyond the United States-that push back against settler colonialism on a global scale. I conclude with a discussion of students' final course portfolios, which suggest the pedagogical value of these approaches.

\section{Contextualizing Edited American English}

I came into English 100B with some anxiety about how to approach the issue of “correctness" in Diné College students' writing. I was, of course, familiar with longstanding debates in basic writing studies about the effectiveness of direct grammar instruction, and I was also aware that many of the students in my class had a long and stultifying history with writing instruction that focused almost exclusively on sentence-level concerns. Likewise, I had been following recent conversations in the field about translingualism (Canagarajah, "Codemeshing"; Horner et al; Horner), and I was eager to acknowledge and respect the unique linguistic resources in this setting, including the English language variety that most Diné College students now speak as their primary language.

However, it was clear to me from the English 100B course description, my branch campus's textbook requirement, and conversations with my supervisor and other English faculty that Diné College saw advancing 
students' proficiency with EAE as one of the major objectives of the course. I also took seriously Lyons' "unsexy argument endorsing the value of teaching Standard English to Natives" ("Fencing" 79). Lyons views tribal college writing pedagogy as a matter of providing Native students with access to a powerful "grapholect" ("Fencing" 101). In order to succeed at off-reservation colleges and universities, most Diné College students will need to be proficient in EAE, not least because of the racist interpretations some faculty and employers have of "nonstandard" features in Native students' writing. Furthermore, in the context of settler colonialism, competency in EAE is a necessary tool for exerting tribal self-determination and extending sovereignty in legal settings. Thus, it seemed to me that the question was not whether to teach EAE in English 100B, but how. The approach I took aligns in many ways with the concept of critical language awareness advocated by scholars like Keith Gilyard, who writes, "although English itself, much less its written, academically sanctioned versions, has served slavery, colonialism, class oppression, and gender exploitation...the practical situation is that it's a major linguistic tool that we have had to and will have to employ" (38). Gilyard argues that basic writing courses can be spaces in which we help students become aware of the role language plays in both reproducing and reimagining these structures of power-to show them the "revolutionary possibilities of appropriation" (38).

My first step in building such awareness was to contextualize EAE in relation to colonialism. Early in the semester, we spent an entire week discussing the history of "Englishes" on a global scale. I emphasized the fact that English has been shaped over time by multiple invasions of the British Isles by speakers of various European languages, and that the long history of British colonialism has led to a proliferation of spoken Englishes around the world, many of which are now found in settler states and are ascribed varying statuses within systems of race- and class-based inequality (Bhatt). In order to have a concrete basis from which to discuss English language diversity, we watched video clips from Trainspotting-Ewan MacGregor's famous line about Scotland being "colonized by wankers" got a big laugh from the students-as well as The Wire, Smoke Signals, and the reality television show Here Comes Honey Boo-Boo. In our class discussion, the students readily identified defining features as well as the ascribed status of the different English varieties used in those clips.

From there, we began charting some of the distinctive features of Navajo English. While students were quick to come up with unique lexical features (for example, the common exclamation of surprise "Is it?"), it took 
more prompting to get to some of the morphological features that distinguish Navajo English from EAE. Such features include tense markers that function as aspect markers in Navajo English, often interpreted as "verb tense confusion" by English teachers responding to Diné students' writing, as well as different conventions for pluralizing mass nouns (see Thurston; Schaengold; Webster, "On Intimate Grammars"). Several students initially described their own English to me as "bad" or "broken" — characterizations I found downright distressing-so we devoted significant time to deconstructing "Standard English" ideologies, particularly as they function in relation to racism and classism in the settler state. To my mind, discussing, historicizing, and validating Navajo English addresses the college's stated mission to advance student learning through "the study of Diné language[s], history, and culture."

We then turned our attention to EAE as a written language variety: its history, its affordances, and its power, as well as whom it privileges and how it is often (and inaccurately) equated with intelligence, particularly in academic settings. The students examined several examples of writing in English varieties other than EAE, including passages from Irvine Welsh's Trainspotting and Zora Neale Hurston's Their Eyes Were Watching God. We also looked at a facsimile of the first pages of Increase Mather's 1676 A Brief History of the Warr [sic] with the Indians in New England in order to demonstrate how EAE was still in the process of being standardized during the early stages of North American settler colonialism. This text provided an opportunity to talk about how writing has been used to record and privilege settler narratives, an exigency that has prompted responses from Native writers like William Apess, whose "Eulogy on King Philip," published in 1836, directly counters Mather's history of the Pequot War.

With this critical contextualization of EAE in place, we turned to students' own writing-in-progress. Over the course of the semester, their major writing assignments included a literacy narrative, an interview-based essay about the role of writing in a career field they were considering, and a public letter that took a stance on a pressing issue facing students' communities. We took each of these assignments through multiple rounds of revision based on a combination of peer and instructor feedback. When responding to students' writing, I drew on Paul Kei Matsuda's recommendations for helping multilingual students develop metalinguistic awareness. In advanced drafts of students' papers-typically the second or third, after at least one round of feedback and revision addressing more global issues-I began coding patterns of grammar, usage, and punctuation that departed from the conventions of 
EAE. I asked students to use the metalinguistic commentary provided on a code key to inform specific editing decisions in their drafts and to develop personalized "editing checklists"—essentially, reflective editing logs-over the course of the semester. I also discussed some of these patterns with students in individual conferences about their drafts.

The goal of this formative feedback and reflection was to give students the opportunity to become aware of their own patterns of "nonstandard" usage and approach editing with these features in mind. I encouraged students to think of editing as making rhetorical choices about usage based on purpose and audience, rather than as "correction." I encouraged them to incorporate words and phrases in Diné bizaad into their writing when it suited their rhetorical purposes, and to consider their audience carefully when deciding whether and how to translate those words into English. I proceeded from the understanding that we were not "fixing" students' "broken" English, but rather honing their ability to use a powerful written English variety, one that would, as the Diné College mission states, help prepare students for "further studies and employment in a multicultural world" and equip them to use writing to "contribute to the well-being of the Navajo Nation."

\section{Writing Diné Self-Determination}

Once we had contextualized EAE, we began to look at the role writing has played in the history of Diné efforts to retain their lands, defend treaty rights, and assert self-determination and sovereignty in the context of U.S. settler colonialism. We began with the Treaty of 1868 (Naaltsoos Sáni). The signing of this document, which is still celebrated on the Navajo Nation each June, enabled the Diné to return to their homeland after a devastating scorched-earth campaign, forced removal to an internment camp at Bosque Redondo (Hwéeldi), and four years of incarceration, all at the hands of the U.S. Army (Iverson, Diné). In some ways, the treaty exemplifies the double-edged role of writing in the context of settler colonialism: it was used to "contain" the Diné on designated reservation lands in order to secure broader settlement projects in the Southwest, but it also created the legal means for Diné people to reclaim their territories after years of removal. Likewise, the treaty recognized a measure of tribal sovereignty that has been the basis of modern Diné nation-building efforts over the subsequent century and a half.

In English 100B, we examined both facsimiles of the original 
hand-written treaty document (complete with the "X-mark" signatures of Barbonicito, Manuelito, and other well-known Diné leaders during this period) as well as copies of the typed version of the treaty, which is still a living legal document. Only one student in the class had ever read the treaty before, and in small group discussions of the text, students were quick to identify a number of federal promises that had not been met. We talked about how this text and a series of executive orders in the following decades created most of the current boundaries of the Navajo Nation; students were well aware of many of the political and economic implications of these boundaries, although they were less familiar with the legal history that had given rise to them. This led to ongoing discussions of topics like land allotment, termination policies, jurisdiction issues and tribal law enforcement, grazing rights, dry laws, and the racialized socioeconomics of bordertowns like Gallup and Farmington. These last points touched on heated local political issues that sometimes revealed significant differences of opinion within the class, and our debates inspired several students' choice of topics for their final public letter assignment. The Treaty of 1868 thus became the starting point for an unfolding conversation throughout the rest of the semester about the ways that writing, particularly law, continues to shape the social geographies of Diné people's lives in the context of settler colonialism.

Following our extended examination of the treaty, we went on to discuss some of the ways that Diné people used writing in the first half of the twentieth century to pursue greater self-determination and resist settler colonialism. To do this, we looked at several texts from Peter Iverson's volume of primary Diné historical documents (For Our Navajo People). These texts included a series of Diné-authored public letters, speeches, and petitions. One set demanded better teachers and resources for local schools. These appeals for educational resources demonstrate the value that generations of Diné people have assigned to acquiring literacies for contending with the unequal power relations of settler colonialism. They also foreshadow the long-standing desire for community control over the education of Diné children that would come to fruition during the educational self-determination movements of the 1960s (Stein, Tribally Controlled). These letters became an opportunity to discuss the key leadership role that Diné people have played in these pan-Native movements. Some students were proud to learn that the first tribally-controlled community schools and postsecondary institutions in the United States were founded right there on the Navajo Nation.

The second set of documents we examined came from the extended 
campaign for full voting rights for Native people in the Southwest. This discussion was particularly timely during the waning days of the Fall 2012 election. The twentieth-century effort to secure voting rights was an important way that Diné people sought to exert greater presence and influence within the settler state. These uses of writing signal Diné people's desire to participate in that state's future-to help shape its direction and secure greater self-determination within it-rather than fading into the past, as settler narratives demand. As in many college classrooms, students' investments in electoral politics varied widely: several were quite politically engaged at the local and Navajo Nation level, and a few were closely following the national presidential race; other students were uninvolved or cynical about the entire political process. However, many of the students had been unaware that Native Americans did not have the right to vote in New Mexico state elections until 1962. While some of the letters from Iverson's collection were more interesting to students than others, they demonstrated that Diné people have been using writing to seek greater self-determination and resist settler colonialism as far back as students' great- and great-great-grandparents' generations.

\section{Writing Indigenous Transnationalism}

During the final third of the semester, we expanded our scope beyond the Navajo Nation to look at some of the ways writing has figured in transnational Native American and Indigenous movements since the 1960s. I was initially startled to realize that most of the students in the class knew relatively little about the Red Power movement: in late October, when I brought up the fact that the American Indian Movement (AIM) activist Russell Means had recently passed away, only one student in the class knew who he was. We started our conversation about pan-Native political writing by discussing the 1969 Occupation of Alcatraz by Native American rights activists. We read the Alcatraz Proclamation, a public statement released by the activists that claimed the San Francisco Bay island for all Native Americans by right of discovery (Smith and Warrior) and examined how it satirizes the discourses of settler colonialism to critique settler history as well as living conditions on mid-twentieth-century reservations. Students immediately caught the humor as well as the bite of this document, expressing surprise that such a radical statement had been widely circulated by the mainstream news media. More than forty years after the Proclamation was written, students still recognized and appreciated its edge.

During this unit, we also had the opportunity to hear firsthand from a 
Diné activist who had been involved with pan-Native political movements since the 1960s. Jean Whitehorse, a librarian at the campus who has played a major role in efforts to expand internet access across the Navajo Nation, took part in the Occupation of Alcatraz as a young woman and went on to participate in many AIM-related activities over the decades. After hearing about her ongoing political work from another instructor, I invited Whitehorse to visit our class as a guest speaker. She told students about the many Native American political causes for which she has worked and the role that writing plays in her collaborations with activists across the country. Whitehorse discussed the importance of literacy for the well-being of the Navajo Nation, citing examples that ranged from understanding corporate coal mining leases to negotiating government land disputes to her own story of being involuntarily sterilized by Indian Health Service doctors after signing release forms she believed were for an emergency appendectomy. These examples-the environmental exploitation of Diné lands, unresolved controversies over land rights, and what Whitehorse referred to as genocidal federal power over Indigenous women's bodies (see Lawrence)—are all dimensions of settler colonialism that she has experienced within her lifetime. The English 100B students were riveted by Whitehorse's presentation, as well as by the realization that their librarian had been a witness to and a player in the history we were discussing. As one student said on the way out of class, "I thought she was just an old lady."

Finally, as part of a broader discussion about students' takeaways from English 100B during the last week of class, I passed out copies of the United Nations Declaration on the Rights of Indigenous Peoples, passed in 2007 after decades of Indigenous activism (Pulitano). As it turned out, the students knew little about the United Nations and were not familiar with the Declaration. Some, in fact, had been only vaguely aware that there were Indigenous people in other parts of the world who shared similar experiences of settler colonialism, past and present. While we did not have as much time as I would have liked to dig into the Declaration or to look at the role that writing is playing in global Indigenous activism, the students' level of interest in other Indigenous experiences suggests that this would be a fruitful topic to expand in future iterations of the course, perhaps with greater attention to the possibilities of social media and other forms of digital writing for a new generation of Indigenous activists. 
While there are certainly things I will do differently if I have the opportunity to teach this course again, the students' performance in their end-of-semester portfolios suggests to me that framing the course around the exigencies of settler colonialism was a promising approach for achieving Diné College's goals for English 100B in the context of its broader institutional mission. In these portfolios, I asked students to submit final versions of two of their three major writing projects for a letter grade (they had the option of dropping the project they felt was weakest) along with all of their draft materials, their complete editing checklist, and a reflective cover letter. For the cover letter, I asked students to address a series of questions, including:

- How have you grown as a writer this semester? In other words, what are you able to do now as a writer that you weren't able to do in August? Please provide specific examples of this growth from your writing projects.

- How are you using (and how do you plan to use) what you've learned in English 100B in your other college courses? How are you using what you've learned in your life outside of college?

In their cover letters, nearly all of the students stated that they believed their ability to use EAE had improved over the course of the semester, and the contents of their portfolios corroborated these claims. All nine 2 of the students who completed the course produced final drafts that demonstrated greater familiarity with the conventions of EAE. In her portfolio cover letter, Angela 3 went so far as to quantify her improvement over time, writing, "In draft 1, I made 86 mistakes as compared to my second draft, which I made thirty-six mistakes and in my third draft I made only five mistakes." While Angela's use of the word "mistakes" reveals that I was not as successful as I would have liked in reframing students' understanding of patterns of "nonstandard" usage, it is clear that she took pride in her language learning and seemed to appreciate that the editing checklist enabled her to track that learning in a concrete way. However, lest readers suspect that all English 100B did was turn basic writing students into error counters, I will point out that Angela went on to write the following:

I also learned about my history, which I never knew about before. I will educate my children about their history and others as well. I also learned about different Englishes. I now look at the way other people 
talk differently. I know because of their environment, family, and primary language it effects the way and how they speak.

Angela's comments regarding her changed perspectives on language and history were echoed in other students' cover letters, which suggests that this course accomplished Diné College's learning goals for English 100B while furthering student learning through the study of Diné language(s), history, and culture.

In their cover letters, several students also noted their appreciation that the course was not focused solely on grammar. As Rose wrote, "The class was actually fun; it did not seem like an English class...I thought we would be doing grammar nonstop and less writing at first, but the class was different. Thank you for making class not so boring it was the first English class I liked." Comments like Rose's encourage my belief that framing the course around the exigencies of settler colonialism was intellectually engaging for students and helped them begin to understand writing as something more-and more interesting — than just "grammatical correctness." Such comments also affirm that basic writing students at Diné College appreciate being challenged with complex ideas, substantive writing assignments, and high expectations, provided they are also given the scaffolding and instructor support to succeed.

Some English 100B students were particularly galvanized by their expanded sense of how writing could help them make positive changes for Diné people. As Corey wrote, "Standard Written English4 is the key type of writing for our generation, because it has the power to change and make laws for our constitution." Corey's comments reflect an understanding that there are multiple varieties of English, some of which have powerful legal and political affordances. Furthermore, his comments suggest that he found those affordances motivating. In a broader sense, his observations also demonstrate that basic writing courses at tribal colleges-even those that unapologetically assume the goal of "teaching Standard English to Natives" (Lyons, "Fencing" 79)—are not a form of assimilation. On the contrary, they exist to equip students with the linguistic, rhetorical, and literate resources to improve conditions in reservation communities, further tribal self-determination and sovereignty, and resist settler colonialism by maintaining Native political alterity. By framing the course in terms of the rhetorical exigencies of settler colonialism, I believe I made those objectives more explicit to both myself and my students.

\section{CONCLUSIONS/BEGINNINGS}


The basic writing course I taught at Diné College was in many ways a test drive: I started out with what I thought I knew in August 2012, and I made frequent recalibrations as I got to know my students better and learned from long-time Diné College writing faculty. In the year and half since I taught the course, I have spent a lot more time on the road thinking, talking, and writing about writing at Diné College. This essay reflects what I thought I was doing at the time and how I have come to view the experience through the rearview mirror. The aspects of my pedagogical approach that seemed to get some traction offers several insights to other tribal college composition faculty, to writing instructors at off-reservation institutions serving Native students, and perhaps to basic writing faculty in other two- and four-year college settings, as well.

First, this approach moves beyond the well-meaning but misguided worry that teaching academic literacies to Native students is inherently assimilationist. The ubiquity of writing courses at tribal colleges-as well as the extent to which tribal nations subsidize these courses at off-reservation institutions through scholarships (see Gray-Rosendale, Bird, and Bullock) demonstrates that these nations value academic literacies precisely because they can be used to further tribal self-determination in the context of U.S. settler colonialism. The question, as I have suggested, is not whether to teach these literacies, but how. Lyons observes that there is an Ojibwe national literature stretching back to the nineteenth century, one that consists primarily of public writing, which can and should be the basis for tribal college writing instruction (Lyons, "Fencing"). Much of this public writing responds to historically situated exigencies of settler colonialism. The Navajo Nation also has a literature of this sort-Iverson's collection of primary documents is one excellent compendium-as do other tribal nations. These national literatures are as much a part of Native students' heritage as oral traditions, and they can be productive readings for writing courses that affirm Native students' identities and enable them to see themselves as part of a long line of Native rhetors who have used writing to advance their peoples' interests and "refigure "the Indian"” (Powell 400) for national and global audiences.

My experiences in English 100B also contribute to ongoing conversations about the politics of EAE in basic writing instruction. There has, unfortunately, been relatively little scholarly discussion of the role of Native American English varieties in the writing classroom (for exceptions, see Thurston; Lyons, "Fencing"), even less examination of the aesthetic affordances of these English varieties (Webster, “'Still”"), and no discussion of how to help 
students make effective rhetorical choices using the full range of linguistic resources at their disposal. I am not wholly satisfied with the approach I took in 100B - at the time, I did not know enough about the features of Navajo English to discuss it with students as precisely or affirmingly as I would have liked. However, Diné College students' level of interest in the colonial history of English language diversity and in deconstructing Standard English ideologies supports the idea that this is a promising way to contextualize EAE for Native students. Critically situating world Englishes in the broader history of colonialisms and economic globalization-and understanding EAE as both an instrument and a means of resisting the racialized socioeconomic inequalities that result from these histories-could be a productive approach in many basic writing classrooms.

Finally, the introduction of settler colonial theory contributes to the long tradition of critical pedagogical approaches within basic writing studies. Scholars like Ira Shor, Patricia Bizzell, Mike Rose, Min-Zhan Lu, Bruce Horner, Keith Gilyard, and Tom Fox have long advocated basic writing pedagogies that invite students to undertake rigorous intellectual work that includes critical examination of the discourses, language ideologies, and socioeconomic structures that impact their lives and perpetuate classand race-based inequalities. For Native students, such critical pedagogies must include examination of their locations within the structures of U.S. settler colonialism, which shape their social geographies, political realities, and the rhetorical exigencies to which much of their writing responds. However, settler colonialism is not simply a Native issue. All Americans live within a settler state, and the fact that some of us can ignore that reality is itself a function of settler colonialism's ideological structures (Veracini; Wolfe). My work with Diné College students has convinced me that any critical pedagogy should acknowledge the role that settler colonialism, now deeply intertwined with global capitalism, plays in perpetuating the socioeconomic structures in which all our students live, learn, and write. Including Indigenous perspectives in the writing classroom is not simply a matter of multicultural "coverage." As the Diné rhetors in my 100B course taught me, those perspectives enable all of us to locate ourselves in new, critical ways. Since August 2012, I have loaded up my Ford and crisscrossed this country several times over, and it looks different to me now: the land and the people on it have been refigured. Now, I see Native presence, and I see my own accountability to help foster conditions that support positive, self-determined Native futures.

\section{Acknowledgements}


Many thanks to Scott Lyons, Frank Kelderman, and Gail Gibson for their helpful feedback on early drafts of this article, as well as to Cheryl Smith, Hope Parisi, and the two anonymous reviewers whose suggestions contributed much to the final version. I can never sufficiently thank the Diné College faculty, staff, and students who have taught me so much over the last three years, particularly the students in my English 100B and English 102 courses in Crownpoint, New Mexico. I will be forever grateful for their intellectual curiosity, good humor, and willingness to share their stories.

\section{Notes}

1. The Navajo Nation is the legal name for the landbase and government of the people commonly referred to as Navajo. In Diné bizaad, the Navajo language, these people call themselves "Diné," or "the People," which is the preferred term in many Diné College materials.

2. Two of the eleven students who enrolled in English 100B did not complete the course. In both cases, the students were struggling primarily with family and transportation issues rather than insurmountable academic difficulties.

3. The students quoted in this article granted permission to use these passages from their cover letters, and are referred to using pseudonyms of their choosing.

4. In order to align with the terminology favored by the other English instructor at the branch campus, with whom many of my students would be taking English 101 the following semester, I used the term "Standard Written English" rather than EAE in English 100B.

\section{Works Cited}

“ACCUPLACER Tests.” ACCUPLACER. n.p., 25 Apr. 2012. Web. 16 Dec. 2013.

AIHEC-AIMS FactBook 2007. American Indian Higher Education Consortium, 2007. Print.

Barwell, Jay. "Strategies for Teaching Composition to Native Ameri- 
cans." Conference on College Composition and Communication: Dallas, TX, March 1981. Print.

Bhatt, Rakesh M. "World Englishes." Annual Review of Anthropology 30 (2001): 527-550. Print.

Bizzell, Patricia. "Basic Writing and the Issue of Correctness, Or, What to Do with“ Mixed' Forms of Academic Discourse." Journal of Basic Writing 19.1 (2000): 4-12. Print.

---. "What Happens When Basic Writers Come to College?" College Composition and Communication 37.3 (1986): 294-301. Print.

Boyer, Paul. Native American Colleges: Progress and Prospects. A Special Report. San Francisco: Jossey-Bass Publishers, 1997. Print.

Canagarajah, A. Suresh. "Codemeshing in Academic Writing: Identifying Teachable Strategies of Translanguaging." The Modern Language Journal 95.3 (2011): 401-417. Print.

---. "The Place of World Englishes in Composition: Pluralization Continued." College Composition and Communication 57.4 (2006): 586-619. Print.

Clark, Ferlin. "In Becoming Sa'ah Naaghai Bik'eh Hozhoon: The Historical Challenges and Triumphs of Dine College." Dissertation. University of Arizona, 2009. Print.

Condon, William. "Large-Scale Assessment, Locally-Developed Measures, and Automated Scoring of Essays: Fishing for Red Herrings?" Assessing Writing 18.1 (2013): 100-108. Print.

Cushman, Ellen. "The Rhetorician as an Agent of Social Change." College Composition and Communication 47.1 (1996): 7-28. Print.

Daniell, Beth. "Against the Great Leap Theory of Literacy." Pre/Text 7 (1986): 181-93. Print.

--- "Narratives of Literacy: Connecting Composition to Culture." College Composition and Communication 50.3 (1999): 393-410. Print.

Demographic Analysis of the Navajo Nation Using 2010 Census and 2010 American Community Survey Estimates. Window Rock, AZ: Arizona Rural Policy Institute, 2010. Web. 14 June 2014.

Deyhle, Donna. "From Break Dancing to Heavy Metal Navajo Youth, Resistance, and Identity." Youth and Society 30.1 (1998): 3-31. Print.

"Diné College 2011-2012 General Catalog." Print.

"Diné College 2012-2013 General Catalog." Print.

Fox, Tom. "Basic Writing as Cultural Conflict." Journal of Education 172.1 (1990): 65-83. Print.

Gay, Geneva. Culturally Responsive Teaching: Theory, Research, and Practice. New York: Teachers College Press, 2010. Print. 
Gilyard, Keith. "Basic Writing, Cost Effectiveness, and Ideology." Journal of Basic Writing 19.1 (2000): 36-42. Print.

Ginsberg, Margery B., and Raymond J. Wlodkowski. Diversity and Motivation: Culturally Responsive Teaching in College. 2nd ed. San Francisco: Jossey-Bass Publishers, 2009. Print.

Glau, Gregory R. "Returning Power: Native American Classroom (Dis) comfort and Effective Communication." Writing Instructor 10.1 (1990): 51-58. Print.

Gold, David. Rhetoric at the Margins: Revising the History of Writing Instruction in American Colleges, 1873-1947. Carbondale: Southern Illinois University Press, 2008. Print.

Gray-Rosendale, Laura, Loyola K. Bird, and Judith F. Bullock. "Rethinking the Basic Writing Frontier: Native American Students' Challenge to Our Histories." Journal of Basic Writing 22.1 (2003): 71-106. Print.

Grijalva, Michelle. "Teaching American Indian Students: Interpreting the Rhetorics of Silence." Writing in Multicultural Settings. Ed. Carol Severino, Juan C. Guerra, and Johnella E. Butler. New York: Modern Language Association of America, 1997. 40-50. Print.

Horner, Bruce. "Relocating Basic Writing." Journal of Basic Writing 30.2 (2011): 5-23. Print.

Horner, Bruce, Min-Zhan Lu, Jacqueline Jones Royster, and John Trimbur. "Language Difference in Writing: Toward a Translingual Approach." College English 73.3 (2011): 303-321. Print.

House, Deborah. Language Shift Among the Navajos: Identity Politics and Cultural Continuity. Tucson: University of Arizona Press, 2002. Print.

Hughes, Katherine L., and Judith E. Scott-Clayton. "Assessing Developmental Assessment in Community Colleges." Community College Review 39.4 (2011): 327-351. Print.

Huhndorf, Shari M. "Mapping the Americas: The Transnational Politics of Contemporary Native Culture." American Quarterly 62.1 (2009): 359-381. Print.

Iverson, Peter. Diné: A History of the Navajos. Albuquerque: University of New Mexico Press, 2002. Print.

---. "For Our Navajo People": Diné Letters, Speeches \& Petitions, 1900-1960. Albuquerque: University of New Mexico Press, 2002. Print.

Konkle, Maureen. Writing Indian Nations: Native Intellectuals and the Politics of Historiography, 1827-1863. Chapel Hill: University of North Carolina Press, 2004. Print.

Lawrence, Jane. "The Indian Health Service and the Sterilization 
of Native American Women." The American Indian Quarterly 24.3 (2000): 400-419. Print.

Lu, Min-Zhan. "Conflict and Struggle: The Enemies or Preconditions of Basic Writing?” College English 54.8 (1992): 887-913. Print.

---. "From Silence to Words: Writing as Struggle." College English 49.4 (1987): 437-448. Print.

Lyons, Scott Richard. "Actually Existing Indian Nations: Modernity, Diversity, and the Future of Native American Studies." The American Indian Quarterly 35.3 (2011): 294-312. Print.

---. "Rhetorical Sovereignty: What Do American Indians Want from Writing?" College Composition and Communication 51.3 (2000): 447-468. Print.

---. "The Fine Art of Fencing: Nationalism, Hybridity, and the Search for a Native American Writing Pedagogy." JAC: A Journal of Rhetoric, Culture, and Politics 29.1/2 (2009): 77-105. Print.

Matsuda, Paul Kei. "Let's Face It: Language Issues and the Writing Program Administrator." WPA: Writing Program Administration 36.1 (2012): 141-163. Print.

McCarty, Teresa L., and Tiffany S. Lee. “Critical Culturally Sustaining/ Revitalizing Pedagogy and Indigenous Education Sovereignty." Harvard Educational Review 84.1 (2014): 101-124. Print.

McCarty, Teresa L., Mary Eunice Romero-Little, and Ofelia Zepeda. “Native American Youth Discourses on Language Shift and Retention: Ideological Cross-Currents and Their Implications for Language Planning." International Journal of Bilingual Education and Bilingualism 9.5 (2006): 659-677. Print.

Perelman, Les. "Construct Validity, Length, Score, and Time in Holistically Graded Writing Assessments: The Case against Automated Essay Scoring (AES)." International Advances in Writing Research: Cultures, Places, Measures. Ed. Charles Bazerman, Chris Dean, Jessica Early, Karen Lunsford, Suzie Null, Paul Rogers, and Amanda Stansell. Fort Collins, CO: WAC Clearing House, 2012. 121-150. Print.

Powell, Katrina M., and Pamela Takayoshi. "Accepting Roles Created for Us: The Ethics of Reciprocity." College Composition and Communication 54.3 (2003): 394-422. Print.

Powell, Malea. "Rhetorics of Survivance: How American Indians Use Writing." College Composition and Communication 53.3 (2002): 396-434. Print.

Pulitano, Elvira. "Indigenous Rights and International Law: An Introduction." Indigenous Rights in the Age of the UN Declaration. Ed. Elvira Pulitano. Cambridge: Cambridge University Press, 2012. 1-30. Print. 
Rose, Mike. Back to School: Why Everyone Deserves a Second Chance at Education. New York: The New Press, 2012. Print.

Ruoff, A. LaVonne. "Freshman Composition and the Urban Native American.” ADE Bulletin 37.3 (1973): 3-8. Print.

Schaengold, Charlotte. "The Emergence of Bilingual Navajo: English and Navajo Languages in Contact regardless of Everyone's Best Intentions." When Languages Collide: Perspectives on Language Conflict, Language Competition, and Language Coexistence. Ed. Brian D. Joseph, Johanna Destefano, Neil G. Jacobs, and Ilse Lehiste. Columbus: The Ohio State University Press, 2003. 235-254. Print.

Scott-Clayton, Judith E. Do High-Stakes Placement Exams Predict College Success? Community College Research Center: Columbia University, 2012. Print.

Smith, Linda Tuhiwai. Decolonizing Methodologies: Research and Indigenous Peoples. London: Zed Books, 1999. Print.

Smith, Paul Chaat, and Robert Allen Warrior. Like a Hurricane: The Indian Movement from Alcatraz to Wounded Knee. New York: The New Press, 1996. Print.

Spolsky, Bernard. "Prospects for the Survival of the Navajo Language: A Reconsideration." Anthropology and Education Quarterly 33.2 (2002): 139-162. Print.

Stein, Wayne J. “Tribal Colleges: A Success Story.” New Directions for Community Colleges 80 (1992): 89-96. Print.

---. Tribally Controlled Colleges: Making Good Medicine. New York: Peter Lang, 1992. Print.

Sullivan, Patrick. “'A Lifelong Aversion to Writing': What If Writing Courses Emphasized Motivation?" Teaching English in the Two-Year College 39.2 (2011): 118-140. Print.

Thurston, Kay. "Mitigating Barriers to Navajo Students' Success in English Courses." Teaching English in the Two-Year College 26.1 (1998): 29-38. Print.

Tierney, William G. Official Encouragement, Institutional Discouragement: Minorities in Academe- the Native American Experience. Norwood, NJ: Ablex Publishing Corporation, 1992. Print.

Toth, Christie. "Locally Responsive Composition Pedagogy: A Tribal College Case Study." Dissertation. University of Michigan, 2014. Print.

Veracini, Lorenzo. "Introducing: Settler Colonial Studies." settler colonial studies 1.1 (2011): 1-12. Print.

Vizenor, Gerald. Manifest Manners: Narratives on Postindian Survivance. 
Lincoln: University of Nebraska Press, 1999. Print.

Webster, Anthony K. "On Intimate Grammars with Examples from Navajo English, Navlish, and Navajo." Journal of Anthropological Research 66.2 (2010): 187-208. Print.

---. “'Still, She Didn't See What I Was Trying to Say': Towards a History of Framing Navajo English in Navajo Written Poetry." World Englishes 29.1 (2010): 75-96. Print.

Willeto, Paul. "Dine College Struggles to Synthesize Navajo and Western Knowledge.” Tribal College Journal 9.2 (1997): 11-15. Print.

Wilson, Shawn. Research Is Ceremony: Indigenous Research Methods. Black Point, Nova Scotia: Fernwood Publishing, 2008. Print.

Wolfe, Patrick. "Settler Colonialism and the Elimination of the Native." Journal of Genocide Research 8.4 (2006): 387-409. Print.

Wright, Bobby, and William G. Tierney. "American Indians in Higher Education: A History of Cultural Conflict." Change: The Magazine of Higher Learning 23.2 (1991): 11-18. Print.

Zolbrod, Paul. "On the Reservation, Balancing Literacy and the Oral Tradition." Chronicle of Higher Education 29 Oct. 2012.

---. "Talking Circle: Reading and Writing in a Cross-Cultural Classroom.” Tribal College Journal 17.3 (2006): 22-23. Print.

---. "Teaching on the Margin: Notes from a Classroom at Navajo Community College." Profession (1999): 180-192. Print. 


\title{
Noticing the Way: Translingual Possibility and Basic Writers
}

\author{
Sarah Stanley
}

ABSTRACT: This article presents a pedagogical practice for noticing and negotiating error in a multilingual classroom. Two examples from a classroom are compared to demonstrate the importance of "noticing" in the context of translingual pedagogy. The author's first example offers an attempt to negotiate an error with a multilingual writer without such noticing, compared with a more successful negotiation where noticing plays a part in developing a writer's rhetorical attunement. The concept of noticing derives from second language acquisition (SLA) scholarship in which to notice invites attention to a linguistic feature which may belie a writer's expressed purpose. Without noticing error with their students, teachers dismiss errors' relevance to the impact of writing, and also miss opportunities for an entire class to notice and negotiate sentence-level writing.

KEYWORDS: error; translingual; second language acquisition; noticing; grammar

Error, like voice, is a deceptive topic.

-Tracy Santa

$\mathrm{Ty}^{1}$, a multilingual writer, shares his sentence for our last sentence workshop of the year. He writes this sentence on the classroom's dry erase board:

I think that having so many "standard" English's we sometimes lose ourselves in what "standard" English that we need to speak in.

On the digital recorder, there is a pause, then Sherlyn, another multilingual writer, asks him,

Why is there an apostrophe between the English and the 's'?

In a practical-process view of writing, Sherlyn's question to Ty would seem insignificant-the presence of an apostrophe is not the point of Ty's

Sarah Stanley is an Assistant Professor of English and directs University Writing at University of Alaska Fairbanks. She teaches courses on writing pedagogy and mentors beginning teachers. Her research and programmatic interests entail how critical theories can be applied to change policy and redesign writing curricula for more relevance in a dynamic, shifting world.

(C) Journal of Basic Writing, Vol. 32, No. 1, 2013 
sentence. The ideas of Ty's sentence are provocative. Besides, the apostrophe is a matter of editing and so it will be fixed at a later stage. Alternatively, in a theoretical-translingual view, Sherlyn pointing out Ty's mistake may suggest what Anis Bawarshi refers to as "default reactions" to a standardized English (198). Bawarshi explains how a default response about correct or wrong language use are caught up in experiences of linguistic elitism, a set of beliefs surrounding ideas that one way of putting an idea is inherently better than another. David Foster Wallace in "Tense Present" cleverly names linguistic elites, those who may insist on upholding the distinction between among and between being upheld or who point out an errant use of an apostrophe, as "Snoots." In this perspective, Sherlyn's why evokes a Snoot pointing out a mistake-and the response, once the mistake has been noticed, is quite clear: the 's should not be there. The translingual perspective goes further than a critique of the Snoot, however, as it would highlight how Sherlyn's question and its intended response is problematic because it belies the possibility of Ty working English more pliably. That is, her question ignores rather than invites playful readings of Ty's "mistake."

In the translingual turn, language authority is no longer understood as located "in" standardized language varieties published in grammar handbooks, and exercised through teachers' red pens; instead, authority belongs to language users and their texts as written. Aimee Krall-Lanoue refers to the departure as a "detraining of teaching practices" because a teacher "must focus on the text, not what a student 'meant to do'" (237). Min-Zhan Lu and Bruce Horner similarly highlight a distinction in practice which should involve "asking students to explore not what to do and not do, but how they are doing English and why" (41). Agency, or languaging, emerges out of the negotiation that we, as language teachers, must encourage students to explore. In this stance, Ty's sentence needs to be read as already having authority, rather than quickly reading —assuming — that he has made a mistake in writing English's. Consider that Ty mentions the shifting nature of standards ("so many"), and the consequences of these multiple standards when he writes "we sometimes lose ourselves." Ty could be enacting the meaning by committing the mistake intentionally. Or, by writing "in what 'standard English," Ty could be presupposing that "English" itself is in fact multiple. When we take into account the three languages he speaks and writes on a daily basis (in which English is the only one that uses the apostrophe), the apostrophe could be read as an enactment of a proprietary identity. Despite the multiplicity here, because Ty is ignorant of the apostrophe as a linguistic feature, I read English's as an error. In fact, at this point in the transcript of 
the recording documenting this sentence workshop, I'm aware that Sherlyn has created a space for our class to notice the error together.

It is certainly possible to enact a translingual reading without noticing error with multilingual students; yet, to do so assumes a writer may be working English to already realized purposes. In the case of Ty, he may need to fully explore these purposes; he may need some linguistic knowledge because currently he may not be understanding the critical meaning potential between the forms Englishes and English's. In this way, a translingual reading of Ty's sentence without stopping to notice the error may limit Ty's meaning potential. That is, just as we recognize the problematics of assuming basic writers have made "mistakes" in writing, we must similarly recognize that errors can be limit situations for all writers. Errors, we may say, seem to be "unnoticed" by error makers, until brought to attention and noticed-it is only then when errors can be critically negotiated. Noticing error, noticing ambiguity, in fact, can be made just as relevant to foster discursive agency as a content-based discussion concerning a given claim or warrant for a claim in a written argument. The aim of noticing error and translingual pedagogy is not error-free-once-and-for-all-correct and to-a-given-standard writing; instead, noticing can enable social negotiation leading to what Rebecca Lorimer Leonard refers to as "rhetorical attunement" (228). In other words, an agility with translingual possibility.

My article's opening focus on Sherlyn noticing Ty's error draws from a classroom practice I designed which is a sentence workshop. In sentence workshops, students are able to engage in what Second Language Acquisition (SLA) scholarship refers to as self-initiated focus on form (see Ellis, Basturkmen, and Loewen; Williams). Having students select a sentence from their own writing, inviting them to share their purpose in that writing, and then expecting them to field questions from the class audience were ways I set up my Basic Writing classroom, which eventually prompted multilingual students to notice error, and then negotiate it. The role noticing played in helping basic writers see linguistic possibilities of their errors was an emergent feature; I did not start the Basic Writing semester with a disposition toward noticing before negotiating error. Discovering the role noticing played in negotiating error, I shifted how I worked with students, leading here to an argument for deeper consideration of formal matters in translingual practice.

To demonstrate the emergence, I draw on two contrasting cases of student writing and transcripts from two sentence workshops from the same Basic Writing class. The first case is a missed opportunity while the latter one is a full example of noticing "caught on camera!" In short, successful 
negotiation necessitates noticing the difference between error and mistake. In the current discussion surrounding error and mistake in U.S. translingual scholarship, the distinction between an error and a mistake needs to be made clearer in our theorizing, so that we can create interactive spaces in our classrooms where the difference between a mistake, which is readily noticed and resolved when pointed out, and error, which is a miss-communication between writer and reader, is able to be noticed, explored, and negotiated.

\section{The Need for Noticing Errors and Mistakes in Current Translingual Discussion}

Outlining the translingual approach to language difference and writing in College English, Bruce Horner, Min-Zhan Lu, Jacqueline Jones Royster, and John Trimbur address the role of error in a question and answer section titled "Implications for Writing Programs" (310). Their response to the second question- "Does translingualism mean there's no such thing as error in writing?"-is revealing, regarding the state of error in a translingual approach:

No. All writers make mistakes, and all writers are usually eager to remove mistakes from their writing. Taking a translingual approach, however, means that teachers (and students) need to be more humble about what constitutes a mistake (and what constitutes correctness) in writing, rather than assume that whatever fails to meet their expectations, even in matters of spelling, punctuation, and syntax, must be an error. (310)

In this approach, correcting or editing any feature, even a feature that seems to us outside a linguistic boundary, without discussion of the consequences or stances in the writing, would be problematic, especially from the standpoint of critical pedagogy. ${ }^{2}$ A translingual pedagogy would also necessitate discussion, or negotiation, of features that can be read as different. For Basic Writing teachers, translingual pedagogy necessitates slowing down our response and reading differently. However, I also note that in their answer, Horner, Lu, Royster, and Trimbur take up the question about error and use the term "mistake." The terms in use here reflect an orientation that errors are what teachers notice and mistakes are what writers do. That is, errors are the spaces where "[failed] expectations" are encountered. Mistakes, however, are simply miss-takes, and are readily resolved once pointed to, usually by way of the teacher's authority which is certainly noticeable, since "[a]11 
writers make mistakes, and all writers are usually eager to remove mistakes from their writing." Given this difference in orientation, Horner, Lu, Royster, and Trimbur argue that teachers should read differently, and through this reading create a space for negotiation with the writer about error.

Yet, exactly how and when this negotiation occurs must be addressed in Basic Writing classrooms. We, as teachers, struggle within and among ambiguities because of how mistakes, errors, and choices get muddled in our work with students. Tracy Santa's historical taxonomy of error points out that "the dilemma of where, when, and how to exercise an inevitable authority is not easily resolved" (111). In fact, Santa makes this point in her review of 1990s-era U.S. scholarship on error. In this particular period of error studies, the understanding of error was tied to the assumption that "error in large part reflects choice on the part of the student writer" (111). Or tied to another assumption, as Lu demonstrated, error as a contact zone can lead to "self conscious and innovative experimentation" ("Professing" 444). Santa questions in these cases if forced negotiation, particularly when students may seek knowledge of conventions that an "expert," the teacher, might be perceived by the student as withholding, is itself a problematic power relationship which simply displaces the alternative. In other words, before we attempt to create a space for negotiation, we need to first notice errors and mistakes alongside our students. Such noticing reflects the tensions $\mathrm{Lu}$ recognizes within the contact zones of style in our classrooms.

Some evidence of the practical struggle is also in recent translingual scholarship by Suresh Canagarajah, as he highlights the close association between errors and mistakes ("Translanguaging" 9). Canagarajah observes that for the translingual movement "[a]n important consideration is if there is a place for error or mistake" (9). One recent article demonstrates the practical need for mistakes based on his own teacher research of his students' work in translanguaging. In a detailed discussion of a graduate student writer enrolled in his translingual strategy class referred to as Buthainah, Canagarajah presents how the student mistakenly uses three different forms to refer to "Ma Sha Allah" (An Arabic phrase that literally translates "as God has willed") in her writing ("Translanguaging" 22). The student refers to this "mistake" as an error (22). Replying to his inquiry ("Did you think the readers will easily understand your meaning and therefore you don't have to worry too much about editing problems?" (22)), she is "quite embarrassed about this error (and another mistake below)" (22). Definitions follow. Canagarajah writes that 
Mistakes appear to be unintentional and unsystematic choices ... [h] owever, when choices that are intentional fail to gain uptake, we can consider them errors. They can fail for many reasons. They may not have much rhetorical purchase. They may not also achieve success in encouraging readers to co-construct meaning. ... Errors occur when certain translanguaging choices are not effectively negotiated for meaning. Thus we can arrive at a practice-based or performative orientation to error, different from a norm- or formbased definition. (22)

Canagarajah's theorizing here highlights errors through time, as moments "when choices which are intentional fail to gain uptake"; however, a spatial dimension to written errors also applies. Errors can also be distinct from translanguaging choices when a writer is unaware of semantic difficulty on the part of the reader. Or when an error is found to be a semantic misunderstanding between the writer and the reader because of the writer's limited knowledge about a specific linguistic feature in the text, which has a formal meaning to the reader.

In this way, a translingual error is bound not only by interactive time, but also by linguistic space. Recognizing this relationship between writer and reader suggests to me that a spatial definition of error is still relevant, especially for BW. Moreover, the difference between an error and a mistake is an interactive difference, where the error, unintentional and unrecognized by its maker, needs to be noticed before negotiated in writing. When erring, a writer does not know an error has been made; whereas, a mistake, when pointed out, is simple enough to fix because the mistaken writer knows the answer-understands where the corrector is coming from. The difference between an error and a mistake rests in the error-maker's relationship to forms and a meta-knowledge of a given form's meaning-making possibility, knowledge of which makes a difference. Wouldn't a writer, serious about the impact of his or her ideas, appreciate the chance to learn more about error so that the ideas themselves are clearer and have a chance for wider impact?

As teachers, we cannot ignore an error and then engage the error-maker in a negotiation of it. In stating this claim, we are not the only audience that notices errors because our students also notice them, and "noticing" is where "dynamic learning processes" occur (Hanaoka and Izumi 344). Enabling noticing is not simply a matter of pointing out error to a basic writer because "in planned focus-on-form conditions, teachers' intended pedagogical focus does not always match the actual attentional focus of 
the students" (Hanaoka 460). And so, possibilities for meaning are lost. The concept of "noticing" and its relationship to learning is a much-discussed pedagogical concept in Second Language Acquisition (SLA) scholarship. SLA pedagogies thus advocate that teachers notice developmental patterns of error and bring them to a learner's attention in an interactive manner. In this research perspective, an error often represents learning as errors are unnoticeable to the error maker. Empirical studies have referred to this as the Noticing Hypothesis, an "important cognitive process" (Qi and Lapkin 278), in which noticing is an "awareness of a stimulus via short-term memory" where a stimulus is "anything that rouses one's attention . . . with respect to language" (279).

Error, then, is an especially rich opportunity both for language development and for knowledge about a given language's limits, in BW, specifically. When the expected or conventional use of language in a context is violated and creates semantic confusion, we must not assume "mistake" and likewise we cannot immediately engage in correcting or reading error as language authorities. Simply put, given that conscious access to neither systematic English rules and grammars nor rhetorical traditions and cross-cultural understanding is equitable in our classrooms, we need to reorient ourselves and our students toward noticing and talking about error as enabling further possibility for basic writers. We must encourage exploration of the semantic potential by working toward conditions and practices where noticing error can occur, followed by enough time to navigate with our students what is possible. While the teacher should work to enable a noticing which is grounded in meaning realized through some formal translingual options, the teacher is not simply "notice-r" - the role of noticing happens as writers interact.

In this direction, I offer a critical-functional approach to error and basic writers, when three conditions are met: First, there is functional error in the descriptive grammar of the course context-since grammar is fundamental to how we make meaning with language and communicate to others. Second, the violation corresponds to a semantic misunderstanding which muddles the writer's expressed purpose. Third, there exists a knowledge gap between the language users. Once these conditions are met, in a social learning environment, such as Basic Writing, another reader must notice the gap and enable the writer to negotiate. In what follows, I offer how this approach to error developed over a semester of Basic Writing, taught in Fall 2009. 


\section{Teaching Sentences: Teacher-Research Design in Basic Writing Fall 2009}

Familiar with multiple experimental research designs on the relationship between explicit grammar instruction and writing, I recognize how our "intended pedagogical focus" does not always "match the actual attentional focus of students" (Hanaoka 460). Acknowledging this mismatch, I designed a sentence workshop practice so that Basic writers could have interactive experiences with sentence-level choices for their own writing in process. Through the whole class workshop, my primary pedagogical goal was to disrupt some of the determinism that a basic writer can experience about choices, mistakes, or errors in sentence writing. Provided their sentences were "still in process," the entire class would have an opportunity to shape decisions about sentence level writing. In this vein, I sought to enable writers to take more risks in their sentence writing, and through such risks, to learn from the multiple resources writers with diverse language backgrounds always bring to a writing situation.

My experience with student sentence workshops in previous semesters encouraged me to learn more about the reasons behind the decisions that basic writers made in their texts. I was also eager to learn more about the relationships between my teaching and the experience of the workshops from the perspective of the basic writers' revisions post-workshop. As a researcher, I wondered what came up in workshops-what about sentences were students noticing and what reasons were given about what they noticed? I was teaching a shared Basic Writing curriculum in a public research University in the North East, where the Basic Writing course, its teachers, and its students had substantial institutional and programmatic support, including four hours of instructional time per week in computer classrooms, publication opportunities for students, incentives for teachers to research their practices, and graduation credit for the course because it qualified as a "diversity" credit. Students were placed into the class based on their performance on a timed essay exam which was developed by our program director, and then read and scored by teachers of our program in the summer. I was an involved, experienced graduate student who had helped design the curriculum and scored placement exams in the summer. I was also persuaded by current scholarship at the time surrounding World Englishes, multilingualism, and cross-language relations.

Explicit Teaching Yields Mini-Lessons. For these reasons, I felt I was positioned to engage in classroom research about sentence workshops. Before 
teaching the course, I worked with the pedagogical idea of scaffolding, both in terms of my sentence instruction as well as my research inquiry. I taught sentences as critical thinking; and such teaching was embedded in or synced with the existing Basic Writing curriculum. I weaved my research inquiry about sentence level choices alongside the existing course's focus on various literacies, contexts, and power relationships involved with linguistic identities. In order for sentence workshops to elicit the kind of attention I believed would be the most valuable to basic writers, I had to scaffold my teaching of sentences, which I decided would involve explicit teaching of specific sentence techniques or principles, or, mini-lessons occurring each unit. My goal was to help students recognize how the "wording" of ideas positions a writer in unconscious ways. In this teaching, I would select sentences from our program-designed course reader (Multiple Literacies) to teach sentences as constructed, manipulated utterances. I began with our curricular goals and framework and then imagined what aspects of the sentence I sought students to notice. I created framing questions for each unit about which aspect of the sentence I wanted writers to engage with, which worked alongside the assignment sequence. Encouraged by Laura Micciche's “Case for Rhetorical Grammar," I drew on additional rhetorical, functional, and critical theories of language to frame choices in sentence writing as "positioning tools" (see Appendix A as a scaffolding table of these ideas). This explicit teaching amounted to approximately ten minutes of mini-lessons ten times over the semester.

During the explicit instruction, I shared my reasons for selecting a sentence, and I articulated how I understood the sentence's connection to our curricular interest in the unit. I also highlighted a rhetorical principle. For each unit, I selected strategies about sentence level meaning-making that I believed would complement the cognitive processes we as a program believed supported critical thinking (again see Appendix A). In the case of the observation unit, for example, I would choose sentences which I believed would enable noticing a writer's arrangement of words and how arrangement reflects a valuing and positioning of certain ideas over others. One explicit teaching moment drew on Martha Kolln's concept of "end focus," pairing it with a sentence from Perri Klass's "Learning the Language": "And I am afraid as with any new language, to use it properly you must absorb not only the vocabulary but also the structure, the logic, the attitudes" (10). For my teaching, I asked students to consider the four items Klass highlights regarding language in the sentence-then, I asked "Why do you think Klass arranges the four items in the series the way that she does?" I wanted students to use observation as a technique for sentence revision and possiblility. 
Student-Directed Learning: The Sentence Workshops. In addition to this explicit sentence instruction which merged form and content, students went through a recurring writing process each unit, where they would do a week of exploratory writing, followed by drafting and peer review activities. In the process pedagogy, the sentence workshops took place an entire week before the final paper due date to encourage more conceptual revision beyond substituting one word for another. In this way, the practice of asking students to select a sentence from their own writing in progress, rather than my selecting a sentence from their work or finding an example in a published work, offers a chance for noticing to occur for negotiation. I required students to have a reason, but did not require a specific type of sentence to be chosen; in fact, some students chose sentences of which they were proud. Before each of the four workshops, I asked them to reflect in writing on what they hoped would happen in the workshop as well as what sentence they had chosen.

By analyzing the transcripts which showed peer-to-peer as well as my interaction in sentence workshops, I started to pay more attention to what my students noticed, and through my noticing, I noticed an assumption in my pedagogical design about the difference between mistakes and errors. ${ }^{3}$ I realized I was working through a deep anxiety about my sentence-level instruction being perceived by my students as "snooty." This disposition toward error and mistakes was affecting how I interacted in the workshops, and because of it, noticing could not flourish. I saw how in earlier sentence workshops my students were attempting to notice error, even as I thwarted this possibility by leaping too quickly into negotiation.

In the next section, I introduce Pik, a multilingual, U.S. immigrant student from China, who helped me notice noticing. In the example, Pik shares a sentence with an error, but it goes unnoticed. What's more is that without noticing the error, Pik attempts to re-work the sentence and ends up creating a statement which I argue belies her purpose. At this point in the semester, I had not yet theorized the importance of noticing with my sentence pedagogy, and so consequently, neither could Pik or her peers. Instead, I tried to help her negotiate meaning as if she, like myself, recognized her initial mistake.

\section{Not Noticing Error as a Teacher: Pik's Tradition Rule}

By the midterm of Fall 2009, I had not yet recognized the distinction between error and mistake and the role of noticing before negotiating. So, during the second unit of the semester, as students were working on applying what they were learning about language and literacy use in context, a mul- 
tilingual student named Pik shared a sentence with a lexical-grammatical error that went unnoticed before it was negotiated. Pik had been participating in these discussions, and the transcript below is from her first sentence workshop in front of her peers. The workshop is brief, and this too is part of my discovery; it is brief because noticing was not present. She chose the following sentence:

I never thought silence would be a problem since I got used to it when I was little. It turned out to be a tradition rule in our family.

The first question after Pik shared this sentence was from Sonya, a second-generation immigrant, who identified as knowing only English:

What do you mean by tradition rule?

Here, Sonya notices the error. Before Pik can answer, someone else asks her about the "rule":

Is the rule "in your family," or is it a "rule where you are from"?

Pik: I think it is like a rule in my family.

I interrupt. I attempt to get Pik to negotiate the "error":

Me: Tradition, I think, suggests larger than just a family, a tradition. So I think you might need another adjective in there, like: it turned out to be a family tradition. Period. Because when you say traditional rule, we are sort of thinking, "oh it's even bigger." But you're really talking about your family tradition.

At the time, I felt good about the conceptual distinction I provided between the forms "tradition rule" and "family tradition." I felt I was being explicit and helpful. From this perspective, I had applied a descriptive rule of English grammar, order of nouns, to the meaning of Pik's sentence. I had listened to her peers' questions, and offered her a choice. However, I hadn't listened to Pik talk about her understanding of her forms-- there was no space for interaction. Instead, as the authority, I had interrupted, quickly and implicitly, inviting her to negotiate, but without providing the time and space for Pik to notice and work with the limits of her error. I came to these 
conclusions when I read how Pik revised her sentence-after the workshop, she edited the sentence as follows:

Original: It turned out to be a tradition rule in our family. Edited: It turned out to be a tradition rule in my family.

The edit evidences two insights-one, Pik understood the semantic distinction between "our" and "my" in her writing, and two, the syntaxical error had gone unnoticed. Pik's sentences are also examples of a writer interpreting implicit feedback to linguistic features in an incorrect manner, a kind of implicit instructional feedback that John Truscott has demonstrated results in problematic negotiation by English Language Learners (see also Ferris on "error" and Second Language Writing). Since my suggestion reflected an implicit understanding of syntax which I had and Pik was still acquiring, my authority squashed the potential discussion of Pik's translingual potential; the difference between "in your family" and a "rule where you are from" was not pursued by her peers in her workshop. Consequently, I did not recognize that Pik needed to field some questions from her peers: Did she mean such and such? Could it be that? Was she offering something like this? Instead of interactive dialogue, I had decided to say back the "right" wording, a form of implicit feedback in this context. This feedback, which did not notice the error as error, was then negotiated by Pik in a manner that may have belied her purpose.

I also have concerns that the "our" to "my" individualizes Pik in a kind of Western-individual discourse, a discourse that Pik may or may not resist. The new sentence takes its cue from a common convention that "my" is a Western particularization of experience, and is more idiomatic than "our." Yet, it is an ideological revision that I cannot claim is hers because I do not know her intention, and yet again, my authority in shifting her sentence is clear to me. I'm imagining, for instance, Pik being encouraged to experiment with the wording of "tradition rule," and perhaps getting at semantic possibilities that I, as a monolingual speaker of English, could not have anticipated. In this case, I care that our communication-that is, between what I asked her to consider and how she took up that consideration-resulted in her meaning remaining not just wrong but unclear. Others might claim that the continued iteration of "tradition rule" in the sentence is an example of agency. I'm still wondering, however, what does she mean by tradition rule? What's different, to her, about the meaning of tradition and rule? 
In Pik's workshop, we did not notice the error, and because we did not notice it, we also could not discuss the meaning which needed to be negotiated. The consequence: Pik could not continue developing deeper understandings of how form and content of English work for her purposes. If I had worked to help Pik and the other students notice the error, I could have then encouraged more interaction surrounding Pik's intention in the sentence. This sort of play is only possible, however, with more explicit awareness of the rules of a language system in which one is operating, and of that system's nature as a lexical-grammar. ${ }^{4}$

By contrast, in the classroom scene below, Ty experiences a revision which I can claim as his. Ty, like Pik, did not, at the beginning of his workshop, understand his options well enough to make a choice for how to represent his intention. Yet, unlike Pik, he was able to notice his error during the workshop and before he was asked to draw on the experience in his writing post-workshop. Another difference was my orientation to error and mistake. At this point in the semester, I had come to problematize my pedagogy toward granting students the space to notice error.

\section{Noticing Error as a Workshop: Ty's English's}

For the fourth and last workshop of the semester, Ty stood at the front, and waited. He wrote his sentence on the dry erase board, read it aloud, and listened for our response. His sentence, "I think that having so many "standard" English's we sometimes lose ourselves in what "standard" English that we need to speak in," received no suggested revisions at first. Instead, it was met with Sherlyn asking him, perplexed,

Why is there an apostrophe between the English and the ' $s$ '?

Her question prompts Ty's reasoning:

Ty: Well, English is. . well, that's what it did, the autocorrect when I was writing, cuz without the apostrophe it put a red line on it so I right clicked and it said put the apostrophe, possessive or something. Is that correct to use? I don't. . .

Ty's response brings a context into our classroom that had before this point been "invisible" - the role of MS Word's grammar checker. His response is motivated by a simplistic notion of correctness and trust in spell-check as 
a determiner of correctness. His question to the workshop about whether the apostrophe is "correct to use" is answered by the effect of Ty's use of the apostrophe, since, as Sherlyn says to him,

I just don't know what it means.

The confusion about what the convention means takes up a considerable amount of Ty's workshop. In the discussion, Ty shares some of his linguistic background, which includes use of the German language, in which apostrophes are not used, as well as the awareness that apostrophes are important because they reveal relationships between nouns:

Ty: I've never used apostrophes before, so. . . because in Germany you don't need the apostrophes, you don't have. . . my mom was telling me the use of them, the possessive or something like. . . when you say "someone's dogs" or whatever you put the apostrophe because that's their dog or whatever. . . . So, is it like that? I don't know.

Throughout the workshop, Ty is often looking for confirmation or security in his discussion of his reasoning, which develops into a rhetorical reasoning about this choice. I notice his anxiety throughout our exchange. I purposefully withhold answers, as I wish to investigate the reasoning behind his decision to write English's, and because the opportunity to discuss in-depth how grammatical coding functions is an important aim in critical reasoning about form.

Me: Ok, so you are understanding the rule of the apostrophe... . Ty: Yea.

Me: And, Microsoft Word's grammar checker told you to put it there, but is there a possession, I mean, what did. . . your application of it, Ty?

Ty: Is wrong?

Me: What's wrong?

Ty: The apostrophe where I put it?

Me: How do you understand what the rule is supposed to mean. .. and...

Ty: Well English belongs to the Standard, doesn't it? No? 
Ty, however, doesn't seem convinced. He's applying the rule of the possessive to his sentence. He does so through his reasoning involving MS Word's grammar checker and his mother's teaching of the general rule, and these contexts taken together likely construct his paradoxical, and philosophical, statement: "English belongs to the Standard, doesn't it?" At this point, while I sense his frustration, I still don't want to provide him with critical thinking about this form—-that's his job.

Me: I mean, I think, you are making Standard English plural, right? Ty: Yea.

Me: And do you think that Microsoft Word understands the radical nature of making Standard English plural?

Ty: I don't think so. . .

Me:. . . the. . . pluralization of English isn't going to be understood by MS Word. But what MS Word is able to do, oh, you put an "s" on a word that I don't think ever has an "s" it must be a possessive use and so it gave you the red squiggle and you looked at it, and thought, get this off my screen. Accept change.

Ty: Yea, that's pretty accurate. ... So, no apostrophe?

Me: I don't know.

I said "I don't know" because I hesitated to "answer" Ty's question about what to do. If I had offered him an answer, I would not help him with noticing his choice. I saw such a (lack of) response was productive for his workshop, in fact, as it created a more interactive space.

Ty: I don't know either, that's why. . . it looks cool but. . .

Taquana: You should take it out.

Someone: Hmmm. . .

Taquana: You aren't saying English is. . .

Tejada: It's not possessive.

This interactive exchange, prompted by Sherlyn's confusion about the apostrophe-s, essentially tells Ty what he should do based on what his intention is and what he means, which is distinct from a prescriptive correction-based reasoning about this same choice and his language background about the lack of apostrophes. In this way-given my prompting that MS Word is based on standardized English and therefore would not understand Ty's meaning-making — the reasoning behind Taquana and Tejada's suggestion 
to "take out" the apostrophe is an example of noticing. While I initiated the critical reasoning for Ty's choice, these other students realized and made clear to Ty that his use of "English's" is wrong.

Based on this analysis, it's revealing that, had this happened quickly in the workshop-by a simple editing suggestion from a peer, perhaps-Ty wouldn't have had the same experience. In fact, by slowing down the writing classroom, we were able to support his meaning-making by allowing him space to develop his misunderstanding, something that brought a kind of clarity to the discussion.

Sherlyn was engaged here, and after Tejada stated for Ty that he should not be using the apostrophe, she brings up a related issue. How should he spell it?

Sherlyn: e-s or just s.

Me: So, if you are trying to make a word that the dictionary in Microsoft Word is not getting, right? In some ways, this is maybe bringing our context, your purposes of English into this sentence, right? How are you going to write Standard Englishes so that we know what that is? And. . Sherlyn just said you could write "s" or "e-s." So how do you know which one you should spell?

Ty: But I...

Me: you are going to have to think and apply...

Ty: Spell it myself?

Me: How would you spell it?

Ty: Like that, without the apostrophe.

Taquana helps him out again by bringing up the stylistic nature of spelling in his case. He gets to choose how he wants to spell it.

Taquana: But if you write it -es, isn't that a style factor or whatever. Like, when you are making up a word, not, kind of making up a word, you have as a writer you can choose how you want to spell it or not, so it's not necessarily wrong.

Here, Ty perhaps starts to apply his own rhetorical reasoning, as he remembers that there are conventions to spelling that relate to the place of English. 
Ty: Well, I know like, when, here, in America you spell color c-o-1o-r, but in Europe you spell it c-o-l-o-u-r.

Taquana: Really?

AJ: Yea.

Me: Yep that's British English versus American English [sic]... . So, I think that using your multilingual background, Ty, think about the spelling. I will say "s-h" as an ending of a word that gets an "s" the rule is?

Sherlyn: -es.

Me: So, think about that. Or, Google it and see if other people are using "Englishes" and how they are referring to it and choose it that way. Just because you can't find it in Microsoft Word telling you what to do, doesn't mean that you can't have a principle for what you are choosing.

Throughout this exchange, there is evidence of prescriptive and descriptive reasoning concerning Ty's choices whether to remove the apostrophe or keep it and how to spell "Englishes." Ty's peers push him to consider his options before he simply chooses to focus on the spelling of the word. This occurs when he answers my question regarding how he would spell it, using his initial spelling prior to the auto-correction in Word. Taquana pushes him to consider the stylistics behind spelling, just as AJ and Ty himself remember that spelling can also identify an English speaker as a specific type. In this way, our rhetorical consideration opens Ty up to not only consider correctness and communication, but now also the contexts of the English language, as well as its audience. In this way, the collaborative atmosphere of the workshop keep Ty's purposes in mind, and yet also work to extend those purposes, by considering the effects his choices of spelling and punctuation have on his audience. As I join the discussion, I deliberately ask him to consider context and to better own his intention to make "English" plural.

Ty, who was still drafting at the time of the workshop, did not elect to change his original use of English's in his draft. He did, however, in post-workshop writing, use the more appropriate for his purpose term "Englishes." Clearly other aspects of Ty's practice need to be noticed by him and encouraged by me: namely, revision as re-seeing; because, yes, in a pedagogical reading, his choice to write "Englishes" is reduced in effect by the continued presence of "English's" in his final draft. And so, yes, as his teacher, I was disappointed that Ty did not revise his paper with the experience of the workshop in mind. Yet, from the standpoint of a noticing 
pedagogy, the contrast between both English's and Englishes in the paper does help one recognize the impact of the workshop on Ty's writing. For me, his final essay demonstrates that, from the moment of the workshop on, Ty was making a choice to write Englishes, despite the red squiggle. Even now as I write Englishes, the red line appears. I can imagine now how one might notice the red squiggle but still not notice the reasons for it appearing. Whether or not Ty right-clicked on Englishes to "add" it to his dictionary in order that the red squiggle did not appear again cannot be known because I never asked him about his process post-workshop. Despite not knowing, however, I like thinking in divergent ways of whether or not Englishes still appears in red in his word processing program. Put another way, the sentence workshop helped Ty acquire and develop some intuition with standardized language. He now may take a second look at the red squiggle appearing in future instances. In his working of English, he may decide that he can turn nouns into pluralized forms for his own rhetorical effects.

\section{Noticing Englishes}

At the time I taught this class, the term "translingual" was not yet circulating; instead, as referenced, I was working with ideas surrounding the politics of linguistic diversity in its forms in ways similar to current treatments in translingual discussion. As I aligned my classroom with such pedagogical goals, I also ignored features in student texts that were wrong. I failed to recognize how my linguistic authority read through language for intentional meaning - a reading which did not enable the kind of learning and working with Englishes we seek. Pik and Ty as examples should now pose questions to our role as language authorities in BW: Are we there to help students negotiate mistakes? Or, are we there to help students notice and negotiate error? Through noticing such questions, we uncover power relationships both inside and outside BW.

My concern about power and its relationship to error matters especially in a time when zeal for translingualism poses definitional questions for the field of Second Language Writing. In a provocative dialogue in the Journal of Second Language Writing, Canagarajah writes that "second language writing" as a concept is "misleading" and should be questioned given current calls for all writing to be understood as translingual ("The End" 441). Unfortunately, discussions of translingualism often reduce SLA to being focused primarily on "target" proficiency. Horner, for example, in pointing to an intersection between SLA scholarship and past BW understanding of error, equates the 
concept of "interlanguage" to BW's discourse of error, an equating which Horner reads as evidence of BW's risk of directing students away from "interlanguage" and toward monolingual norms ("Relocating" 11). Horner goes on to reference scholarship specific to BW, such as David Bartholomae, Glynda Hull, and Elaine Lees as part of the SLA tradition, putting forth the argument that "interlanguage" was then and still is a fraught concept. "Interlanguage" in SLA theory, discussed in the recently edited collection Interlanguage: Forty Years Later, however, is similarly shifting its goals and ends. According to Diane Larsen-Freeman's contribution, "interlanguage" is a good example of shared premises between translingualism and SLA. Larsen-Freeman understands language as "an open system, always changing, never fixed," and asserts that its speakers reflect "a dynamic network of language-using patterns: emergent, mutable, and self-organizing" (213). Further, this articulation is not new. Larsen-Freeman's work, in fact, has resonance with Horner's recent arguments in Journal of Basic Writing about the need for incorporating time and timing within our approach to working English. "In other words," as Larsen-Freeman puts it, "we need a camcorder, not a camera" (159).

The SLA model, in previous scholarship by Horner, is discussed as associated with the eradicationist and assimilationist models, and as such is thought to maintain a "tacit politics of English Only" in the teaching of writing (Horner and Lu "Rethinking" 144). Horner seems to encourage us to turn away from SLA empirical research findings about the treatment of error and interlanguage. In earlier scholarship, Horner and co-author Lu critique this treatment as the "Second-language-interlanguage" model ("Rethinking" 144). Basing this claim on such a description of SLA error analysis involves, according to Lu and Horner, "proofreading skills to identify deviant marks," as the goal is the "production of writing in conformity with the conventions of EAE/SWE" (145-146). Clearly, Horner and Lu's interpretation of this model rests in a prescriptive notion of usage, which they read as wired into SLA theory. Even at face value their critique raises a problem, as some readers would argue that the practice of teaching conventions does not translate to "conformity," because teaching is additive and students always exercise choice. On a deeper level, though, we need to recognize that our students' power to choose is dependent and relative to the number of options possible. Limits to these options occur when errors go un-noticed, and thus limit the range of semantic potential to be negotiated. In my view, there is a power in both linguistic and rhetorical knowledge, including knowledge of error, which can, if noticed, be used to bring about translingual possibility. Moreover, we must not allow the critique-that SLA is snooty-to dismiss the productive 
aspects of SLA pedagogical theory in our increasingly linguistically diverse Basic Writing classrooms.

At the same time that we question the political motives of BW, we need to notice that variance in writers' intentionality is not the same as differing levels of conscious knowledge about how a particular example of language use could work in a given context, by diverse audiences. Recognizing how power operates in the distinction between error and mistake is what leads me to insist on a theory of error which differs from mistakes and failed negotiations, and to imagine how we might teach translanguaging, given the differences in conscious linguistic knowledge present in our classrooms. We must continue to question entrenched language attitudes about Basic writers. We should not question our feelings that prescriptive takes on language can be disastrous for fostering critical awareness about words and wording. Yet, at the same time that these beliefs contribute to a disciplinary understanding of error as less a "feature of text" than a feature of "context" (see Santa; Lunsford and Lunsford), this understanding also reflects the privilege of a standardized reader, who can choose to read through language. Our classes, our students, our languages are changing, and so, we need to also pay attention to what may seem to our students and ourselves as a contradiction-analyze the features of language as meaningful for constructing social context; yet ignore error to find meaning in a student text. We need to create spaces in our classrooms for students to notice the linguistic features of their working English so that they can also become moments for noticing the way toward translingual possibility. And, we must continue to reclaim the sentence from notions of "rules" and "violations," emphasizing its translingual potential in much the same way we approach the teaching of writing. Noticing those moments in our work with Basic writers where the distinction between an error and mistake can be muddled, we can in those same moments allow noticing to unfold-offering our guidance to help Basic writers find themselves in a productive space for translingual possibility.

\section{Acknowledgments}

Thank you to students in Basic Writing 2009, Anne Herrington, and Hope Parisi for helping me notice error. 


\section{Notes}

1. The IRB-approved protocol for this project included a question about whether and how students wanted to be named. All students chose how to be named and to use their actual names.

2. In Education for Critical Consciousness, Paulo Freire writes that "[a]cquiring literacy does not involve memorizing sentences, words, or syllables-lifeless objects unconnected to an existential universe-but rather an attitude of creation and re-creation, a self-transformation producing a stance of intervention in one's context" (45). A language policy that enforces one standard rather than also engaging the multiple standards of its participants' literacies violates this premise.

3. Through a systematic analysis, a process in which I refined categories and coded student reasoning, I had also learned how my students developed more nuanced understanding about the relationship between form and content in their own writing. For instance, I was able to notice how many of these students arrived in Basic Writing with an arhetorical orientation about their own sentence writing. Students would report how they did not believe there was really a difference between one word and another (privilege v. luck, for example) but through the semester, I learned how the sentence scaffolding with the existing critical Basic Writing curriculum was contributing to students arriving at more conscious understanding about linguistic forms and how they relate to their own purposes in writing. This discovery was tempered by the discovery of noticing which I believe has implications for all writing classrooms.

4. Pik's placement challenged my grammatical sense that in U.S. edited English, nouns modify other nouns when the relationship of modification has meaning in the system of language that speakers use. That is, while it is permissible to say "family tradition" since family, a noun, modifies tradition by semantically specifying tradition as a "type," it is nevertheless not permissible to modify "rule" with tradition in the same way, as these two nouns are not conventionally used to modify one another. Semantically, tradition and rule violate a poetic syntax of order. Knowledge of this syntax is often implicit unless it becomes explicit.

\section{Works Cited}

Bakhtin, Mikhail. "Dialogic Origin and Dialogic Pedagogy of Grammar: Stylistics as Part of Russian Language Instruction in Secondary School.” 
Liudmila A.Gogotishvili, Trans. Journal of Russian and East European Psychology. 42.6 (2004): 12-50.

Basic Writing Editorial Collaborative. Multiple Literacies. Boston: Pearson Custom Publishing, 2009.

Bawarshi, Anis. "The Challenges and Possibilities of Taking Up Multiple Discursive Resources in U.S. College Composition." Cross Language Relations. Eds. Bruce Horner, Min Zhan Lu, and Paul Matsuda. Carbondale: SIUP, 2010: 196-203.

Canagarajah, Suresh. "Introduction.” Writing as Translingual Practice in Academic Contexts. Ed. Suresh Canagarajah. London: Routledge, 2013: 1-10.

---. "Multilingual Strategies of Negotiating English: From Conversation to Writing." JAC. (2009): 17-48.

---. "The End of Second Language Writing?" Journal of Second Language Writing. 22.4 (2013): 440-41.

---. "The Place of World Englishes in Composition: Plurization Continued." College Composition and Communication. (2006): 586-619.

---. "Translanguaging in the Classroom: Emerging Issues for Research and Pedagogy. Applied Linguistics Review. 2 (2011): 1-28.

Ellis, Rod, Helen Basturkmen, and Shawn Loewen. "Learner Uptake in Communicative ESL Lessons.” Language Learning. 51.2 (2001): 281-318. Hanaoka, Osamu. "Output, Noticing, and Learning: An Investigation into the Role of Spontaneous Attention to Form in a Four-Stage Writing Task." Language Teaching Research. 11.4 (2007): 459-79.

Hanaoka, Osamu, and Shinichi Izumi. "Noticing and Uptake: Addressing Pre-articulated Covert Problems in L2 Writing." Journal of Second Language Writing. 21.4 (2012): 332-47.

Ferris, Dana R. Treatment of Error in Second Language Student Writing. Ann Arbor: U of Michigan P, 2011.

Freire, Paulo. Education for Critical Consciousness. New York, Bloomsbury P, 1973.

Gee, James. An Introduction to Discourse Analysis Theory and Method. 2nd Edition. London: Routledge, 2005.

Horner, Bruce. "Introduction: Cross-Language Relations in Composition." Cross Language Relations in Composition. Spec. Issue of College English. 68 (2006): 569-73.

---. “Relocating Basic Writing.” Journal of Basic Writing. 30.2 (2011): 5-23.

Horner, Bruce and Min-Zhan Lu. "Resisting Monolingualism in 'English': Reading and Writing the Politics of Language." Rethinking English in Schools: Towards a New and Constructive Stage. Ed. Viv Ellis, Carol Fox, 
and Brian Street. London: Continuum, 2007: 141-57.

Horner, Bruce, Min-Zhan Lu, Jacqueline Jones Royster, and John Trimbur. "Opinion: Language Difference in Writing: Toward a Translingual Approach." College English. 73.3 (2011): 303-21.

Halliday, Michael A. K. An Introduction to Functional Grammar. Baltimore: Edward Arnold, 1985.

---. Language as Social Semiotic: The Social Interpretation of Language and Meaning. Baltimore: U Park P, 1978.

---. "Things and Relations: Regrammaticising Experience as Technical Knowledge." J.R. Martin and R. Veel, eds. Reading Science: Critical and Functional Perspectives on Discourses of Science. London: Routledge, 1998: 185-235.

Halliday, Michael A. K. and Ruqaiya Hasan. Language, Context, and Text: Aspects of Language in a Social-Semiotic Perspective. London: Oxford UP, 1989.

Kolln, Martha. "Rhetorical Grammar: A Modification Lesson.” The English Journal 85.7 (1996): 25-31.

---. Rhetorical Grammar: Grammatical Choices, Rhetorical Effects. 4th Ed. Boston: Pearson, 2003.

Krall-Lanoue Aimee. “'And Yea I'm Venting, But Hey I'm Writing Isn't I': A Translingual Approach to Error in a Multilingual Context." Writing as Translingual Practice in Academic Contexts. Ed. Suresh Canagarajah. London: Routledge, 2013: 228-34.

Larsen-Freeman, Diane. "Another Step to be Taken-Rethinking the End Point of the Interlanguage Continuum." Interlanguage: Forty Years Later. Eds. ZhaoHong Han and Elaine Tarone. Philadelphia: John Benjamins, 2014: 203-21.

---. "Chaos/complexity Science and Second Language Acquisition." Applied Linguistics 18.2 (1997): 141-65.

Leonard, Rebecca Lorimer. "Multilingual Writing as Rhetorical Attunement." College English. 76.3. (2014): 227-47.

Lu, Min-Zhan, "An Essay on the Work of Composition," College Composition and Communication. 56 (2004): 16-50.

---. "Professing Multiculturalism the Politics of Style in the Contact Zone." College Composition and Communication. 45.4 (1994): 442-58.

Min-Zhan Lu and Bruce Horner. "Translingual Literacy, Language Difference, and Matters of Agency." College English. 75.6 (2013): 582-607.

Lunsford, Andrea A., and Karen J. Lunsford. “'Mistakes are a Fact of Life': A National Comparative Study." College Composition and Communication. 59.4 (2008): 781-806.

Micciche, Laura R. "Making a Case for Rhetorical Grammar." College Com- 
position and Communication. 55.4 (2004): 716-37.

Qi, Donald S., and Sharon Lapkin. "Exploring the Role of Noticing in a Three-stage Second Language Writing Task." Journal of Second Language Writing. 10.4 (2001): 277-303.

Santa, Tracy. Dead Letters: Error in Composition, 1873-2004. New York: Hampton P, 2008.

Truscott, John. “The Effect of Error Correction on Learners' Ability to Write Accurately." Journal of Second Language Writing. 16.4 (2007): 255-72.

Wallace, David Foster. "Tense Present: Democracy, English, and the wars over usage." Harper's. April 2001.

Williams, Jessica. "Learner-Generated Attention to Form." Language Learning. 49.4 (1999): 583-625.

---. "The Potential Role (s) of Writing in Second Language Development." Journal of Second Language Writing. 21.4 (2012): 321-31. 
Sarah Stanley

Appendix:Table A

Scaffolding Sentence Instruction in the

Basic Writing Curriculum

\begin{tabular}{|c|c|c|}
\hline Type of Essay & $\begin{array}{c}\text { Theoretical Approach and } \\
\text { Pedagogical Strategies }\end{array}$ & $\begin{array}{c}\text { Pedagogical Questions and } \\
\text { Theoretical Concepts }\end{array}$ \\
\hline $\begin{array}{l}\text { Mapping Literacies } \\
\text { through Experience } \\
\text { (a short essay explor- } \\
\text { ing one way they make } \\
\text { meaning with others) }\end{array}$ & $\begin{array}{l}\text { Positioning parts of the } \\
\text { sentence (such as phrases } \\
\text { and words) to make } \\
\text { different meanings. } \\
\text { *Rhetorical Grammar } \\
\text { (Bakhtin; Kolln). }\end{array}$ & $\begin{array}{l}\text { How does where a word } \\
\text { is placed matter to the } \\
\text { sentence's meaning? } \\
\text { How else could you ar- } \\
\text { range this sentence? } \\
\text { (parataxis, hypotaxis; } \\
\text { end focus) }\end{array}$ \\
\hline $\begin{array}{l}\text { Bringing Literacies Home } \\
\text { through Close Reading } \\
\text { (essay that brings at least } \\
\text { one course perspective to } \\
\text { bear on a choice of being } \\
\text { silent or speaking) }\end{array}$ & $\begin{array}{l}\text { Analyzing the choice(s) } \\
\text { of a sentence in terms } \\
\text { of its lexical, conven- } \\
\text { tional and grammatical } \\
\text { aspects, then mapping } \\
\text { that choice onto other } \\
\text { options for it. } \\
\text { *Functional Grammar } \\
\text { (Halliday). }\end{array}$ & $\begin{array}{l}\text { What is the difference } \\
\text { between the writer's } \\
\text { choice and another } \\
\text { option the writer could } \\
\text { have chosen? Why does } \\
\text { the choice make sense } \\
\text { based on the writer's } \\
\text { context? } \\
\text { (given new contract; } \\
\text { modality) }\end{array}$ \\
\hline $\begin{array}{l}\text { Examining Literacies of } \\
\text { Power through Privilege } \\
\text { (essay that brings in at } \\
\text { least three perspectives } \\
\text { that relate to a generative } \\
\text { theme) }\end{array}$ & $\begin{array}{l}\text { Examining the relation- } \\
\text { ship(s) that choice(s) of } \\
\text { sentence structure has } \\
\text { to wider ideological con- } \\
\text { texts and discourses. } \\
\text { Critical Grammar (Gee). }\end{array}$ & $\begin{array}{l}\text { In this use, what about } \\
\text { the concept is being } \\
\text { highlighted and what is } \\
\text { not being highlighted? } \\
\text { What are the conse- } \\
\text { quences and effects of } \\
\text { this choice? } \\
\text { (backgrounding and fore- } \\
\text { grounding; discourse). }\end{array}$ \\
\hline $\begin{array}{l}\text { Unschooling Literacy } \\
\text { through a Writerly Sense } \\
\text { of Purpose } \\
\text { (a reflective essay } \\
\text { applying our curricular } \\
\text { reading to a theoretical } \\
\text { concept) }\end{array}$ & $\begin{array}{l}\text { Reflecting on a sentence } \\
\text { as a whole, encoded by } \\
\text { its choices and consider- } \\
\text { ing how a change to one } \\
\text { part necessitates other } \\
\text { changes }\end{array}$ & $\begin{array}{l}\text { Why do you think the } \\
\text { writer chose to form this } \\
\text { idea in this way? What } \\
\text { does it reveal and how } \\
\text { might you change it? }\end{array}$ \\
\hline
\end{tabular}




\title{
A Basic Writing Course Design to Promote Writer Identity: Three Analyses of Student Papers
}

\author{
Barbara Bird
}

\begin{abstract}
This article presents the results of three comparative analyses on forty-seven student papers in order to examine the effectiveness of a basic writing course in developing students' academic writer identity. The course curriculum, grounded in social identity theory, focuses on the core writing concepts and dispositions that promote writer identity. Since the curricular focus is writing, this course fits within the broad category of a Writing-About-Writing (WAW) course and specifically draws on David Bartholomae's "Inventing a University" article and Roz Ivanič's research on writer identity. These two scholars present pedagogy that draws on social identity either implicitly (Bartholomae) or explicitly (Ivanič). My comparative analyses demonstrate students' significant development and short-term transfer of textual writer identi$t y$, and the analyses reveal advanced textual writer identity compared with students who tested out of basic writing. This research contributes to writer identity theory and demonstrates the efficacy of writer identity content specifically and a WAW-type course generally for basic writing.
\end{abstract}

Key words: basic writing; curriculum; WAW; writer identity; qualitative research

\begin{abstract}
Our colleges and universities, by and large, have failed to involve basic writing students in scholarly projects, projects that would allow them to act as though they were colleagues in an academic enterprise. (Bartholomae "Inventing the University" 11)
\end{abstract}

[P] eople learn by apprenticeship ... and by taking on the identity of community membership among those who use literacy in particular ways. (Ivanič “Discourses of Writing and Learning to Write” 235)

Students need opportunities for the kinds of writing contexts that help them both understand and join the "academic enterprise" (Bartholomae 2, 11); such opportunities simultaneously help students understand and adopt the "identity" of academic writers (Ivanič "Discourses" 235). While having somewhat different emphases on student writing development, both

A basic writer herself, Barbara Bird serves as Professor of English and Director of the Writing Center at Taylor University. The research in this article is part of a four-year study focusing on how basic writing students develop as academic writers and enact their academic writer identity across classes and years.

(C) Journal of Basic Writing, Vol. 32, No. 1, 2013 
Bartholomae's and Ivanič's work rely on social identity theory to explain how students learn academic writing. This theory, in its broad form, posits that successful behavior in any community stems from well-informed participation and self-identification with that community. Teaching academic writing from this theoretical standpoint, then, requires explaining core academic discourse concepts to equip basic writers with the "whys" behind academic writing conventions while also teaching and fostering dispositions that encourage basic writers' self-identification as contributors to academic discourse.

This focus on the fundamental purposes—the "whys"-of academic writing and on the core academic dispositions fits learning within a social identity perspective. This perspective foregrounds the interconnectedness of the learning process with the affective and holistic personhood of the learner. As Paul Prior explains, a social theory of learning addresses "the formation of a person's consciousness through participation in social practices, [and] stresses affect, motivation, perspective, embodied ways of being in the world, and identity as well as conceptual development" (22). Approaches to curriculum and pedagogy that only emphasize cognitive knowledge not only limit students' understanding as whole beings, but they also reduce the impact of learning since students may not internalize the community understandings. Approaches that engage students' participation in "social practices," however, involve ways of thinking and "embodied ways of being," both of which promote a deeper internalization of community knowledge. Thus, students can develop self-identities as academic writers since they have the basic knowledge (purpose of academic writing) and dispositions that are essential components of this social identity. Conceptually, these characteristics of "academic writer" are at a much higher level: instead of focusing curriculum and pedagogy on textual features like genre forms or topic sentences, this approach focuses on academic texts as conversations on important issues. So, within this framework, students understand the convention of "developing claims," for example, not as a rule but instead as the natural outcome of engaging their own intellectual work, a disposition essential for fulfilling the meta-purpose of academic writing-contributing to a conversation. Pedagogy and curriculum grounded in social identity theory emphasize the impetus-purposes and dispositions-instead of the result-discourse characteristics. This context gives students greater control and flexibility as writers: seeing the why improves the how.

One kind of basic writing curriculum that is well suited for applying social identity theory is a Writing-About-Writing (WAW) approach. I 
define WAW as using writing as curricular content in a freshman writing class, which follows Elizabeth Wardle's definition: “a basic philosophical approach to teaching writing [... that] assumes that declarative and procedural knowledge about writing cannot be separated in a useful way" ("Re: WAW"). My basic writing course uses content on academic writers' purposes and dispositions, with a focus on developing students' own academic writer identities, drawing on both Bartholomae's and Ivanič's use of social identity theory. Identity involves the affective, and holistic-oriented teaching evidences improvement in writing performance both for the short-term and long-term (Bereiter 22; Geisler 208-209; Nelms and Dively 218; Wardle “Understanding" 76-77). Students' writing performances become more controlled and authentic as students understand how academic writing connects to their own identity. My research indicates that this WAW-type course on writing purposes and dispositions effectively equips students to develop an academic writer identity: their texts have several key qualities that the academic community expects, and their texts evidence key academic dispositions, even a semester after completing the course.

According to research in both social identity and learning theories, academic writing competence relies on internalizing core identity dispositions like confidence and motivation (Bereiter; Biggs; Geisler; Leamnson). In their discussion of transfer, Gavriel Salomon and David Perkins argue that high-road transfer requires "mindful abstraction" (emphasis original, 124), arguing that “(a) the abstraction must be understood, and (b) the understanding requires mindfulness" (126). Dispositions and meta-purposes are conceptual abstractions that guide academic writing. Students who mindfully read, discuss, and respond to these concepts significantly improve their abilities and their willingness to transfer both their understanding of academic writing and internalizing of academic dispositions, especially when they simultaneously integrate their own identities into these abstract concepts of academic writing.

Bartholomae and Ivanič both recognize the critical importance of understanding academic discourse's conceptual meta-knowledge. Without this knowledge, Bartholomae notes, "the writer must get inside a discourse he can only partially imagine" (19). Our students don't have to try to imagine the inside, or purposes of academic discourse if we teach them core concepts that drive academic writing. Similarly, without understanding and integrating key academic identity dispositions, students would have a weak sense of their discoursal identity as academic writers since "writers construct a discoursal self from socially available discoursal resources" (Writing 330). These 
resources include students' "membership of, their identification with, the values [or dispositions] and practices of one or more communities" (Writing 83). If we teach our students how to integrate their academic community identification with their current identity memberships, they can develop their own academic writer identity. Both Bartholomae and Ivanič point out that what proceeds from the discoursal resources of purposes and dispositions is controlled academic performance.

In what follows, I summarize Bartholomae's and Ivanič's appropriations of social identity theory before detailing my basic writing course that draws on their work. I then discuss the research I conducted after this course design had been taught for five years (by three teachers, including me). The three comparative textual analyses from my research show how this course enables students to demonstrate improvement in academic writer identity (first study); transfer of their expanded writer identity (second study); and evidence greater authority compared to students who tested out of basic writing and who are in non-WAW courses (third study).

\section{TWO RELATED MODELS OF ACADEMIC SOCIAL IDENTITY}

Though Bartholomae never discussed social identity theory in his "Inventing the University," his implied argument that students should be taught discourse community expectations aligns with a social identity perspective. He represents students' struggle with academic writing as their attempt to act like they are part of the academic community even before they understand the community's purposes for academic writing. But as we know, if basic writing students do not understand academic writing purposes, their efforts will be focused on mimicking the textual features instead of developing an authentic engagement with content.

Authentic engagement is further enhanced when students adopt some elements of the community identity. Roz Ivanič and other scholars who view writing as identity performance focus on the negotiation of one's identity within a community. Amy Burgess and Roz Ivanič believe that when students work to acquire the social identity of academia, holistically engaging it, they can be "positioned" as insiders (11). For Ivanič, writer identity means that students "participate in the practices which constitute a discourse, and thereby affiliate themselves with others who engage in the same practices" ("Language" 16). Students construct their academic affiliation once they understand academic purposes and dispositions, that is, the whys behind discourse practices. This understanding gives students power to choose 
how they want to negotiate their academic selves in connection with their non-academic lives. Ivanič's perspective on joining the academic community is much like Linda Flower's on creating meaning: both are negotiated. For writer identity, such negotiation means writers may adopt some values and reject others, bringing to the new academic identity elements from already inhabited identities. This negotiation is what allows students to have a holistic and authentic writer identity rather than a superficial, mimicked writer performance.

Bartholomae's and Ivanič's work, as examples of social identity theory applied to the teaching of basic writing, support assignments and curricula that emphasize both internalizing reasons for specific academic conventions (purposes) and ways of being an academic (identity). In the new academic journal, Literacy in Composition Studies, Robert Yagelski explains why social identity theory is so important to the teaching of writing: "writing is wrapped up in how we understand ourselves as beings in the world, and the act of writing has the potential to shape our sense of who we are and how we relate to the world around us" (58). These literacy scholars situate student writing and learning as opportunities for students to develop ideas that they personally connect with on an identity level. As Ivanič notes, "people are likely to begin to participate in particular practices to the extent that they identify themselves with the values, beliefs, goals and activities of those who engage in those practices" ("Discourses" 235). If we want basic writing students to participate authentically and not resort to surface-level mimicry, then we will want them to understand the purposes for academic texts and to self-identify with the academic community.

Basic writing students may experience tension as they negotiate how much and which academic identity characteristics to adopt, but it is important to mention here that no student is expected to become "a little academic," replacing current social identities with one dominant academic identity. In "Discoursal Construction of Identity," Michael Michaud applies Ivanič's identity theory in his research, noting that his case study student chose not to completely conform to academic role expectations (50). Michaud posits two potential authorial identity expectations which the student may have been rejecting: being a novice, being a "cultural observer," or more likely, some combination of the two (50). If an assignment or course requires an identity role a student resists, the student can reject that role or create an identity that merges the expected role with another role or identity. Scholars who view student writing from an identity standpoint are not suggesting a wholesale adoption of an academic social identity that displaces other iden- 
tities. Students need to understand and adopt some of the dispositions of the academic community while simultaneously bringing their autobiographical or outside-school identities to academic writing in order to create their own blended writer identity.

For Ivanič, writer identity development enables greater student agency because students can "own or disown aspects of [the discourse]" and bring "their life-histories and the social groups with which they identify" to their academic writing (Identity 32). Beyond Ivanič's work, for over a decade, other scholars have studied similar kinds of holistic, "identity-type" learning: dispositions toward learning (Driscoll and Wells; Perkins et al.); emotional involvement (Brandt; Micciche); authorship confidence (Greene; Rodgers); and the intermingling of "multiple literate identities" (Roozen 568). All of these scholars argue that for deep, lasting learning, students need holistic ownership of themselves as academic writers.

Although identity development is primarily internal, Ivanič makes it clear that writer identity is visible in student texts. Burgess and Ivanič explain that within a writer's text is the "representation of herself, her view of the world, her values, and beliefs that the writer constructs through her writing practices; [this self-representation] is a set of interpretable signs from which readers will obtain an impression of the writer" (240). Burgess and Ivanič understand that a writer's identity actually exists outside of language, but the self-inscribed-on-paper is "interpretable" from the text.

\section{THREE COMPONENTS OF ACADEMIC SOCIAL IDENTITY TO FOSTER}

Across its five-year development, my basic writing WAW curriculum gained an increasingly tighter focus on the purposes and dispositions of academic writing in order to guide students in developing their own writer identities. I found one academic writing meta-purpose (or threshold concept) that especially affected students' own academic writer identity development: contributing to discourse conversations. My curriculum now has these four outcomes: 1) students will understand that all (or virtually all) academic texts contribute to some larger academic discussion; 2) students will understand and negotiate their internalization of core academic dispositions; 3 ) students will create an academic writer identity based on knowledge of academic writers' purposes and dispositions; 4) students will develop proficiency in producing academic texts that accomplish the meta-purpose of contributing to conversations while also expressing their own writer identity. To achieve 
these four outcomes, I sought to focus on the three components of writer identity that I adapted from Ivanič's work: autobiographical writer identity, discoursal writer identity, and authorial writer identity. Students' cognitive and affective synthesis of these three components results in greater ownership of academic writing's core purpose, adoption of academic dispositions, and creation of their own writer identity.

The autobiographical component is the presence of the writer in the text, primarily through the writer's own ideas but also including relevant personal experiences or examples. Ivanič believes that academic writing often includes some aspect of the writer's personal history (Ivanič Writing 24-25; Burgess and Ivanič 238). This personal history may be explicitly represented in the text or only implicitly visible. The important aspect of this component for students is developing personally meaningful ideas in response to whatever academic conversation they engage. Students' ideas can evolve from interpreting concepts in a text (or texts); from applying ideas in a text to their own experiences; or from their unique synthesis of ideas from various sources, their own experiences, and their prior knowledge. The key point of this component for students is developing their own ideas in response to scholarly conversations. Unlike most students' high school writing experiences, college professors expect students to generate their own "take" on issues, not merely repeat well-known ideas or the ideas of one writer. Specifically, autobiographical identity is the students' unique perspective on an issue in the form of claim statements or personal experiences used as examples.

The discoursal component is adhering to academic writing conventions. Ivanič describes this component as "discourse characteristics" and wording that meet community expectations (Ivanič Writing 25; Burgess and Ivanič 238). For my basic writing class, I chose to focus on two specific discourse conventions: creating clear claims and tying evidence (specifically, examples and quotes) to claims. Creating clear claims that can be supported, and linking evidence to claims, are both taught first from the conceptual level of writing as contributing to conversations and then at the concrete level. All skills are taught in this same manner. This focus on claims enables students to gain greater mastery of these two conventions while indirectly improving related academic discourse characteristics such as overall cohesion and clarity.

The authorial component is the writer's authority (Ivanič Writing 26; Burgess and Ivanič 240). I define this component as students' ownership of their ideas and their confidence in themselves as thinker-writers who have 
authority to speak their ideas into academic conversations. To distinguish authorial from autobiographical, students' idea-claims (claims that are students' own ideas/perspectives) are autobiographical, but their authority over those ideas is demonstrated through their intellectual development of those idea-claims. In other words, a student would display autobiographical writer identity by making claims that are her own ideas, but if there is very little development of those claims, this student would evidence low authorial writer identity. Sometimes students learn to create their own ideas as their claims but then either fail to elaborate or merely cite others, showing no intellectual development of their ideas. Or, the reverse could be true. A student could make a claim that is merely repeating another writer's idea but then evidence strong authorial writer identity through the student's own critical thinking, explanation, or other means of intellectually supporting a claim. Authorial writer identity is the students' ownership over their intellectual work.

Learning these three components of academic writer identity helps basic writing students understand and be inspired to develop their own identity as academic writers. However, I want to be clear that students do not need such holistic engagement to write college papers. Students can produce moderately successful papers using strategies learned in high school combined with mimicking some academic features. These strategies alone, though, will ultimately fail students: without explicit instruction in academic community purposes and dispositions, few students will understand how to invest, or be motivated to invest, as writers. Writing strategies unattached to academic discourse purposes and separated from holistic dispositional involvement cannot sustain quality writing or enable transfer. Systematically building an academic writer identity grounded in academic purposes and dispositions along with personally held identities gives students much greater motivation and staying power as academic writers.

\section{WAW AND BASIC WRITING: AN APPROPRIATE FIT}

My basic writing WAW course using the content of academic discourse purposes and dispositions and grounded in a writer identity perspective is certainly not the only kind of WAW course. As defined above, WAW means a writing course that teaches any kind of writing content; thus, there could be a variety of WAW-specific content, whether or not the course carries the title of "WAW." Writing-content courses use readings and assignments that lead students to reflect on themselves as writers and to learn writing concepts, 
usually as abstractions that can be applied in different writing contexts. WAW courses can include a wide range of writing concepts, depending on the specific institutional context and student population needs. Here are some examples: Dana Driscoll (Oakland University) focuses her WAW course on teaching students several dispositions and attitudes toward writing and themselves as writers, equipping students to improve their knowledge transfer (Driscoll; Driscoll and Wells). Elizabeth Sargent (University of Alberta) teaches a WAW course exploring scholarly debates on writing issues and engaging students in research on their own writing processes (Sargent). Elizabeth Wardle and Doug Downs' WAW textbook examines literacy broadly, focusing on teaching students academic research and helping students view themselves as researchers. The Teaching for Transfer course (TFT) that Liane Robertson and Kara Taczak designed teaches students key writing concepts while engaging students in a semester-long reflective exercise of creating their own theory of writing. Creating this theory enables students to access the concepts and processes learned in TFT and apply them flexibly and reflectively in other contexts (Yancey, Robertson, and Taczak).

What all WAW courses have in common is the use of readings on writing in order to "build procedural and declarative knowledge about and experience with writing" (Downs 1). By teaching students both procedural and declarative knowledge about writing by means of a writing curriculum, students gain a deeper understanding of academic discourse. As they compose their thoughtful responses to these academic readings, students are invited to participate as scholars in the academic community. Both these outcomes of WAW courses make this approach ideal for teaching basic writers.

Although WAW might sound too advanced for basic writing courses, readings and concepts can be adjusted to any institutional context and student demographic. David Bartholomae and Anthony Petrosky's course (and book), Facts, Artifacts, and Counterfacts, though not labeled as a WAW course, showed that using high-level texts as the readings for basic writers is very effective. Shari Sternberg's basic writing course has evidenced that complex concepts such as identity are certainly not too advanced for basic writing students to wrestle with. Similarly, Shannon Carter's basic writing students evidenced success in her basic writing WAW course focused on literacy (The Way Literacy Lives). In addition, there is a growing body of scholarship on the effectiveness of WAW in general, research that could apply to WAW in a basic writing course (see Downs for a bibliography up to 2010). For example, WAW as content in freshman writing courses has been 
shown to improve transfer (Wardle), academic dispositions (Driscoll and Wells), and self-efficacy as writers (McCracken and Ortiz).

Thus, WAW courses accomplish important writing outcomes that can be very effective for basic writing students, mostly due to the deep learning that stems from students reading, discussing, and writing papers on writing concepts. Like all WAW courses, my basic writing WAW course gives students opportunities to deeply interact with academic concepts in a variety of ways: annotating readings, participating in class discussions on the main concepts, personally applying these concepts, and finding one's own connections to specific claims or to larger ideas in the readings. Just as writing in a disciplinary course improves students' grasp of key ideas, writing about writing deepens students' understanding of writing concepts (see Tagg for a great discussion of deep learning and Bird for basic writers' deep learning).

\section{EXPECTATIONS, DISPOSITIONS, AND OPPORTUNITIES: A THREE- UNIT BW COURSE}

To develop students' writer identities, I designed a basic writing WAW course that combines Bartholomae's and Ivanič's course goals: students should understand the key purposes for academic writing (Bartholomae) and cultivate academic writer dispositions that lead to a writer identity (Ivanič). The purposes and dispositions gained through the curriculum are applied in daily work and writing assignments. These are the three units in my basic writing WAW course:

1) Autobiographical identity: generating personally meaningful, unique ideas

2) Discoursal identity: making clear claims and connecting evidence to claims

3) Authorial identity: performing intellectual work, specifically through elaboration and critical thinking

The first unit begins with my teaching the meta-purpose for academic writing: joining conversations. The foundational text is Charles Bazerman's "A Relationship between Reading and Writing: The Conversation Model," which is an important base for two reasons. First, it presents the foundational academic discourse purpose in a form that students already have experience with-a conversation. Second, it unveils one of the most important discourse and identity expectations - that writers must understand what others have 
said and must contribute something new to the conversation. Students gain "a sense of their own opinions and identity defined against the reading material" (Bartholomae "A Relationship" 659). In the process of expressing their own ideas and identities, they discover that these ideas, experiences, and prior knowledge matter to the academic community-their professors expect to see "an original, informed view" and not "a derivative research report" (Bartholomae 660). This explicit encouragement to develop, or author, their own ideas helps students connect their multiple identities to an academic one in meaningful ways. Students begin to view academic writing as "associated with [their] sense of their roots, of where they are coming from, and [understand] that this identity they bring with them to writing is itself socially constructed and constantly changing as a consequence of their developing life-history" (Ivanič Writing 24). When basic writing students see academic writing in this holistic sense, integrally connected to who they are and are becoming, they gain significant motivation to invest as writers.

To further help basic writing students view themselves as capable of making claims that are their own ideas, the next two readings teach students that all reading is interpretation and all readers create personal meaning. Mariolina Salvatori's "Reading and Writing a Text" explains that readers develop meaning from texts through their interpretive processes, which most often means readers are interpreting from their personal history and/or prior knowledge. Then readers in turn generate their own texts to contribute to the conversation. Salvatori's article emphasizes the power of interpretation in creating meaning for both writers and readers: writers make their interpretation of both ideas and sources explicit for readers, and readers engage each text through their own set of lenses. In Lynn Quitman Troyka's “The Writer as Conscious Reader," basic writing students grasp the role of prediction and redundancy in this interpretation process, learning how to express their own meanings in ways that readers understand. This unit teaches two dispositions: viewing texts as interpretations (not facts) and developing confidence to create and express their own interpretations. These dispositions are supported by daily quote-responses that push students to "talk to" the author, creating their own response to the author's ideas.

In the second course unit, students focus on making clear claims and connecting those claims to their evidence (quotes or examples). The readings we use in this unit focus on holistic involvement as writers because this involvement helps basic writing students personally care about the concrete details of academic discourse expectations. Without this holistic connection, learning discourse expectations would turn into mere mimicry. So this unit 
helps students to see how their affective dispositions toward writing make all aspects of academic writing meaningful. Specifically, they learn from Toby Fulwiler's "Looking and Listening for my Voice" the value of their own voice and how their readers interpret their voice based on their use of discourse conventions. They read in Alice Brand's "The Why of Cognition" how to use emotions to enhance both their and their readers' connection to their ideas. These two readings highlight the importance of creating claims (their main ideas) that are personally relevant and how attending to details improves how their readers interpret their writer identity. In William Zeiger's “The Exploratory Essay," students likewise learn how to develop an inquiry disposition to enhance their ideas. These readings and applied concepts alter students' sense of academic expectations: instead of being rules they must follow, expectations become practices they want to employ to accomplish their internally motivated writing goals.

The third unit teaches basic writing students how to intellectually engage as writers to develop their claims. In the first unit, they learned how to create unique claims; in this unit, the focus shifts to fully developing those claims. The first reading, "The Novice as Expert" by Nancy Sommers and Laura Salze, helps students understand the necessity of deeply engaging as writers in order to give something from themselves (identities and personal ideas). Charles Bazerman's "Intertextuality” helps students understand how to use connections between their personal views and prior scholarship to fully develop their claims. This unit ends with a return to discourse identity in two forms: an overview of grammar and its role in academic writing and an ongoing assignment that requires students to find and correct all major errors in their papers by taking their papers to the Writing Center. All assignments focus on how disruptions in discourse expectations skew the readers' interpretation of students' writer identity.

Beyond the foundational purpose of contributing to conversations, all three units help students understand additional writing purposes involved within the three writer identity components and the dispositions that enable students to develop each identity component. As Perkins and Unger note about deep understanding, "To plan, invent, predict or otherwise make good use of a mental representation, one must not just have it but operate with and through it" (97). These basic writing students, through daily assignments, apply the mental and affective representations of academic writing that they learn through course curriculum and pedagogy, applications that allow them to "operate with and through" their academic writer identity. By teaching students writing concepts that they mentally reflect on as part of 
their own identity, they begin to perform as academic writers operating with their undestanding while being meaningfully involved as novice scholars.

\section{RESEARCH INTO WRITER IDENTITY INTERPRETED FROM STUDENT TEXTS}

All three teachers of this course saw significant growth in our basic writing students' holistic development of their own academic writer identities. We would email each other periodically, especially near the end of the semester, with comments about how pleased we were with particular students or with the whole class. Specifically, we noticed that a stack of essays became increasingly distinguished, one from the next, as students improved their authorial identity. In students' final essays, we found much clearer claims, and most students connected their quotes to their claims. Finally, we saw significant expansion of depth, logic, and discussions of each claim, evidencing stronger discoursal identity.

These and other results seemed to be sure signs of an effective curriculum, but I wanted more concrete evidence: which writer identity components were developed the most, in what ways did students maintain (or not) their writer identities across time, and was any growth in writer identity due to the course or what all students evidence from simply being in college? To answer these questions, I created a series of research studies. I developed three different comparative studies on the effectiveness of this curriculum, which I report below, using textual analyses of forty-seven student papers, identifying characteristics in students' writing that evidence each of the three components in academic identity performance: autobiographical, discoursal, and authorial.

\section{Methodology: Collecting and Coding Student Papers}

My research process began the summer of 2010 at the first Dartmouth Research Institute where I gained significant knowledge from lead composition researchers and feedback on my ideas about writer identity and how it can be seen in student writing. I began my first study in the fall of 2011 by requesting that every basic writing student at my small liberal arts college electronically submit their first and last essays from the course. Since I wanted to also understand how my basic writing students' writer identities shifted across time, in the following spring, I requested the same group of students who sent me their fall basic writing papers to also send me their freshman 
writing papers. After beginning to sift through this data over the summer of 2012, I wanted to explore how the basic writing students differed from students who did not have this (or any similar) content. So in the fall of 2012, I asked all basic writing students as well as freshman writing students from four classes that did not have content on writing, to electronically send me their "most significant" paper. These three data collection points (fall 2011, spring 2012, fall 2012) resulted in five sets of student papers, totaling forty-seven papers: basic writing students' first and last paper from fall 2011; those same students' papers the following semester; and papers volunteered out of all the basic writing students and the freshman writing students in the fall 2012. Then I began coding.

Qualitative coding usually requires marking specific units of language within a text, units that range from words (like pronouns) to whole paragraphs. Though I quantified each of the three studies, with all forty-seven papers being from one institution, I know that the results of this research cannot not be generalized to all students everywhere; however, since there were thirty-nine different students involved in the three case studies, I believe my results could be translatable to other contexts.

As Cheryl Geisler notes in her Analyzing Streams of Language, when analyzing texts, coding schemes can be created in four ways: anchoring them in a source (or sources); using built-in comparisons; using intuition; and letting the data "speak to you" (60). I decided to begin by using a coding scheme anchored in both Ivanič's research and the collaborative research of Amy Burgess and Roz Ivanič. Thus, my first coding scheme was divided into three sections-autobiographical writer identity, discoursal writer identity, and authorial writer identity. After my initial round of coding, I modified several specific codes in this scheme based on how I was "hearing" the data relate to both the theory and the course's foundational concept of contributing to academic conversations. For example, in my first round of coding, I had a code for giving an example, but I dropped this code since it didn't cleanly fit both the theory and the course's foundational concept. I also combined several codes into larger conceptual categories in order to reduce the number of codes that showed up only a few times. I then defined each code and invited an outside reader to code ten papers to verify my codes and definitions. Finally, I recoded all papers a third time in order to both reconcile my coding and the outside reader's coding and also to make sure my new coding scheme was aligned well with the data.

Since student papers varied in length, I needed to find the average number of words in each paper to more accurately compare papers. After 
coding, I also counted the number of words within each code in order to more precisely determine how much each code was evidenced in student work since one code unit might be attached to three words in one instance while that same code is attached to thirty words in another instance.

Below I list each code category, the definition of the category, and the specific discourse components I coded. I labeled each writer identity category as a writing performance since these studies did not investigate students' sense of their own identity but instead looked at textual evidence of their writer identity, the identity performed. I also provide a representative passage for the code category. Here I am very careful to choose passages that were truly representative of the majority of passages marked with each code.

\section{Coding for the Three Components}

\section{Autobiographical Component: Contributing One's Own Ideas:}

Definition: Claims that show some originality and examples from the writer's experience or prior knowledge.

Text marked as autobiographical writing performance has these characteristics:

- Making a claim that is the writer's own idea

- Making a claim that applies a known idea in a new way or to a specific issue

- Making a claim that is a "twist" on a known idea

- Giving an example from the writer's experience or prior knowledge

The autobiographical component of academic writing performance is representing self-one's own ideas or experiences. Burgess and Ivanič express this component as that which "the writer brings with her to the act of writing ... all her experiences of life up to that moment with their associated interests, values, beliefs, and social positionings" (238). Ivanič terms this component the "writer-as-performer" (emphasis original, "Writing" 24). Many freshman writers (both basic and non-basic) are used to writing essays with claims that are obvious, purely opinionated, or restatements from a source. None of these types of claims would be considered autobiographical. Opinionated claims may be the writer's own idea, but students provide no evidence or support; claims that were coded as the writer's own ideas are followed with at least some support. Bartholomae expresses what I coded as autobiographical identity in this way: "[students] don't originate a discourse, 
but they locate themselves within it aggressively, self-consciously" (15). Of course, very few student papers, especially from freshmen, show truly original thinking at the level expected of academic professionals. However, there is a difference between a student merely repeating an idea she reads in a source and a student expressing her own take on that idea or expressing the idea in a personally unique way. This coding tries to capture the move away from purely (and usually mindlessly) repeating exactly what the student writer had heard or read and toward self-representation.

Thus, I coded students' claims as "own idea" if the claim differed from the source(s) the student cited or if the claim clearly reflected the student's own background (as evidenced in the paper). For example, this text was coded as autobiographical: "The more we use our voice in a piece of writing, the more a reader can get to know us as a writer and that is where the emotional risk comes into play." This student was writing about voice after reading Toby Fulwiler's article, "Looking and Listening For My Voice." Though the student clearly referenced ideas in Fulwiler's article, this sentence is somewhat unique, not something that is obvious, well-known, or that exactly replicates Fulwiler's ideas. Here is another example: "Instead we should structure our papers based on what others have said and continue with the conversation interjecting our personal thoughts along with comments." This student's paper was in response to Charles Bazerman's article, "A Relationship between Reading and Writing," and the student's claim reflects, but is not identical to, Bazerman's main idea in this article.

\section{Discoursal Component: Making Clear Claims and Linking Evidence to Claims} Definition: Either making a clear claim or relating evidence (examples or quotes) to a claim.

Text marked as discoursal writing performance has these characteristics:

- Making a clear claim

- Defining a term (rarely seen in these texts)

- Relating a quote to a claim

- Relating an example to a claim

To keep a tight focus, I narrowed the indication of discoursal identity from Ivanič's explanation of it. In Ivanič's earlier work, she describes this component as "the way [the writer] wants to sound" (Writer 25), which is quite broad. Later, though, with Amy Burgess, she somewhat refined that description of the discoursal component: "This is the representation of her self, her view of the world, her values, and beliefs that the writer constructs 
through her writing practices; her choices of wording; and other semiotic means of communication" (Burgess and Ivanič 240). To capture the "representation of self" in this component, I included connections between claims and quotes and between claims and examples. These connections show the writer's effort to focus her reader on her own claims and not let examples or quotes take center stage.

This discoursal component of the academic writer identity includes sentences that explicitly tie a quote or an example to a claim. These kinds of connectives are expected in academic papers, indicating writers are using sources credibly since the writers connect the source to their claim. For example, a student had this claim: "A conversation consists of two or more people exchanging ideas, opinions, and comments with each other; this is also what we need to achieve when we write." Under this claim, later in the paragraph, he used this quote: "Charles Bazerrman [sic] sums up what writers ought to do when he said, '[i]ntelligent response begins with accurate understanding of prior comments, not just of the facts and ideas stated but of what the other writer was trying to achieve' (658)." And the student then linked this quote to his claim: "He talks about actually knowing what the previous authors have said and meant within their text, so that we can logically respond to what has been said." The expected discourse conventions for college writing include showing the audience how you are using a source and how it connects with the claims you are making.

Additionally, crafting clear claims is a "semiotic means of communication" (Burgess and Ivanič 240) that is expected in academic writing; thus, I marked all clear claims as evidencing discoursal identity. I also marked definitions since they contribute to the "representation of self" (Burgess and Ivanič 240). The majority of units coded in this discoursal category were not definitions or the connectors to claims; the majority were claim statements. I chose to mark claims as evidence of discoursal identity because I view discoursal as being most distinct from the other two components in this way: discoursal is the only component that emphasizes discourse conventions. Since making clear claims is one specific academic discourse convention that is expected in all disciplines, I wanted to focus on claims as evidencing discoursal identity, that is, as one evidence that the student can perform as a writer of academic discourse. For example, this student's text was coded as a claim: "A relationship between the reader and writer starts with the voice. It sets the story in motion." 


\section{Authorial Component: Displaying Intellectual Work (Depth and Development)} Definition: phrases or sentences that evidence the writer's intellectual work. Text marked as authorial writing performance has these characteristics:

- Rephrasing a complex quote in own words (rarely seen in these student texts)

- Discussing a quote or a claim

- Showing logical development or explanation

Authorial writer identity is textually seen as developing the writer's ideas through logic, explanation, or elaboration-the writer's intellectual work. Papers that evidence this component have a lot of discussion by the writer. As Ivanič notes, this is "how far [writers] claim authority as the source of the content" (Writing 26). Most freshmen throw in quotes and allow the quoted authors to have the authority, but students show their own authority when they discuss a quote or rephrase it in their own words. Though Ivanič only references "choice of content" (27) briefly, I chose to extend this aspect of authorial identity by marking all places where students explain or use logic to develop the content of their essays. For example, this excerpt is coded as "discussing a quote" within this category:

Many different people have already started a conversation based on or similar to your topic of your paper, so your job is to read and absorb what others have said about your similar subject [claim]. Familiarize yourself with prior comments and ideas, taking them into consideration and then respond. Effective speakers know when to interact with the conversation and give their input and we, as students, need to do the same every time we write. Our goal is to relate previous knowledge to new comments that are personal to us.

Here the student explains his idea, draws out implications, and creates a full discussion that incorporates his own ideas. Sentences marked with the authorial code express students' own thinking, which acts as a contribution (even though it might be a small contribution) to the academic discussion. This contribution is their own "content" (Ivanič) and is both an academic discourse expectation (Bartholomae) and reflective of students performing an identity as an academic writer (Ivanič). 
A Basic Writing Course Design to Promote Writer Identity

\begin{tabular}{|c|c|c|c|}
\hline Component & $\begin{array}{l}\text { Auto-biographical: } \\
\text { Creating New Ideas/ } \\
\text { Claims and Expressing } \\
\text { Unique Experiences }\end{array}$ & $\begin{array}{l}\text { Discoursal: } \\
\text { Making Clear Claims } \\
\text { and Linking Evidence } \\
\text { to Claims }\end{array}$ & $\begin{array}{l}\text { Authorial: } \\
\text { Contributing Intellec- } \\
\text { tual Work (Discussion, } \\
\text { Logic, and Develop- } \\
\text { ment) }\end{array}$ \\
\hline Definition & $\begin{array}{l}\text { Phrases and sentences } \\
\text { that evidence personal } \\
\text { ideas, beliefs, or ex- } \\
\text { pressions }\end{array}$ & $\begin{array}{l}\text { Phrases and sentences } \\
\text { that either make a clear } \\
\text { claim or relate evidence } \\
\text { to a claim }\end{array}$ & $\begin{array}{l}\text { Phrases and sentences } \\
\text { that evidence the } \\
\text { writer's own thinking }\end{array}$ \\
\hline Specific codes & $\begin{array}{l}\text { - Making a claim or } \\
\text { statement that is the } \\
\text { writer's own idea } \\
\text { - Making a claim or } \\
\text { statement that } \\
\text { applies a known } \\
\text { idea in a new way } \\
\text { or to a specific issue } \\
\text { - Making a claim or } \\
\text { statement that is a } \\
\text { "twist" on a known } \\
\text { idea } \\
\text { - Giving an example } \\
\text { from the writer's } \\
\text { experience or prior } \\
\text { knowledge }\end{array}$ & $\begin{array}{l}\text { - Making a claim } \\
\text { - Defining a term } \\
\text { - Relating a quote to } \\
\text { a claim } \\
\text { - Relating an example } \\
\text { to a claim }\end{array}$ & $\begin{array}{l}\text { - Rephrasing a complex } \\
\text { quote in own words } \\
\text { - Discussing a quote or } \\
\text { claim, or showing } \\
\text { logical development } \\
\text { or explanation } \\
\text { - Making a claim that } \\
\text { explicitly differs } \\
\text { from a source cited }\end{array}$ \\
\hline
\end{tabular}

\section{Table 1: Summary of All Three Writer Identity Components}

\section{Analyzing the Data}

After collecting all forty-seven papers across the two-year time span, I then began analyzing the data. I chose to conduct three sets of analyses in order to evaluate three different comparisons. The first comparison set was the first and last papers from the fall 2011 basic writing students. The second set included the same second (last paper) subset from fall 2011 and the "most significant" paper from these same students in the following semester (from their regular freshman writing class). The third set included the "most significant" paper from basic writing students in the fall of 2012 and the "most significant" paper of a control group, a group of students who were in the regular freshman writing class that same semester who had never had a WAW course. In summary, then, these are the three sets of papers for my three analyses:

1) The beginning paper and ending paper of the fall 2011 semester of basic writing students 
2) The ending paper of the fall 2011 basic writing students and "most significant" paper at the end of spring 2012 freshman writing (from the same students who were in basic writing the prior fall)

3) The "most significant" paper at the end of fall 2012 for basic writing students and the "most significant" paper at the end of fall 2012 for freshman writing students

Since my overall goal was to find out, in general, how students in this basic writing WAW course developed and maintained (or grew) in the three writer identity components, I needed to quantify my results to see the general trend. In order to make sure I had accurate results, I asked a social scientist statistician to calculate both statistical significance and effect size. Statistical significance indicates how much confidence we have in inferring the results of the analyses. Do we trust that these results can be inferred to the population of students we are studying a smaller sample of? If the results are statistically significant, we do. Effect size is quite different. It indicates how big an empirical effect is. For example, if the results comparing some aspect of basic writers' first paper to their last paper in a semester show statistical significance, it means we trust these results enough to infer them to the population of students our sample represents. Effect size, on the other hand, tells us how big a difference there was between the first papers and the last papers. A small effect size indicates a small change in the papers while a large effect size indicates a large difference between the first and last papers. Statistical significance is normally reported as being true or false although the actual mathematics are more complicated and based on probabilities. In these analyses all results were deemed statistically significant if they were significant at the $\mathrm{p}<0.05$ significance level (which is the commonly used level for statistical significance ion social science research). Effect size was calculated using a statistical tool that provides a value ranging anywhere from zero to one. If the statistical tool (Cramer's V is used in these analyses) produces a value of zero, there was no difference between the sets of papers. If the result is a V value near one (which is extremely rare), it would mean there was a huge difference between the sets of papers.

Eight of the nine analyses achieved statistical significance. With one exception, then, these results infer well to the population of students at the campus where the research was done. Being statistically significant, the results are worth considering, but then we need to consider the effect sizes to see just how big the change in writer identity was. For example, in the 
first comparison group, the beginning-of-semester papers (1a in the chart below) showed nearly the same percentage evidence for writer identity in the discoursal component as the end-of-semester papers (1b). Thus, the effect size measure is .05. There is a very small effect. Having a small effect does not mean that the comparison has no practical significance-it does. We often engage in practices that make small changes in our students but believe these changes are very important, and having a small effect means that there is indeed a change.

The full analysis of all three comparisons included a total of fourty-seven student papers. There were twenty papers in the first analysis, eighteen papers in the second analysis (though ten of those papers came from the second set of the first anlaysis), and nineteen papers in the third analysis.

\begin{tabular}{|c|c|c|c|c|c|}
\hline $\begin{array}{l}\text { 1a) Fall } 2011 \\
\text { BW, first } \\
\text { paper } \\
10 \text { papers }\end{array}$ & $\begin{array}{l}\text { 1b)Fall } 2011 \\
\text { BW, last } \\
\text { paper } \\
10 \text { papers }\end{array}$ & $\begin{array}{l}\text { 2a) Fall } 2011 \\
\text { BW, last } \\
\text { paper } \\
\text { (the same set } \\
\text { of papers as in } \\
\text { 1b) }\end{array}$ & $\begin{array}{l}2 \text { b) S p r i n g } \\
2012 \text { FW, } \\
\text { last paper } \\
\text { (from the } \\
\text { same student } \\
\text { group as those } \\
\text { in both } 1 \mathrm{~b} \text { and } \\
\text { 2a) } \\
8 \text { papers }\end{array}$ & $\begin{array}{l}\text { 3a) Fall } 2012 \\
\text { BW } \\
9 \text { papers }\end{array}$ & $\begin{array}{l}\text { 3b) Fall } 2012 \\
\text { FW } \\
10 \text { papers }\end{array}$ \\
\hline $\begin{array}{l}9,260 \\
\text { words }\end{array}$ & $\begin{array}{l}15,966 \\
\text { words }\end{array}$ & $\begin{array}{l}15,966 \\
\text { words }\end{array}$ & $\begin{array}{l}16,009 \\
\text { words }\end{array}$ & $\begin{array}{l}7,260 \\
\text { words }\end{array}$ & $\begin{array}{l}10,142 \\
\text { words }\end{array}$ \\
\hline $\begin{array}{l}\text { Average } \\
\text { words per } \\
\text { paper: } 926\end{array}$ & $\begin{array}{l}\text { Average } \\
\text { words per } \\
\text { paper: } 1,596\end{array}$ & $\begin{array}{l}\text { Average } \\
\text { words per } \\
\text { paper: } 1,596\end{array}$ & $\begin{array}{l}\text { Average } \\
\text { words per } \\
\text { paper: } 2,001\end{array}$ & $\begin{array}{l}\text { Average } \\
\text { words per } \\
\text { paper: } 807\end{array}$ & $\begin{array}{l}\text { Average } \\
\text { words per } \\
\text { paper: } 1,014\end{array}$ \\
\hline
\end{tabular}

Table 2: Summary of Student Papers Used in the Three Analyses

Comparison 1: BW students' first and last papers: Improving thinking and claim articulation (authorial and discoursal identity)

The first analytical study aimed to assess how students' evidence of academic writer identity changed across the semester in each of the three academic writer components, comparing students' first and last papers for the course. 


\begin{tabular}{|l|l|l|l|}
\hline $\begin{array}{c}\text { Academic Writer } \\
\text { Identity } \\
\text { Components }\end{array}$ & $\begin{array}{l}\text { Fall 2011 BW First } \\
\text { Paper }\end{array}$ & $\begin{array}{l}\text { Fall } 2011 \text { BW, Final } \\
\text { Paper }\end{array}$ & Size of Effect \\
\hline $\begin{array}{l}\text { Autobiographical } \\
\text { Component }\end{array}$ & $22.5 \%$ & $15.5 \%$ & .08 small effect \\
\hline Discoursal Component & $11 \%$ & $15 \%$ & .05 very small \\
\hline Authorial Component & $42 \%$ & $47 \%$ & .04 very small \\
\hline
\end{tabular}

Table 3: First Comparison: BW Students' First and Last Papers

In the first set of BW papers, the autobiographical component, which is expressing students' own experiences or views, decreased across the semester. In the first paper, students, on average, evidenced this component in $22.5 \%$ of the total words, and in their final paper, students displayed autobiographical elements in $15.5 \%$ of the total words. Although this component decreased, since there was an increase in both discoursal and authorial components, this reduction in voicing personal views most likely indicates that the higher percentage of thinking and connecting their evidence to their claims might be what caused the percentage of words expressing personal views or experiences to be lower. In other words, as students expanded the percentage of words given to their idea development, they lowered the percentage of words given to claim articulation: few claims and more discussion.

Students increased their use of the discoursal component, which represents students' articulation of clear claims and their connections between evidence/quotes and their claims (instead of merely "plopping" in quotes or evidence). The students' first papers had on average $11 \%$ and their final papers had on average $15 \%$ of the words indicating this discoursal component.

In this set of papers, we see an increase in the authorial component, which means students increased the amount of thinking they expressed in their papers. The students' first papers had on average $42 \%$ of the words coded for authorial, and their last papers had on average $47 \%$ of the words coded for this component. Thus, students improved in how much they demonstrated their own thinking, mostly through logical development or discussion/explanation of ideas.

The increase in the percentage of both authorial and discoursal components, though small, is a real statistical effect. Since these two components are often markers of what we might loosely term, discussion, it appears that students in this type of WAW basic writing class expand the percentage of words used to discuss their claims. 
Comparison 2. Students in BW class and the following semester: Increasing claim connections (discoursal identity)

Although my longitudinal study is only comparing results from fall to spring semesters of one school year, this brief longitudinal analysis still provides some indication of how well these academic writer identity components continue to be present in basic writers' work.

As we can see in Table 4, overall, there is an increase in the percentage of two of the three components of academic writer identity.

\begin{tabular}{|l|l|l|l|}
\hline $\begin{array}{l}\text { Academic Writer } \\
\text { Identity } \\
\text { Components }\end{array}$ & $\begin{array}{l}\text { Fall 2011 BW, last } \\
\text { paper }^{\mathbf{a}}\end{array}$ & $\begin{array}{l}\text { Spring 2012 FW, last } \\
\text { paper }^{\mathbf{a}}\end{array}$ & Size of Effect \\
\hline $\begin{array}{l}\text { Autobiographical } \\
\text { Component }\end{array}$ & $15.5 \%$ & $17 \%$ & .12 small \\
\hline $\begin{array}{l}\text { Discoursal } \\
\text { Component }\end{array}$ & $15 \%$ & $29 \%$ & .16 moderate \\
\hline $\begin{array}{l}\text { Authorial } \\
\text { Component }\end{array}$ & $47 \%$ & $46 \%$ & .005 no effect $^{\mathrm{b}}$ \\
\hline
\end{tabular}

Table 4: Second Comparison: Students in BW Class and the Following Semester

a. Since many sections were coded with more than one code, these percentages may exceed $100 \%$ and since not every word or sentence is coded, the percentages may not reach $100 \%$.

$b$. This component did not make statistical significance and had no effect.

In the autobiographical component, there was a small effect of the statistically significant difference in percentages of words devoted to expressing students' own ideas or experiences, with this writer component being $15.5 \%$ of words in the fall and increasing to $17 \%$ in the spring papers.

Students improved most dramatically in the discoursal component, connecting examples, quotes, and evidence to their claims. The discoursal component showed not only a statistically significant increase but also an increase that has a stronger effect, improving from $15 \%$ in the fall student papers to $29 \%$ in the spring papers. This increase had a moderate effect.

The authorial component basically remained the same. In order to better understand why these students did not increase the percentage of words indicating their own thinking or analysis (authorial), I looked more closely 
at the number of instances of authority phrases/sentences. I found a higher percentage of times students in the spring class used logical development compared to the other two codes in authorial writer identity, "rephrasing an author's claim" and "making a different claim than an author". In the fall, the basic writing students had, on average, $82 \%$ of the authorial code being logical development, and in the spring, these students had, on average, $92 \%$ of the authorial code being logical development. In other words, even though the overall number of words marked with authorial went down from the fall, the words coded as logical development increased. This means that students used fewer words marked as claims and more words marked as logical development in the spring semester than in the fall semester. Thus, even though the overall percentages for the authorial component remained basically the same across the year, these basic writing students still evidenced improvement in one aspect of this authorial component: logical development.

Comparison 3. Students in BW and FW: Expanding logical development (authorial identity)

Out of the three comparative studies, this one was the only one that used two very different groups of students: those who placed into basic writing and those who were exempt from basic writing.

Overall, despite being placed in a lower-level writing course, the papers from the basic writing students evidenced higher levels of authorial and autobiographical components and a lower level of the discoursal component compared with the papers from the FW students.

\begin{tabular}{|l|l|l|l|}
\hline $\begin{array}{l}\text { Academic } \\
\text { Writer I d e n tit y }\end{array}$ & $\begin{array}{l}\text { Fall } 2012 \text { BW, their } \\
\text { "most significant" } \\
\text { paper of the } \\
\text { semester }\end{array}$ & $\begin{array}{l}\text { Fall } 2012 \text { FW, their } \\
\text { "most significant" } \\
\text { paper of the } \\
\text { semester }\end{array}$ & Size of Effect \\
\hline Autobiographical & $9 \%$ & $3 \%$ & .13 very small \\
\hline Discoursal & $13 \%$ & $17 \%$ & .06 very small \\
\hline Authorial & $23 \%$ & $10 \%$ & .18 moderate \\
\hline
\end{tabular}

Table 5: Third Comparison: BW and FW

For the autobiographical component, the BW papers evidenced this trait in about 9\% of the students' total words compared with 3\% in the FW papers. This means that the BW students displayed more of their own ideas, 
either in claims or in examples, than the FW students. Though several FW papers included significant portions of their papers that were life narratives, these sections were not coded as "autobiographical" since I wanted to restrict this code to students' ideas and students' experiences that were specifically tied to claims as examples. In other words, a paper that merely told a story about an event would not fit the academic goal of contributing to conversations, whereas a paper that made claims that were students' own ideas and gave personal examples to support those ideas would fit this academic writing goal and thus be marked with this category code. Narratives from either the BW or FW students were not included in this analysis.

The BW papers, though, had less of the discoursal component. Since this component is making claims and relating ideas to claims, in light of the research finding on development/logic in the authorial analysis, it is probable that the BW students spent a higher percentage of their words on developing fewer claims, and the FW spent a higher percentage of their words on making more claims but not developing each claim as much.

The higher percentage of the authorial component in the BW papers compared with the FW papers is actually the strongest effect results in this entire research. The BW papers had 23\% authorial component compared with the $10 \%$ in the FW papers. Of the three qualities in this component, the discuss/reason/explain quality showed the greatest contrast between the BW papers and the FW papers. The basic writing students had a higher percentage of words developing their ideas than the freshman writers.

Looking at the authorial and autobiographical components together, the BW student papers had more of their own input-more of their own ideas (the autobiographical component) and more of their own authority as academic thinkers (the authorial component).

\section{DISCUSSION AND IMPLICATIONS}

My basic writing WAW course is grounded in writer identity theory, especially drawing on ideas from David Bartholomae's "Inventing the University" and from Roz Ivanič's work. This basic writing WAW course teaches students one meta-purpose of academic writing, to contribute to scholarly conversations. It also teaches other academic purposes connected to the three components of writer identity: to contribute one's own personally meaningful ideas to the academic conversation (autobiographical), to fulfill academic discourse expectations by connecting evidence and quotes to claims (discoursal), and to perform their own intellectual work by adding 
depth and development of ideas (authority). Thus, the course equips students to build their own writer identities as they begin to holistically understand and incorporate key academic writing purposes and dispositions.

The three comparative research studies showed that this basic writing WAW course improved students' academic writing in these ways:

1. Across one semester in this basic writing WAW course, students improved discourse proficiency and expanded their intellectual work (their authority). They improved the amount of discussion, explanation, and logic used in their papers to show greater authority; they also increased the number of words used to relate evidence to their claims to display greater discoursal competence.

2. From the end of their basic writing WAW course to the end of their following semester's regular freshman writing course, students further increased their authority with expanded discussion and intellectual contributions.

3. At the end of both the basic writing WAW course and four nonWAW freshman writing courses, the basic writing students had significantly greater authority evidenced in their papers. Specifically, the basic writing students used a significantly higher percentage of words to develop their ideas as intellectual contributions than the freshman writers. In addition, basic writing students had more claims that expressed their own ideas than the freshman writers. Taken together, basic writers evidenced more of their own input-more of their intellectual work (the authorial component) and more of their own ideas (the autobiographical component).

Thus, basic writers demonstrated improvement (first study), short-term transfer (second study), and expanded intellectual contributions-their authority-as compared with freshman writers (third study).

Beyond the one-year transfer studied in this research, other transfer outcomes from this course can be anticipated based on research on the role of the affective in learning. For instance, confidence and motivation have the greatest likelihood of transferring beyond FYC (Nelms and Dively; Pea; Wardle). Because students tend to naturally be more motivated as writers when expressing their own ideas and beliefs, students will more likely continue to use what they know about academic discourse purposes when they view academic writing as opportunities to contribute their own per- 
spectives. Additionally, having dispositions toward academic writing-for example, knowing to view writing assignments as being an opportunity to join conversations-increases the likelihood of transfer (Bereiter; Driscoll and Wells). Personal investment and a sense of belonging in academia have been evidenced as contributing to future academic success (Brook; Haskell; Geisler Academic; Lucas). In fact, belonging is so critical that Brook emphasized this affective attribute as necessary before students can become academic writers, saying that students "must first see themselves as more than just students in our classrooms, as real thinkers with power and ability" (152).

All of these scholars note that achieving transfer requires several key academic expectations and dispositions, most of which are taught in this basic writing WAW course: how to contribute new ideas, how to present themselves as academic writers, and how to contribute their own intellectual work in support of their claims. This course emphasized internalizing and individualizing the academic concepts and dispositions, and whatever is internalized is far more likely to transfer across domains and time than rules that are reproduced in mere mimicry.

\section{ALTERNATIVE APPLICATIONS OF WAW AND WRITER IDENTITY}

First, as mentioned above, the course described in this article is only one approach of many WAW course options. Although WAW approaches have been used in some form for over a decade (a few composition experts have used some versions of WAW long before it was labeled "WAW"), with the exception of Deborah Dew's course (see Dew's 2003 WPA article), research on WAW for basic writing courses has been a more recent trend. Starting in 2010, there have been six Conference on College Composition and Communication presentations on WAW and basic writing (including a short workshop presentation), and a 2009/10 issue of BWe which highlighted three articles on basic writing WAW courses (Bird; Carter; Charlton). This article extends this recent trend, and the empirical research reported here will hopefully encourage others to use a WAW basic writing curriculum that intentionally invites students to participate as scholars-emphasizing high-level academic participation and dispositions toward writing.

Second, this application of writer identity theory can be applied in various ways. Literacy scholars have been developing this theory for decades (Burgess and Ivanič; Hyland; Ivanič; Ivanič and Camps; Starfield; Stacey; Street). Recently, composition scholars have been using this theory in our own research (Hull; Lu; Roozen). Additionally, a new journal is devoted to 
this issue: Literacy in Composition Studies. Since writer identity seems to be tied to both transfer and deep learning, we need more research in composition studies on how this theory supports the teaching of writing.

We all want to help our basic writing students gain access to the academic community and gain the confidence and expertise necessary to represent themselves in academic conversations. This access and expertise requires immersion in academic texts and in concepts that lead students from mimicking academic discourse (Bartholomae) to participating holistically, self-identifying as academic writers. Since students are "positioned by the discourses they participate in" (Burgess and Ivanič 237), we can significantly improve students' ability to participate by teaching them core writing concepts and encouraging academic dispositions. This teaching, though, must also include opportunities for "[involving them] in scholarly projects" (Bartholomae 11). That is, basic writing students need to "operate with and through" academic writing concepts and dispositions. This kind of WAW curriculum and pedagogy equips basic writers to do more than mimic: they can authentically perform their academic writer identities as those who belong.

\section{Acknowledgements}

I want to thank the anonymous reviewers for their insightful feedback and thank my writing center consultant, Hannah Adderley, for her expertise as a close reader. Dr. Steve Bird is the social scientist who calculated the statistical significance and effects used in this research and who significantly contributed to the methods section. Without his help, my analysis would not have been possible. Most importantly, I am truly grateful to Hope Parisi, co-editor of JBW, for her patience and generous feedback.

\section{Works Cited}

Bartholomae, David. “Inventing the University." Journal of Basic Writing 5.1 (1986): 4-23. Print.

Bartholomae, David, and Anthony R. Petrosky. "Facts, Artifacts, and Counterfacts: A Basic Reading and Writing Course for the College Curriculum." 
A Sourcebook for Basic Writing Teachers, Ed. Theresa Enos. New York: Longman, 1987: 275-306. Print.

Bazerman, Charles. "A Relationship between Reading and Writing: The Conversational Model.” College English 41.6 (1980): 656-61. Print.

---. "Intertextuality: How texts rely on other texts." What Writing Does and How it Does It: An Introduction to Analyzing Texts and Textual Practices. Ed. Charles Bazerman and Paul Prior. New York: Routledge, 2004. 8396. Print.

Bereiter, Carl. "A Dispositional View of Transfer." Teaching for Transfer: Fostering Generalization in Learning. Ed. Anne McKeough, Judy Lupart, and Anthony Marini. Mahwah, NJ: Erlbaum, 1995. 21-34. Print.

Biggs, John. Teaching for Quality Learning at University: What the Student Does.

Buckingham, England: Society for Research into Higher Education and Open UP, 1999. Print.

Bird, Barbara. "Meaning-Making Concepts: Basic Writer's Access to Verbal

Culture.” Basic Writing e-Journal 8/9 (2009/10): n. pag. Web. 20 Apr. 2014. Brand, Alice G. "The Why of Cognition: Emotion and the Writing Process." College Composition and Communication 38.4 (1987): 436-43. Print.

Brandt, Deborah. Literacy as Involvement: The Acts of Writers, Readers, and Texts. Carbondale, IL: Southern Illinois UP, 2011. Print.

Burgess, Amy, and Roz Ivanič. "Writing and Being Written: Issues of Identity Across Timescales.” Written Communication 27.2 (2010): 228-55. Print. Carter, Shannon. "Writing About Writing in Basic Writing: A Teacher/ Researcher/Activist Narrative." Basic Writing e-Journal 8/9 (2009/10): 151-169. Web. 20 June 2014.

---. The Way Literacy Lives: Rhetorical Dexterity and Basic Writing Instruction. New York: SUNY Press, 2009. Print.

Charlton, Jonnika. "Seeing is Believing: Writing Studies with 'Basic Writing' Students." Basic Writing e-Journal 8/9 (2009/10). Web. 20 June 2014.

Dew, Deb Frank. "Language matters: Rhetoric and Writing I as Content Course.” WPA: Writing Program Administration 26.3 (2003): 87-104. Print. Downs, Doug. "Writing-About-Writing Curricula: Origins, Theories, and Initial Field-Tests.” WPA-CompPile Research Bibliographies, No. 12. (2010). Web. 14 June 2013.

Downs, Doug, and Elizabeth Wardle. "Teaching About Writing, Righting Misconceptions: (Re)envisioning 'First Year Composition' as 'Introduction to Writing Studies.'" College Composition and Communication 58.4 (2007): 552-84. Print

Driscoll, Dana Lynn. "Department of Writing and Rhetoric.” Oakland Uni- 
versity. (2014). n. pag Web. 20 June 2014.

Driscoll, Dana Lynn, and Jennifer Wells. "Beyond Knowledge And Skills: Writing Transfer And The Role Of Student Dispositions." Composition Forum 26 (2012). Web. 14 June 2013.

Flower, Linda. The Construction of Negotiated Meaning: A Social Cognitive Theory of Writing. Southern Illinois UP, 1994. Print.

Fulwiler, Toby. "Looking and Listening for My Voice." College Composition and Communication 41.2 (1990): 214-20. Print.

Geisler, Cheryl. Academic Literacy and the Nature of Expertise: Reading, Writing, and Knowing in Academic Philosophy. Hillsdale, NJ: Erlbaum, 1994. Print.

---. Analyzing Streams of Language: Twelve Steps to the Systematic Coding of Text, Talk, and Other Verbal Data. New York: Pearson/Longman, 2004. Print.

Greene, Stuart. "The Role of Task in the Development of Academic Thinking Through Reading and Writing in a College History Course." Research in the Teaching of English 27.1 (1993): 46-75. Web. 1 August 2013.

Haskell, Robert E. Transfer of Learning: Cognition and Instruction. San Diego: Academic Press, 2000. Print.

Hyland, Ken. "Projecting an Academic Identity in Some Reflective Genres." Ibérica 21 (2011): 9-30. Print.

Hull, Glynda A. and Mira-Lisa Katz. "Crafting an Agentive Self: Case Studies of Digital Storytelling" Research in the Teaching of English 41.1 (2006): 43-81. Web. 9 Sept. 2014.

Ivanič, Roz. "Discourses of Writing and Learning to Write." Language and Education 18.3 (2004): 220-45. Print.

---. "Language, Learning and Identification." Language, Culture, and Identity in Applied Linguistics. Ed. Richard Kiely, Pauline Rea-Dickins, Helen Woodfield and Gerald Clibbon. London: Equinox, 2006. 7-30. Print.

---. Writing and Identity: The Discoursal Construction of Identity in Academic Writing. Vol. 5. Amsterdam, Netherlands: John Benjamins Publishing, 1998. Print.

Ivanič, Roz, and David Camps. "I am How I Sound: Voice as Self-Representation in L2 Writing." Journal of Second Language Writing 10 (2001): 3-33. Print.

Leamnson, Robert. Thinking About Teaching and Learning: Developing Habits of Learning with First Year College and University Students. Sterling, VA: Stylus, 1999. Print.

Lu, Min-Zhan. "An Essay on the Work of Composition: Composing English against the Order of Fast Capitalism." College Composition and Communication 56. 1 (2004): 16-50. Web. 9 Sept. 2014. 
Lucas, Leyland M. “The Role of Culture on Knowledge Transfer: The Case of the Multinational Corporation." The Learning Organization 13.3 (2006). 257-75. Print.

McCracken, I. Moriah, and Valerie A. Ortiz. "Latino/a Student (Efficacy) Expectations: Reacting and Adjusting to a Writing-about-Writing Curriculum Change at an Hispanic Serving Institution. " Composition Forum 27 (2013): n.pag 25 July 2013. Web. 20 Apr. 2014.

Micciche, Laura R. Doing Emotion: Rhetoric, Writing, Teaching. Portsmouth: NH: Boynton/Cook, 2007. Print.

Michaud, Michael. "Discoursal Negotiation of Identity in the Writing of Adult Students: A Case Study." Writing Pedagogy 5.1 (2013): 31-55. Print. Mlynarczyk, Rebecca Williams, and Marcia Babbitt. "The Power of Academic Learning Communities." Journal of Basic Writing 21.1 (2002): 71-89. Print.

Nelms, Gerald, and Ronda Leathers Dively. "Perceived Roadblocks to Transferring Knowledge from First-Year Composition to Writing-Intensive Major Courses: A Pilot Study." WPA: Writing Program Administrators 31.1-2 (2007): 214-40. Print.

Pea, Roy D. "Socializing the Knowledge Transfer Problem." International Journal of Educational Research 11.6 (1987): 639-63. Print.

Perkins, David N., and Chris Unger. "Teaching and Learning for Understanding." Instructional-Design Theories and Models: A New Paradigm of Instructional Theory. Vol. II. Ed. Charles M. Reigeluth. New York: Routledge, 2013. 91-114. Print.

Perkins, David, Shari Tishman, Ron Ritchhart, Kiki Donis, and Al Andrade. "Intelligence in the Wild: A Dispositional View of Intellectual Traits." Educational Psychology Review 12.3 (2000): 269-93. Print.

Piorkowski, Joan L., and Erika Scheurer. “It's the Way that They Talk to You': Increasing Agency in Basic Writers Through a Social Context of Care.” Journal of Basic Writing 19.2 (2000): 72-92. Print.

Prior, Paul. Writing/Disciplinarity: A Sociohistoric Account of Literate Activity in the Academy. Mahway, NJ: Erlbaum, 1998. Print.

Rodgers, Johannah. "Defining and Experiencing Authorship(s) in the Composition Classroom: Findings from a Qualitative Study of Undergraduate Writing Students at the City University of New York." Journal of Basic Writing 30.1 (2011): 130-55. Print.

Roozen, Kevin. "From Journals to Journalism: Tracing Trajectories of Literate Development." College Composition and Communication 60.3 (2009): 541-72. Print. 
Salvatori, Mariolina. "Reading and Writing a Text: Correlations between Reading and Writing Patterns." College English 45.7 (1983): 657-66. Print. Sargent, Elizabeth, and Cornelia Catherine Paraskevas. Conversations About Writing: Eavesdropping, Inkshedding, and Joining In. Scarborough, Ontario, Canada: Nelson, 2005. Print.

Solomon, Gavriel, and David N. Perkins. "Rocky Roads to Transfer: Rethinking Mechanisms of a Neglected Phenomenon." Educational Psychologist 24.2 (1989): 113-42. Print.

Sommers, Nancy, and Laura Saltz. "The Novice as Expert: Writing the Freshman Year." College Composition and Communication 56.1 (2004): 124-49. Print.

Stacey, Jennifer. "Writer Identity While Learning Discipline-specific Academic Literacy in an Additional Language." Southern African Linguistics and Applied Language Studies 27.3 (2009): 345-56. Print.

Stenberg, Shari. "Learning to Change: The Development of a (Basic) Writer and Her Teacher." Journal of Basic Writing 21.2 (2002): 37-55. Print.

Street, Brian V. "At Last: Recent Applications of New Literacy Studies in Educational Contexts." Research in the Teaching of English 39.4 (2005): 417-23. 04 April 2013. Web.

Tagg, John. The Learning Paradigm College. Boston, MA: Anker Publishing Co., 2003. Print.

Troyka, Lynn Quitman. "The Writer As Conscious Reader.” A Sourcebook for Basic Writing Teachers. Ed. Theresa Enos. Manchester, MO: McGraw Hill, 1987. 307-17. Print.

Wardle, Elizabeth. "Intractable Writing Program Problems, Kairos, and Writing about Writing: A Profile of the University of Central Florida's First-Year Composition Program." Composition Forum 27 (2013). Web. 20 Apr. 2014.

---. “Re: WAW.” Message on WPA-L. 05 Sept. 2014. E-mail.

---. "Understanding 'Transfer' from FYC: Preliminary Results of a Longitudinal Study." WPA: Writing Program Administration 31.1-2 (2007): 65-85. Print.

Wardle, Elizabeth, and Doug Downs. Writing About Writing: A College Reader. 2nd ed. Boston: Bedford/St. Martin, 2014. Print.

Yagelski, Robert P. "Literacy and Consequences: A Response to Kate Vieira.” Literacy in Composition Studies 1.1 (2013): 56-59. Print.

Yancey, Kathleen, Liane Robertson, and Kara Taczak. Writing Across Contexts: Transfer, Composition, and Sites of Writing. Logan, UT: Utah State UP, 2014. Print. 
A Basic Writing Course Design to Promote Writer Identity

Zeiger, William. "The Exploratory Essay: Enfranchising the Spirit of Inquiry in College Composition." College English 47.5 (1985): 454-66. Print. 


\section{Appendix: Curriculum}

\begin{tabular}{|l|l|}
\hline \multicolumn{2}{|c|}{ Authorial Component: Joining the Conversation by } \\
Contributing One's Own Thinking \\
\hline Reading texts as conversations & Bazerman \\
\hline Personally connecting to texts & Salvatori \\
\hline Examining academic writing & Troyka \\
\hline \multicolumn{2}{|c|}{ Connecting Evidence to Claims } \\
\hline \multicolumn{2}{|c|}{ Discoursal Component: Joining the Conversation Credibly } \\
\hline Voice & Fulwiler \\
\hline Emotion \& writing & Brand \\
\hline Connecting to academic essays & Zieger \\
\hline \multicolumn{2}{|c|}{} \\
\hline Authentically by Making a Personally Meaningful Contribution \\
\hline Authority as writers & Sommers \& Salze \\
\hline Intertextuality & Bazerman \\
\hline Style, syntax, \& grammar & excerpts from Hartwell and \\
& Lunsford; handouts \\
\hline
\end{tabular}

\section{Readings Used}

Salvatori, Mariolina. "Reading and Writing a Text: Correlations between Reading and Writing Patterns." College English 45.7 (1983): 657-66. Print. Troyka, Lynn Quitman. "The Writer As Conscious Reader.” A Sourcebook for

Basic Writing Teachers. Ed. Theresa Enos. Manchester, MO, McGraw Hill: 1987. 307-17. Print.

Brand, Alice G. "The Why of Cognition: Emotion and the Writing Process." College Composition and Communication 38.4 (1987): 436-43. Print.

Zeiger, William. "The Exploratory Essay: Enfranchising the Spirit of Inquiry in College Composition." College English 47.5 (1985): 454-66. Print. 
Sommers, Nancy, and Laura Saltz. "The Novice as Expert: Writing the Freshman Year." College Composition and Communication 56.1 (2004): 124-49. Print.

Bazerman, Charles. "Intertextuality: How texts rely on other texts." What Writing Does and How It Does It: An Introduction to Analyzing Texts and Textual Practices. Ed. Charles Bazerman and Paul Prior (2004): 83-96. Print.

Hartwell, Patrick. "Grammar, Grammars, and the Teaching of Grammar." College English 47.2 (1985): 105-27. Print.

Lunsford, Andrea A., and Karen J. Lunsford. "Mistakes are a Fact of Life: A National Comparative Study." College Composition and Communication 59.4 (2008): 781-806. Print. 


\section{Subversive Complicity and Basic Writing Across the Curriculum}

\section{Victor Villanueva}

ABSTRACT: What follows is a simple assertion: time for basic writing to get out from under, a call for us to inculcate a Basic Writing Across the Curriculum. It is time yet again to move away from the concept that basic writers are in need of remedies, in part because all composition courses are in some sense remedial, and to a greater degree because the "illness" that we seek to remedy is in being at least discursively other-cultural. Within this essay there are reflections, speculations, considerations of how to go about what is demanded of us-enculturation and assimilation — while doing what it is we believe we ought to do-promote critical consciousness, something that many of us in many disciplines seek to do, even if those in other disciplines are unaware of the term.

KEYWORDS: Basic writing; programs; writing across the curriculum; discourse communities; racism; assimilation; remediation; enculturation

\section{A Memory, 1984}

We finally have health insurance, so Carol can deliver the child who will be AnaSofía in a birthing room in a hospital, Virginia Mason, Seattle, Washington. The dilation has been sudden, precipitous. Unprepared for a long stay at the hospital, I call my friend Virginia for some help: my medicines, toothbrush, those kinds of things.

Virginia shows up in the midst of Carol's contractions. She tells me that the basic writing program that I have been in charge of is going to be cut, so she has made an appointment for me with the provost for the next day. I don't know what a provost is, but I get the idea: someone with power.

The baby is born. Some complications. The umbilical cord had become a noose. Two nurses and I unwrap the cord, cut it, rub the feet, and then the squall of life, the baby born. Mom and baby are fine. I've got a provost to meet.

Still shaken by the miracle, I show up at the provost's office. Idon'tunderstand where a provost stands in the hierarchy, but I do understand an office larger than the apartment that houses Carol, me, and three kids with a fourth about to move in. Offices in academics are hegemonically legitimating monuments, primary symbols of power (or the lack: TAs and instructors in the sub-basement).

Victor Villanueva is Regents' Professor, Edward R. Meyer Distinguished Professor, and the current Director of the Writing Program at Washington State University. This year marks his thirtieth year in service to those who tend to be underserved. 
The provost explains that the university is about higher education, not remediation, especially given the times (one of many budget crises in my career; they come often; financial crises are a normal part of capitalism, according to Marx and to Keynes, though each providing different ways of dealing with crisis). The university cannot afford the luxury of remediation.

Well, if that's the case, I say, then why do we offer algebra or even regular 101 comp courses? Seems like remediation to me. The only difference I see is who is being served. It was something like that, that I had said.

The provost appears to get defensive. I'm scared that I've crossed a line. She then explains, patiently, that those algebra and comp courses are the norm, that basic writing falls below the norm, is more a basic literacy, pre-university.

I understand, I say. But I go on to say that, based on personal experience, community colleges have their hands full, that culturally they are somewhat different from the university, and that the job of basic writing as I see it isn't teaching grammar or other discrete skills but moving from one way of doing language to another, moving to the ways of language of the university. Sometime not long after this particular conversation, compositionists began to write of "academic discourse communities."

My intention is not to denigrate the community college. I am finding the available means of persuasion-exploiting the discourse of elitism and the discourse of assimilation to this person in a football-field sized office. I argue that we don'tremediate; we enculturate. And so, Basic Writing survives at that University (and remains to this day, nearly three decades later).

About ten years after that first meeting with a provost, the other state university in the same state: Same conversation, same threat, same result, given the promise of assimilation, a kind of enculturation.

\section{I}

First-year comp has always been remedial, but it gained special notice when it became designed for the poor and the folks of color, not Harvard's comp course but open admissions at City College of New York, in Harlem. In Harlem. And suddenly, these were the New Students (see McAlexander), "the true outsiders" (Shaughnessy, Errors 2). "New" reminds me of the somewhat recent national election's sudden realization that there are Latinos in the U.S., failing to remember that the Latinos, the Spanish, were the supposed discoverers of this continent, the first non-indigenous long-term inhabitants. Been here all along, and tied to the original inhabitants, insofar as rules against miscegeny applied mainly to the Spanish elite (Acuña). In 
much the same way, the New Students weren't all that new. They were the victims of a particular political economy.

So the university decided that those Harvard boys or those Yale boys, products of the best college prep schools of the second half of the nineteenth century, were not quite literate, certainly not for Harvard or Yale, Kelly Ritter reminds us. At Harvard the boys were assigned to English A, and some to English B, and even some to English D, the letters correlating to potential grades in writing in English A, to degrees of heads' boniness, "bonehead" the term used at the University of Utah for its remedial students in the 1940s (Ritter 68), with Shaughnessy saying that the new students weren't even up to par with the boneheads (Errors 2). Or there was Yale's "Awkward Squad," white, middle-class Ivy Leaguers of the 1920s through the 1960s who nevertheless required what we would now call basic writing (Ritter 43-4). And when the likes of Sharon Crowley shouted for an end to the universal requirement for first-year comp, she was hooted down. But when economic crises loom, the racialized, non-middle-class version of "remedial" writing is immediately slated for removal. And the way to save it is to invoke a rhetoric that cobbles together multiculturalism or equal opportunity and assimilation.

Monday, 11 March 2013, The Chronicle of Higher Education, front page: A long column titled "The Second-Chance Club: Inside a Semester of Remedial English." It's a very nice piece, showing how the students have to pass a timed writing-clear thesis sentence, four paragraphs (well, at least it isn't five), answering three questions on the assigned writing. The Chronicle's column contains pictures of the students, Black students, and the white professor (though there is one white student in the pictures, as well; you just have to look closely to find him). The caption under a headshot of the prof declares that "Professors in remedial courses often must be social workers, too." This exposure is good for the survival of basic writing. And the message is clear - a second chance at upward mobility, a dedication to assimilation, a multicultural imperative for an improved economy.

But for all the inherent sympathy, multiculturalism tends to fail because by-and-large it tends not to be anti-racist. The problem with multiculturalism is that it relies on a conception of cultural pluralism, an ideal (a Platonic "Good," even), but given the political economy of the day (no matter which school of "political economy," the political liberal's Keynesian or the economic neoliberal's Friedmanian), the idea of all cultures living together in mutual understanding is not yet here. So we do an injustice in acting as if a mutuality already exists, that with a little effort on thesis sentences and 
coherent paragraphs as defined by Cicero, Aristotle, or Bain, we can level the playing field (and put this way, resorting to a cliché, makes the absurdity apparent). But absurd or not, the rhetoric of the new racism, with its preference for difference over racism, allows for arguments based on assimilation and enculturation to become how best to sell basic writing, whether to central admin or to The Chronicle of Higher Education. Far be it for us to point to absurdity or even the violence inherent in our nation's dominant metaphor, the melting pot. Sometimes rhetoric actually is about duplicity, Plato notwithstanding.

Assimilation, enculturation, remains the general norm, even as we in writing try to write our ways out of that norm. Melting into the pot is seen as the way to maintain a nation, the rhetoric goes; identity politics risk the loss of a national identity. It's a strange notion, when we think in terms of all the cultures (as opposed to "races") contained beneath the umbrella term America. We're really quite capable, apparently, of clinging to ancestry and realizing our national identity. We do better to look to the relations among discourse, the cultural, the political (not only as ideology but as political power more broadly conceived), and the economic.

Gyatri Spivak begins to approach this recognition of the forces at play as she writes not only of epistemologies that give credence to the power of discourse as ideological, but also as she writes of the epistemology of other political economic forces, what she calls (à la Foucault) an epistemology of violence. She is referring to the degree to which "subalterns" (like the disenfranchised, the poor, women, often) are never quite able to speak or write from their own ways of knowing. That is, when Spivak asks "Can the Subaltern Speak?" she argues that since our identities are formed in relation to others, power relations are such that there is no truly autonomous Other, no truly autonomous subaltern whose voice is separate from and stands alongside the voices of those in power. She concludes that the answer to whether the subaltern can speak is no. And this is surely no less true for so many of those, women and men, who find themselves in (or choose to enter into) basic writing classrooms, forced into a particular way of marshaling arguments: Edited American English and Aristotelian logic. Yet what choice do we have as teachers, we ask. Code meshing? It's a great concept: using the rhetorical power available in some dialects that are not available in the Standard, an intentional blending of dialectics. And it is more than simply a great concept; it is right; it is some assertion of the subaltern speaking. But before code meshing could work in sociology or in history or any place in the college or university outside of the English classroom, we would have 
to educate an awful lot of educators. We've been trying for over forty years now, but some notion of "proper English" continues to hold sway.

But maybe, rather than throw up our hands and say that the reality is that we must give in to the power and the economy, to students' own wishes for a chance at the middle class, say in resignation that we teach academic discourse lest the folks in sociology or history or whatever hurt the students, maybe we can gain a force in numbers, forge alliances, insinuate basic writing into WAC. We have our expertise-literacy and its pedagogy-but they have theirs. And as often, they too recognize the politics, just not necessarily the politics in believing writing is simply writing, in believing that the codes are agreed upon, a given. On the one hand, we would do well to insinuate our knowledge into theirs. Some of the most interesting writing and research about racism obtains in sociology (like Bonilla-Silva or Winant); some of the most interesting research and writing about language is happening in psychology (like Martín-Baró in Aron and Corn or Mishler); some of the most interesting uses of written narrative is happening in the medical professions (also Mishler); there's even an entire field of study called Narrative-Based Medicine (see, for example, Greenhalgh and Hurwitz). What we know that they might not is that as language carries meaning, meaning carries cultures and their ideologies, ideologies and their economies.

I have made this argument before, though in another context ("Politics"), that we cannot presume to be the purveyors of critical consciousness. In terms of racism, we stand to learn from those other disciplines while we inform them of the ways of writing and rhetoric. We can learn from folks in business who have economists among them, from historians, from political scientists, from sociologists, as well as from the literary figures and critical theorists from whom we have grown accustomed to learning. We give something to the disciplines-matters of literacy and rhetoric grounded in the sociopolitical; and they give us something - their considerations of the political and the economic. And we introduce them to basic writers, not as needing remedies or in need for proper development (Rose), but as rhetorical power players (Villanueva, Bootstraps). It's time. And it's bound to succeed, since we'd be in the business of justice and maybe even real equality somewhere down the line, not composition teachers who "must be social workers," not missionaries converting the natives to the religion of "proper" discourse.

The missionary. Some of us read Shaughnessy's "Diving In" as a spoof on developmental schemes. So much of the work in education was being tied to developmental models at the time of Shaughnessy: William Perry, 
Maslow, Bloom, and especially Piaget. Shaughnessy was clearly poking fun at the missionary mentality of teachers like her: trained in literature, suddenly faced with the New Student. But it turns out not to be so funny a scheme, since somehow it seems that we can't quite get past "converting the natives" because of the exigencies of power and economics. We remain stuck in the idea that there is only one way for students to succeed: learn the discourse of power, doing almost nothing outside of our closed conversations in Writing Studies to alter that discourse. That Chronicle of Higher Ed article mentioned above clearly honors the successful conversion of the natives. If basic writing is to be no longer missionary in its method, though, no longer social work, then we should be engaging with the other minds across the disciplines who also face the students we face, having those faculty work with us rather than point accusatory fingers at us. We should enter into a dialogue across the disciplines so as better to understand the social processes that could relegate such a large number to the trouble-heap. All of us can use the tools at our disposal to circumvent reproducing a school system that has traditionally failed to educate the woman, the poor, or the person of color at the same rate of efficiency as others. And while we learn from them, we pass on contact zones and critical pedagogies and world Englishes and meshed codes, passing on our particular ways of understanding what many other disciplines also understand, that language is not just the conveyor of knowledge but is the way knowledge becomes known.

\section{II}

But the problem remains: how to teach the written rhetoric of power without negating students' power, the power inherent in their own ways with words. One answer might be to teach a conscious mimicry. This is not a new idea, of course (see, for instance, bell, Bhabha, Fuss). As I mentioned some years ago ("Rhetoric"), Puerto Ricans, as the longest continuous colonial subjects of the modern world, have long used a strategy called jaibería, a jaiba rhetoric. Puerto Rico's situation is one in which political power makes colonialism no longer tenable, yet there remains an economic situation in which nationalism is not feasible. The trick then is maintaining a cultural identity while complying with dominance. That's achieved through a jaibería, a "subversive complicity" (Grosfoguel), kind of like shining someone on, a conscious mimicry. Sociologists Grosfoguel, Negrón-Muntaner, and Goeras call on Diana Fuss's reading of Fanon in Black Skin, White Masks to describe a jaiba politics as a mimicry rather than a masquerade: 
According to Diana Fuss in her essay on Frantz Fanon, there is a tendency within postcolonial and psychoanalytic discourse to distinguish between the practices of mimicry and masquerade. While in psychoanalysis, masquerade is understood as the unconscious assumption of a role, mimicry, according to Homi K. Bhabha, is understood as a colonial strategy of subjugation. Fuss, however, stresses that there can be a mimicry of subversion where the deliberate performance of a role does not entail identification. The performance's contexts thus become crucial in determining its subversive potential ... [In] both Fanon's and Fuss's texts, the most powerful example of subversive mimicry is that of the Algerian Nationalist woman militant who "passes" as a Europeanized subject in order to advance the cause of National liberation. (26-8)

In comp terms, this is where "inventing the university" is a mutually conscious decision, not just foisted on basic writers but encouraged as a jointly agreed upon strategy, not with the idea that students become like teachers but rather that students learn how to gain the trust of teachers so that a communal learning can take place, what Fanon calls "a world of reciprocal recognitions" (218). This is the strategy of a particular program with which I am currently involved, CLASP, which I'll describe a little further below.

Gail Okawa outlines a pedagogy wherein students are asked to look at how people of color are represented in ways that hide their political identities, asking students to remove these masks. By the same token, folks of color can quite intentionally choose to conceal by the wearing of masks, consciously enacting Fanon's white masks, though Okawa refers to Mitsuye Yamada's use of the mask metaphor. In a similar vein, Malea Powell tells tales of the trickster's ways, a rhetoric which "exposes the lies we tell ourselves and, at the same time, exposes the necessity of those lies to our daily material existence" (9). And there is imitatio, a forming of the self through a learning process of mimicry. Jaibería is not a new idea. I talk to a provost, imitating the discourse of assimilation disguised as multiculturalism, so as to be able to provide critical opportunities critically.

Acknowledge that Basic Writing Programs are always subject to the political economy because of a structural racism; recognize the institutional belief that higher education cannot be responsible for what it sees as the shortfalls of lower education (blame always flowing downstream), and we are perforce pulled into a rhetoric of survival, a complicit rhetoric with somewhat subversive motives. In other words, I'm calling for imitatio with an anti-racist critical pedagogy, imitatio taking on a particular mental state-a jaibería, mask- 
ing in a discursive trickery-while students work with us on discourse, work critically and consciously on conventions, and while we-both the students and the teachers of writing - work on introducing those in other disciplines to the basic writer and swap discoveries and conceptions of economics and political power and language.

In the pages of this journal some years back, I told of how I introduce basic writing students (and others) to the idea of writing as epistemological, that language comes from the self in dialogue with one's culture ("Theory"). It's a fun exercise. I invite you to try it. What that article doesn't mention, however (since that wasn't its intent), is what happens after the opening gambit. Once we establish something about language as epistemological and a social construction, we discuss conventions. This is pretty straightforward at first, matters of registers and codes that all students understand immediately - speaking to an elder versus speaking to a peer, say. Then to the "logic" behind academic discourse, the idea that whereas the writing with which they are most familiar within a school context (the fiction and poetry) is designed for surprise, expository and argumentative academic writing tends to work from an older Roman oral legal tradition, in which the jurors or judges must know an argument's general premises or assertions first, so as to prepare listeners for the arguments to follow (and thereby judge). I even show them a short passage from Cicero's de Inventione. Then we go into the matter of vocabulary. This is, of course, an issue for graduate students no less than basic writers, graduate students given to preferring "that's problematic" to "that's a possible problem," just as undergraduates learn "to be cognizant of" rather than simply "get it." Inspired decades ago by a rhetoric by Patrick Hartwell, I provide a number of clichés in "academic" speech, and we work these together: "Refrain from being lachrymose over precipitately decanted lacteal fluid" or "Male cadavers are incapable of yielding any testimony." Soon they see the problem in using a vocabulary which has not yet become their own. As a class, we work through these examples. The students tend to respond. So students are encouraged to let go of the fear, to the extent that's possible, asked to write "naturally," in their own ways. Then we work through papers together. Unlike the standard stage model of the writing process, we begin with editing, mainly marking sentence breaks (since fused sentences and run-on sentences tend to be the greatest problems). Then we translate. Using a student-volunteer's paper, we work together to translate the student's discourse onto something akin to academic discourse, especially as pertains to audience. In the process, students become conscious translators of their own ways with words to those of the academic discourse community. The 
process thereby calls on a conscious understanding of Aristotle's logic, and a conscious understanding of contrastive rhetorics.

I have used this process successfully for many years with students from other cultures, including those students who might look white and middle class but who are at least at one remove from the supposed traditional student. As with any pedagogy (including the one discussed below), I can't claim classes full of critically conscious literacy epiphanies, but most get most of it in the mere fifteen weeks, the forty contact hours, that we have.

\section{III}

Gaining more than forty hours in the acquisition of academic discourse means having to involve our colleagues across the curriculum. At my institution right now, we are involved in a program called CLASP (Critical Literacies Achievement and Success Program). Although the students are those who are first generation, of color, and from poverty, there is no assumption that students are operating from a lack. We take their presence in college at face value, meaning that we simply accept what they themselves believe: that they are capable of college work, a belief substantiated by their very presence at an institution with no open admissions policy, an institution, in fact, subject to a state mandate against racial preferences on admissions (a ban now upheld by the Supreme Court's April 2014 decision in Schuette v. Coalition to Defend Affirmative Action). CLASP is not a remedial program. Rather, it operates from Fanon's "reciprocal recognitions," that whatever the students don't know about how professors operate, the professors are equally ignorant of how these "New Students" operate. At the heart of the program is discussing how to talk with professors, discussing with the students the kinds of questions they might have of the instructor, having the students jot down their questions, and mandating a series of visits during the professors' office hours. The best learning is one-with-one; novice students' great fear is the one-with-one with professors. Through this program, the professors get to discover the students as more than victims; the students get to discover the professors as less than geniuses.

Within CLASP, we include the Writing Commons, an offshoot of the Writing Center, wherein tutors are trained in the grammars of the dominant dialects of the students who participate in CLASP: Chicano English (see Fought) or African American Language (see Smitherman and Villanueva). They're also shown the workings of contrastive rhetoric. And they are taught how to listen-rhetorically-that kind of conscious listening (and 
even eavesdropping) that Krista Ratcliffe describes. And the students learn precisely the same things: rhetorical listening and rhetorics (as plural), and of course, matters of correctness, since infelicities obtain in every dialect and language. The CLASP Writing Commons provides an introduction to the ways of a writing center but within a community with which they are familiar, even though the students contain all the variations on ideology one would expect of "traditional" students. They get to hear each other on racism, class, assimilation, sexuality - the hot-button subjects that are typical of humanities and social science courses. They get to hear each other; they learn to discuss; and again, the tutors get to discover how not-at-all-different the students are. What's more, the students gather more and more awareness of themselves as rhetorical beings, gain greater metalinguistic awareness, develop a vocabulary with which to speak with their professors during those office hours that the program mandates. They become the agents of their own basic writing across the curriculum.

And those of us who work at training faculty who are interested in CLASP from across the curriculum (and the interest is in fact across the curriculum) reinforce what students discover about the organizational patterns and other discourse markers (matters other than simple mechanics) that are manifest in students' early draft writing. The faculty learn from us and from the students that often the students' writing does not reflect a lack of organizational abilities but different organizational patterns. The Arab student or the Latina student who seems to go on long tangents can discuss with faculty, thanks to contrastive rhetoric, how the tangent might not be (and discover the discursive footnote). And the student, in discussion with the faculty who is conscious of contrastive rhetoric, might also discover when a tangent really is a tangent_-and would be a tangent in Spanish or in Arabic academic discourse. So while professors learn (or recall, since many are not monolingual in English) the conventions of other languages and deliver the conventions of particular disciplines, the students-and the professors-become conscious of the conventions-as-conventions. In remaining conscious of students' patterns of predispositions by way of early drafts that give vent to culturally specific discursive ways, the conversation is opened up; the professors and the students work together in assuring students gain access to the places they wish to go by way of the academy without erasing where they've been. Their mimicry, their conscious invention of the university, has the potential of changing the university, broadening the university's conceptions of discourses in action, of the rhetorics that are always at play, more members of the university discovering that, at bottom, we are all creatures of the word. 
From Pablo Neruda:

Nació

la palabra en la sangre,

creció en el cuerpo oscuro, palpitando

y voló con los labios y la boca.

Más lejos y más cerca

aún, aún venía

de padres muertos y de errantes razas,

de territorios que se hicieron piedra

que se cansaron de sus pobres tribus,

porque cuando el dolor salió al camino

los pueblos anduvieron y llegaron

y nueva tierra y agua reunieron

para sembrar de nuevo su palabra.

Y así la herencia es ésta:

éste es el aire que nos comunica

con el hombre enterrado y con la aurora

de nuevos sere que aún no amanecieron

The word

was born in the blood,

grew in the dark body, beating,

and took flight through the lips and the mouth.

Farther away and nearer

still, still it came

from dead fathers and from wandering races,

from lands which had turned to stone,

lands weary of their poor tribes,

for when grief took to the roads

the people set out and arrived

and married new land and water

to grow their words again.

And so this is the inheritance:

this is the wavelength which connects us

with dead men and the dawning

of new beings not yet come to light 


\section{Works Cited}

Acuña, Rodolfo F. Occupied America: A History of Chicanos (7th ed.). Boston: Longman, 2010. 36. Print.

Aron, Adrianne and Shawn Corne, eds. Writings for a Liberation Psychology: Ignacio Martín-Baró. Cambridge, MA: Harvard University Press, 1996. Print.

Bartholomae, David. "Inventing the University." Journal of Basic Writing 5.1 (1986): 4-23. Print.

Berlin, James A. Writing Instruction in Nineteenth-Century American Colleges. Carbondale, IL: Southern Illinois University Press, 1984. Print.

Bhabha, Homi. "Of Mimicry and Man: The Ambivalence of Colonial Discourse." October 28 (1984): 125-33. Print.

Bizzell, Patricia. "William Perry and Liberal Education." College English 46.5 (1984): 447-54. Print.

Bonilla-Silva, Eduardo. Racism without Racists: Color-Blind Racism and the Persistence of Racial Inequality in the United States. Lanham, MD: Rowman and Littlefield, 2006. Print.

Crowley, Sharon. “Composition's Ethic of Service, the Universal Requirement, and the Discourse of Student Need." JAC 15.2 (1995): 227-39. Print.

Fanon, Frantz. Black Skin, White Masks. Trans. Richard Philcox. New York: Grove Press, 2008. Print.

Fought, Carmen. Chicano English in Context. New York: Palgrave Macmillan, 2003. Print.

Fuss, Diana. "Interior Colonies: Frantz Fanon and the Politics of Identification." Diacritics 24.2/3 (1994): 19-42. Print.

Greenhalgh, Trisha and Brian Hurwitz, eds. Narrative Based Medicine. London: BMJ Books, 1998. Print.

Grosfoguel, Ramón. “Feminizando la Politica.” El Nuevo Día. 24 July 1990: 51. Web.

Grosfoguel, Ramón, Frances Negrón-Muntaner, and Chloé S. Goeras. “Beyond Nationalist and Colonialist Discourses: The Jaiba Politics of the Puerto Rican Ethno-Nation.” Puerto Rican Jam: Rethinking Colonialism and Nationalism. Eds. Frances Negrón-Muntaner and Ramón Grosfoguel. Minneapolis: University of Minnesota Press, 1997. 1-36. Print.

Hartwell, Patrick and Robert H Bentley. Open to Language: A New College Rhetoric. New York: Oxford University Press, 1982. Print.

hooks, bell. "Representing Whiteness in the Black Imagination." Displacing Whiteness: Essays in Social and Cultural Criticism. Ed. Ruth Frankenberg. 
Durham: Duke University Press, 1997. 338-46. Print.

Hoover, Eric and Sara Lipka. “The Second-Chance Club: Inside a Semester of Remedial English." The Chronicle of Higher Education, 11 March 2013. Web.

McAlexander, Patricia J. "Mina Shaughnessy and K. Patricia Cross: The Forgotten Debate over Postsecondary Remediation." Rhetoric Review 19.1/2 (2000): 28-41. Print.

Mishler, Elliot. The Discourse of Medicine: Dialectics of Medical Interviews. New York: Ablex, 1984. Print.

---. Storylines: Craftartists' Narrative of Identity. Cambridge, MA: Harvard University Press, 1999. Print.

Neruda, Pablo. "La Palabra," Plenos Poderes. Buenos Aires: Editorial Losada, 1962. 4. Print.

---. “The Word." Trans. Alastair Reid. The Poetry of Pablo Neruda. Ed. Ilan Stavans. New York: Farrar, Straus and Giroux, 2003. 621. Print.

Okawa, Gail Y. "Removing Masks: Confronting Graceful Evasion and Bad Habits in a Graduate English Class." Race, Rhetoric, and Composition. Ed. Keith Gilyard. Portsmouth, NH: Heinemann Boynton/Cook, 1999. 124-43. Print.

Powell, Malea. "Blood and Scholarship: One Mixed-Blood's Story." Race, Rhetoric and Composition. Ed. Keith Gilyard. New Hampshire: Boynton/ Cook Publishers, 1999. 1-16. Print.

Ratcliffe, Krista. Rhetorical Listening: Identification, Gender, Whiteness. Carbondale, IL: Southern Illinois University Press, 2005. Print.

Ritter, Kelly. Before Shaughnessy: Basic Writing at Yale and Harvard, 1920-1960. Carbondale, IL: Southern Illinois University Press, 2004. Print.

Rose, Mike. "Narrowing the Mind and Page: Remedial Writers and Cognitive Reductionism." College Composition and Communication 39.3 (1988): 267-98. Print.

Shaughnessy, Mina P. “Diving In: An Introduction to Basic Writing.” College Composition and Communication 27.3 (1976): 234-39. Print.

---. Errors and Expectations: A Guide for the Teacher of Basic Writing. New York: Oxford University Press, 1977. Print.

Smitherman, Geneva and Victor Villanueva, eds. Language Diversity in the Classroom: From Theory to Practice. Carbondale, IL: Southern Illinois University Press, 2003. Print.

Spivak, Gayatri Chakravorty. "Can the Subaltern Speak?" Marxism and the Interpretation of Culture. Eds. b. Cary Nelson and Lawrence Grossberg. Urbana, IL: University of Illinois Press, 1988. 271-316. Print. 
Villanueva, Victor. Bootstraps: From an American Academic of Color. Urbana: National Council of Teachers of English, 1993. Print.

---. "The Politics of Literacy Across the Curriculum." WAC for the New Millennium: Strategies for Continuing Writing-Across-the-Curriculum Programs. Eds. Susan McLeod, Eric Miraglia, Margot Soven, and Christopher Thaiss. Urbana: National Council of Teachers of English, 2001. 165-78. Print.

---. “On the Rhetoric and Precedents of Racism. College Composition and Communication 50.4 (1999): 645-61. Print.

---. "Theory in the Basic Writing Classroom? A Practice," Journal of Basic Writing 16.1 (1997): 79-90. Print.

Winant, Howard. The World is a Ghetto: Race and Democracy Since World War II. New York: Basic Books, 2001. Print. 
How is this publication thinking about the future?

By becoming part of the past.

This publication is available from

ProQuest Information and Learning

in one or more of the following ways:

- Online, via the ProQuest*

information service

- Microform

- CD-ROM

- Via database licensing

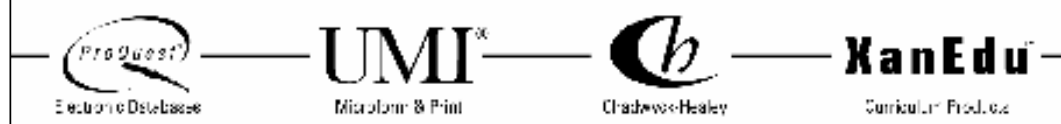

Fir arrse inforrration, rall

I-800-52I-0600, cxt. 2888 (US) ur oI-734-76I-4700 (Internatsond)

swaw.il.procpuest.rom

From:ProC Cuest 


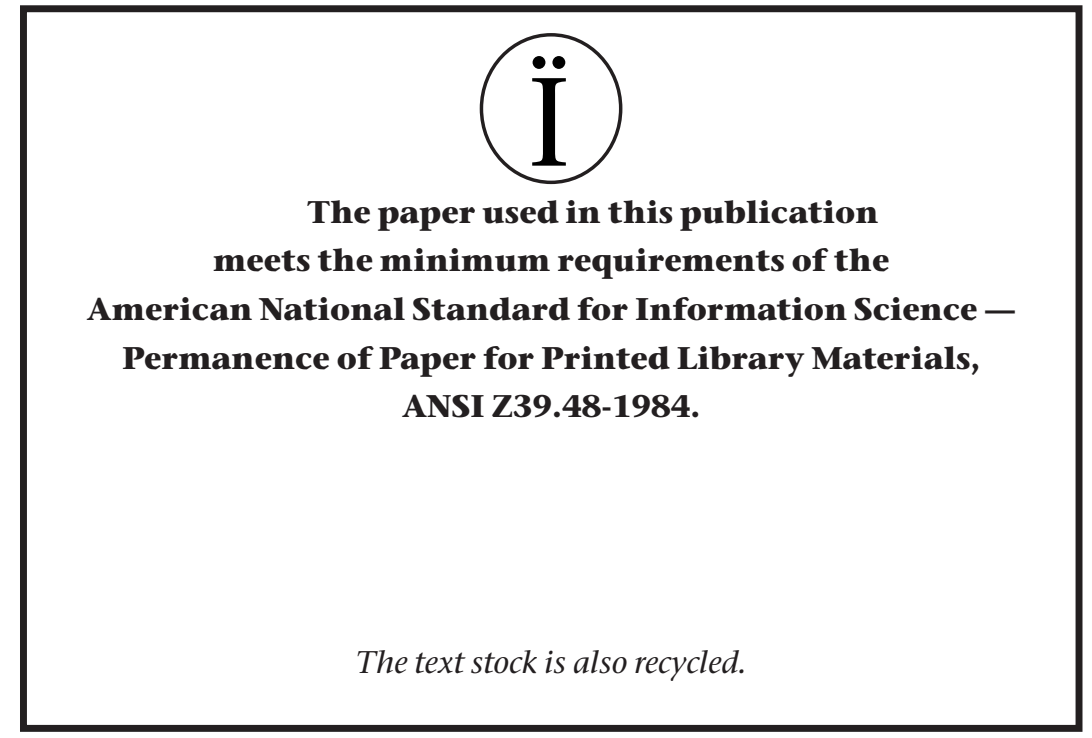




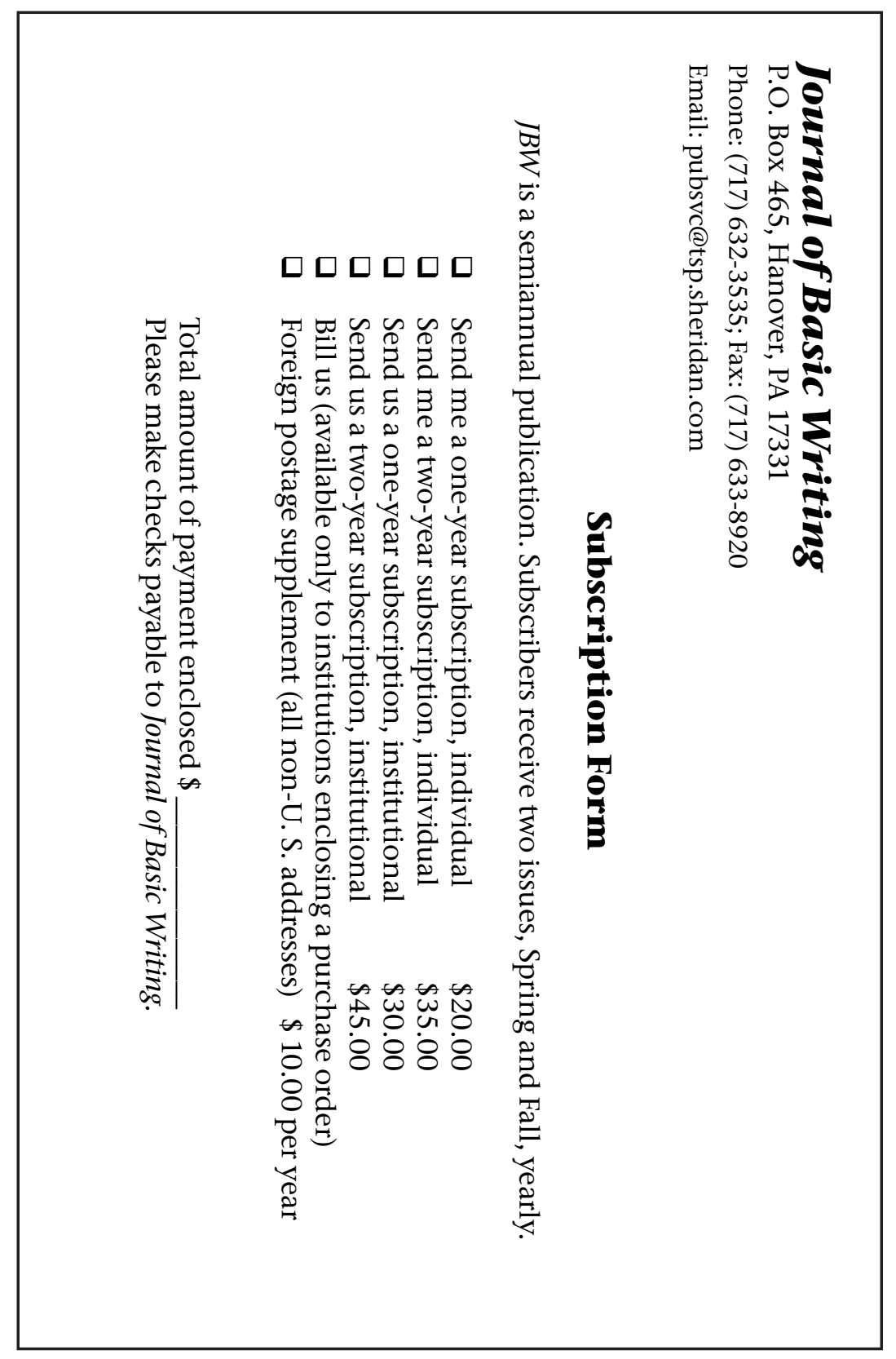



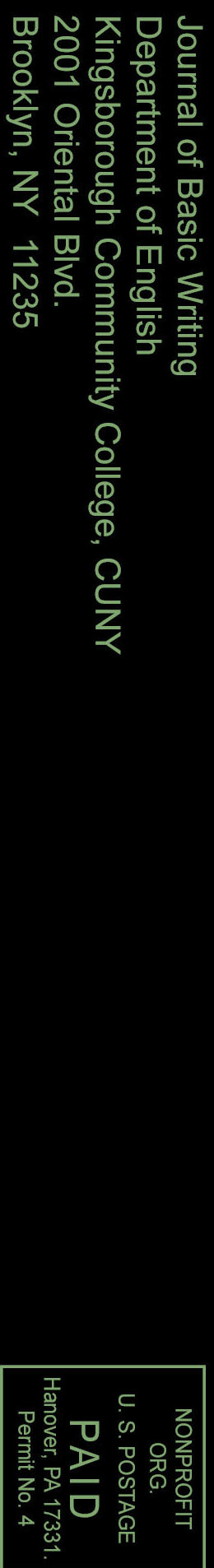